\title{
EL TRANSPORTE AUTOMOTOR DE CARGAS EN AMÉRICA LATINA
}

José A. Barbero 


\section{EL TRANSPORTE AUTOMOTOR DE CARGAS EN AMÉRICA LATINA}

José A. Barbero

Rodolfo Fiadone

María Florencia Millán Placci 


\section{Catalogación en la fuente proporcionada por la \\ Biblioteca Felipe Herrera del Banco Interamericano de Desarrollo}

Barbero, José Antonio.

El transporte automotor de cargas en América Latina / José A. Barbero, Rodolfo

Fiadone, María Florencia Millán Placci.

p. cm. - (Nota técnica del BID ; 1877)

Incluye referencias bibliográficas.

1. Trucking-Latin America. 2. Freight and freightage-Latin America. 3. Business logistics-Latin America. I. Fiadone, Rodolfo. II. Millán Placci, María Florencia. III. Banco Interamericano de Desarrollo. División de Transporte. IV. Título.

V. Serie.

IDB-TN-1877

Códigos JEL: L91; R40; R41.

Palabras clave: Transporte; logística; transporte automotor de

carga; camiones; industria, productividad.

http://www.iadb.org

Copyright ( $\odot 2020$ Banco Interamericano de Desarrollo. Esta obra se encuentra sujeta a una licencia Creative Commons IGO 3.0 Reconocimiento-NoComercial-SinObrasDerivadas (CC-IGO 3.0 BY-NC-ND) (http://creativecommons.org/licenses/by-nc-nd/3.0/igo/ legalcode) y puede ser reproducida para cualquier uso no-comercial otorgando el reconocimiento respectivo al BID. No se permiten obras derivadas.

Cualquier disputa relacionada con el uso de las obras del BID que no pueda resolverse amistosamente se someterá a arbitraje de conformidad con las reglas de la CNUDMI (UNCITRAL). El uso del nombre del BID para cualquier fin distinto al reconocimiento respectivo y el uso del logotipo del BID, no están autorizados por esta licencia CC-IGO y requieren de un acuerdo de licencia adicional.

Note que el enlace URL incluye términos y condiciones adicionales de esta licencia.

Las opiniones expresadas en esta publicación son de los autores y no necesariamente reflejan el punto de vista del Banco Interamericano de Desarrollo, de su Directorio Ejecutivo ni de los países que representa.

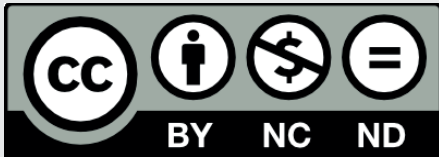

BIDtransporte@iadb.org 


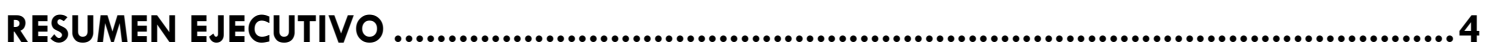

1. OBJETIVOS Y ORGANIZACIÓN DEL INFORME..............................................12

1.1. MOTIVACIÓN Y PROPÓSITO..........................................................................................12

1.2. CONTENIDOS DEL INFORME................................................................................................13

2. CARACTERIZACIÓN DEL TRANSPORTE AUTOMOTOR DE CARGAS ......................14

2.1. EL ROL DEL TAC EN EL MOVIMIENTO DE BIENES........................................................................14

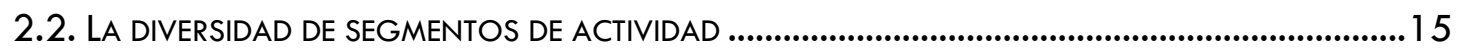

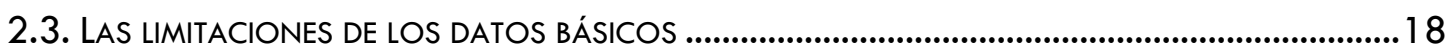



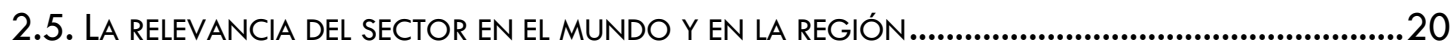

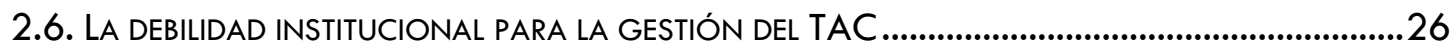

3 - TENDENCIAS EN EL DESEMPEÑO DEL TAC EN LA REGIÓN....................................28



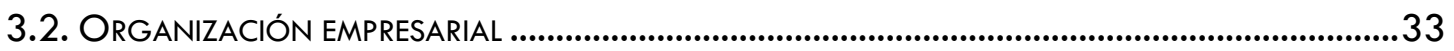

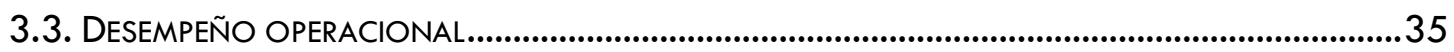







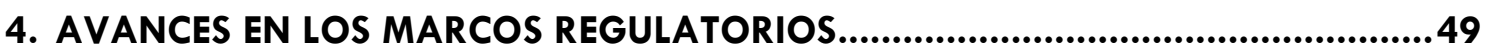

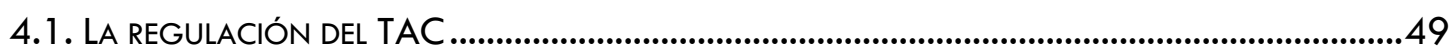

4.2. LOS CAMBIOS EN LA REGIÓN EN LOS ÚLTIMOS AÑOS ............................................................50

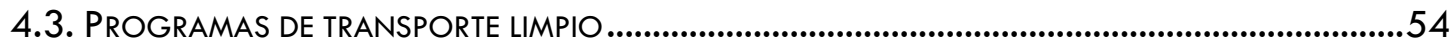

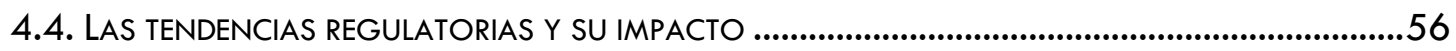

5. LA DINÁMICA DE LA RENOVACIÓN DE FLOTAS..............................................59

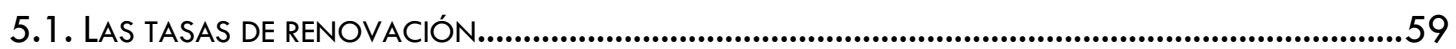

5.2. LOS MECANISMOS DE APOYO GUBERNAMENTAL Y SUS RESULTADOS .....................................61

6. UNA MIRADA AL TAC EN DISTINTAS SUBREGIONES .......................................66

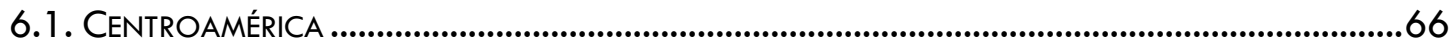



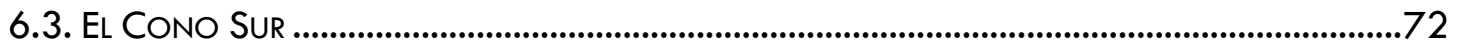



6.5. UN ANÁLISIS COMPARATIVO DE LOS COMPORTAMIENTOS REGIONALES....................................75

7. EVALUACIÓN DE LA PRODUCTIVIDAD DEL SECTOR .........................................77

7.1. LA BRECHA: ENTRE PAÍSES Y ENTRE SEGMENTOS DE ACTIVIDAD ..............................................77

7.2. PRINCIPALES CAUSAS DE LAS DEBILIDADES DEL TAC EN LA REGIÓN...........................................80

8. LAS BUENAS PRÁCTICAS EN EL TAC: EXPERIENCIAS INTERNACIONALES ..........85

8.1. MEJORAR LA SEGURIDAD VIAL MEDIANTE LA CERTIFICACIÓN DE PROCESOS CLAVE........................85

8.2. PROGRAMAS PARA UN TRANSPORTE SUSTENTABLE.........................................................87

8.3. BUENAS PRÁCTICAS IMPULSADAS POR LOS ACTORES DE LA CADENA DE SUMINISTROS .................91

8.4. MEJORAR SEGURIDAD Y EFICIENCIA CONTROLANDO LAS HORAS DE TRABAJO ............................94

8.5. VEHÍCULOS MÁS LIMPIOS DEBIDO A LOS CARGOS POR USO DE LA INFRAESTRUCTURA .................94

9. PERSPECTIVAS EN LOS MERCADOS Y LA TECNOLOGÍA ..........................................96








10. LOS RETOS DEL TAC Y LAS OPCIONES DE POLÍTICA PÚBLICA ........................105

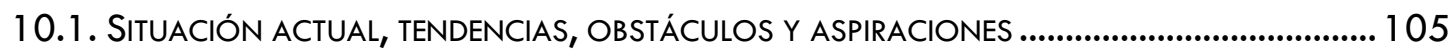

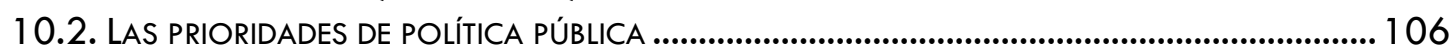

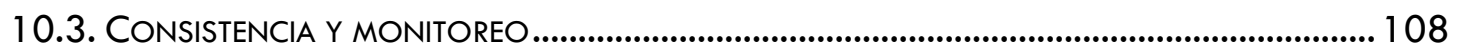





\section{Listado de Gráficos}

Gráfico 1 - Aspectos clave de la contratación del TAC ....................................................18

Gráfico 2 - Evolución de la actividad del TAC en países seleccionados ..............................22

Gráfico 3 - Participación del TAC en el consumo mundial de combustibles........................26

Gráfico 4 - Inversión en infraestructura vial en países de América Latina ............................46

Gráfico 5 - Ejemplo de mapa de cobertura de redes $2 G / 3 G$ y $4 G$..................................47

Gráfico 6 - Vehículos destruidos mediante el Programa de Renovación Vehicular...........63

Gráfico 7 - Tránsito terrestre en Centroamérica según origen y destino............................67

Gráfico 8 - Vehículos-km vacíos como proporción del total en la UE..................................79

Gráfico 9 - Edad comparada de las flotas del TAC ...........................................................84

Gráfico 10 - Participación en el consumo de combustibles por modo de transporte ........89

Gráfico 11 - Buenas prácticas recomendadas por las firmas.............................................92

\section{Listado de Tablas}

Tabla 1 - Modelos de organización empresarial en el TAC .............................................17

Tabla 2 - Matriz de carga en otras regiones del mundo....................................................23

Tabla 3 - Matriz de carga en países de América Latina ........................................................23

Tabla 4 - Dimensiones máximas de los equipos en diferentes países ...............................29

Tabla 5 - Estructura de la flota en países de América Latina..............................................30

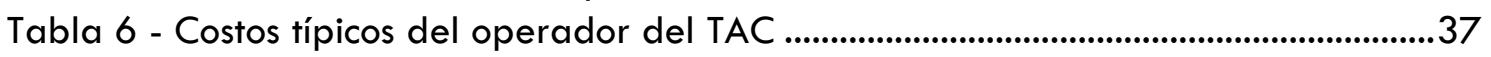

Tabla 7 - Estructura de costos del TAC en Argentina........................................................39

Tabla 8 - Estructura de costos del TAC en Chile ................................................................39

Tabla 9 - Estructura de costos del TAC en Colombia ..............................................................39

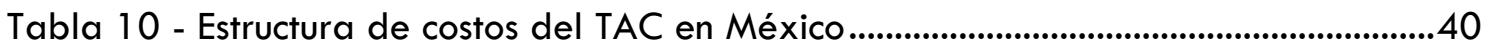

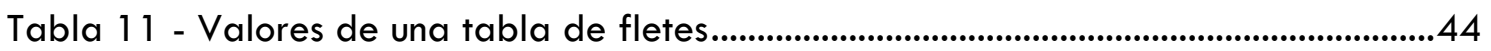

Tabla 12 - Venta de camiones nuevos en Argentina ..........................................................59

Tabla 13 - Particularidades del TAC en las subregiones de América Latina ......................76

Tabla 14 - Estimación de las distancias recorridas por año por vehículos de carga ........77

Tabla 15 - Comparación internacional de fletes por camión...............................................80

Tabla 16 - Participación en las emisiones de GEl de las actividades logísticas..................88

Tabla 17 - Enfoques organizadores de diferentes programas de transporte ....................90

Tabla 18 - Mejores prácticas de acuerdo con la perspectiva de los actores......................93 
Tabla 19 - Acciones propuestas e impactos esperados

\section{Listado de Recuadros}

Recuadro 1 - La baja disponibilidad de datos en el TAC .....................................................19

Recuadro 2 - La relevancia de las condiciones de carga y descarga ................................38

Recuadro 3 - Tarifas mínimas y de referencia ....................................................................43

Recuadro 4 - Los impulsores de la regulación en el TAC ..................................................49

Recuadro 5 - El rol del TAC en el transporte internacional en Centroamérica ....................67

Recuadro 6 - Prácticas sustentables para una logística verde en Argentina ......................91

Recuadro 7 - Expectativas de servicio impulsadas por el B2C ...........................................97

Recuadro 8 - Una visión futurista del transporte de cargas .............................................98

Recuadro 9 - Una nueva generación de bolsas de carga .........................................................99

Recuadro 10 - Nuevas tecnologías en el TAC ........................................................................... 101

\section{Abreviaturas y acrónimos}

ADEFA Asociación de fabricantes de automotores de Argentina.

ALICE Alliance for Logistics Innovation through Collaboration in Europe

ASEAN Association of Southeast Asian Nations

BAM Banda ancha móvil

ELD Electronic logging devices

ERTRAC European Road Transport Research Advisory Council

EU28 28 países de la Unión Europea

FTL Carga completa de un camión (full truck load)

GEl Gases de efecto invernadero

HOS Hours of Service

IEA Agencia Internacional de la Energía

IoT Internet de las cosas

IRU International Road Union

ITF International Transport Forum

KPI Key Performance Indicators

LTL Carga parcial de un camión (less than truck load)

MoMo Modelo de Movilidad

RFID Identificación por radiofrecuencia

OECD Organización para la Cooperación y el Desarrollo Económicos.

TAC Transporte automotor de cargas

TACC Tasa anual compuesta de crecimiento

TIC Tecnologías de la información y las comunicaciones

SIECA Secretaría de Integración Económica Centroamericana 


\section{RESUMEN EJECUTIVO}

\section{Objeto y equipo de trabajo}

El objetivo de este trabajo es actualizar la información referida al transporte automotor de cargas (TAC) en América Latina, tema que fue tratado en un estudio elaborado por el BID en 2015. Este informe procura reconocer las principales tendencias en el sector, evaluar su desempeño comparativo, identificar las causas que explican las brechas con regiones donde se observan las mejores prácticas, y proponer estrategias para superar los obstáculos que condicionan su actuación. El informe abarca América Latina en su conjunto (América Central y Sudamérica), profundizando el análisis en cuatro países: Argentina, Brasil, Chile y México, contemplando al sector en sus diversos ámbitos de actuación: urbano, interurbano e internacional.

El trabajo fue coordinado por José Barbero, y desarrollado por Rodolfo Fiadone y María Florencia Millan Placci, contando con el apoyo de Roberto Santana Muñoz (Chile), Beatriz Berti da Cóstä (Brasil) y Beatriz Robles Linares (México), que elaboraron documentos de soporte.

\section{Los principales resultados}

EI TAC constituye el principal modo de transporte terrestre, en la región y en el mundo, siendo un elemento central en la gestión de la logística de cargas. Brinda conectividad local, regional e internacional en las cadenas de valor, no sólo cubriendo movimientos de larga distancia, domésticos e internacionales, sino que tiene una función clave en la distribución de bienes en las ciudades. Se trata de un sector sumamente heterogéneo, en donde existen casi tantas posibilidades de configuraciones técnicas, operativas y empresariales de transporte por camión como clases de productos y clientes hay en el mercado. Esta diversidad tiene como corolario que muchos datos agregados, que representan promedios generales del sector, encubren varianzas muy significativas. Tal como se advertía en el estudio anterior, la disponibilidad de datos desagregados continúa siendo un obstáculo para el análisis del sector.

La segmentación del TAC se expresa en las características técnicas de los vehículos, los tipos de carga que pueden transportar, el ámbito geográfico de las prestaciones, la modalidad de la organización empresarial y las relaciones contractuales con el generador de cargas. Aunque el sector presenta las características de un mercado ampliamente competitivo, se observa que la cantidad de oferentes se reduce a medida que aumenta la complejidad de las operatorias demandadas. Una característica destacable del sector es la alta prevalencia de la informalidad, y las pocas estimaciones disponibles sugieren que abarcaría entre el $20 \%$ y el $40 \%$ de las operaciones. La informalidad genera competencia desleal, distorsiona costos y tarifas, reduce ingresos para el sector y para el fisco, aumenta los riesgos en la seguridad vial, reduce la calidad de servicio y genera una falta de protección social para los trabajadores. 
La relevancia del TAC puede medirse de diversas formas. Su participación en el PIB tiende a subestimar su rol, dado que no computa el transporte propio (el transporte que realizan las firmas con sus propios equipos), que constituye aproximadamente un tercio de la actividad y que cuenta con las mayores flotas. Otra forma de medirla es por su participación en la matriz de cargas, que expresa la participación de los modos de transporte en el movimiento interurbano de mercaderías. Su rol es dominante en el mundo, sólo desafiado por el transporte ferroviario en los países de grandes dimensiones. En América Latina (ALC) da cuenta de aproximadamente las tres cuartas partes del movimiento doméstico de cargas, significando más del $90 \%$ de las toneladas-km transportadas en la mayor parte de los países, salvo aquellos en los que el ferrocarril ha logrado un mayor desarrollo (México y Brasil). Adicionalmente al transporte doméstico, el TAC tiene un rol relevante en el comercio internacional, compitiendo principalmente con el transporte por agua. En el caso de América del Sur, los camiones transportan aproximadamente el $30 \%$ del volumen del comercio intrarregional, y el $40 \%$ del valor. En el caso de México, el TAC da cuenta del $62 \%$ de las exportaciones, medidas por el valor de la mercadería. En América Central prácticamente todo el comercio intrarregional se realiza por camión (30\% de las exportaciones). El tercer nicho de participación del TAC es en el movimiento dentro de las ciudades. En la logística urbana, el TAC es el modo de trasporte excluyente, con muy escasas excepciones. La actividad de las cargas urbanas ha crecido notablemente, en el mundo y también en América Latina.

La relevancia del TAC también se destaca en el consumo de energía y las emisiones. El transporte de cargas por carretera es un demandante de primer orden de energía, en particular de combustibles fósiles, en los que basa exclusivamente su funcionamiento; produciendo que, los camiones por sí solos representan el 3\% de las emisiones de GEl en el mundo. EI TAC consume la mitad del diésel a nivel global; siendo este, el principal responsable de la contaminación originada por el material particulado y por los óxidos de nitrógeno y azufre, constituyendo una de las mayores causas del deterioro de la calidad del aire en las áreas urbanas.

El desempeño del sector, que se expresa básicamente por su productividad y calidad de servicio, puede ser ponderado en varias perspectivas. En lo referente a las flotas, los datos muestran que han venido creciendo en forma sostenida en la región (la tasa anual en Chile ha sido del 5,7\% anual, y en México del 5,4\%), aunque menos que en los países de Asia; donde existe una tendencia hacia un mayor uso de tractocamiones y semirremolques, en detrimento del camión rígido con acoplado, aunque con excepciones en algunos países. La relación entre semirremolques y tractocamiones es relativamente baja, por debajo de 1,3; comparado con economías desarrolladas como Estados Unidos y Canadá donde esa relación es del orden de 3. La antigüedad del parque es un dato importante, ya que se vincula con factores como la calidad de servicio, el consumo energético o las emisiones de GEl; para este estudio, se encontró que la edad media en los países de la región se sitúa entre los 14 y los 17 años ( 11,7 en la UE).

Otro factor relevante para el desempeño del sector es su organización empresarial. El análisis de diversos países muestra una elevada atomización, reflejada en la alta proporción de operadores individuales (característica que se replica en todo el mundo), una tendencia leve hacia la concentración de los mercados (seguramente más intensa en 
mercados especializados), empresas mayores con flotas más modernas y un transporte propio (flotas de empresas que transportan su propia carga) con un rol muy relevante. La distancia recorrida anualmente por los equipos (que revelan su productividad) muestra un amplísimo rango dentro de cada país, en el que algunos segmentos alcanzan valores similares a los de las economías más desarrolladas. Esta dispersión pone en evidencia que los tiempos muertos, que resultan de los procedimientos de carga y descarga que les impone el cargador, tienen una incidencia muy grande en la productividad de algunos segmentos de actividad del TAC. La ocupación efectiva de los vehículos de carga, sea por la proporción de viajes vacíos que realizan como por la ocupación efectiva de su capacidad cuando transportan cargas, es otro de los indicadores típicos de desempeño operativo. En ALC la ocupación de las bodegas se sitúa en el orden del $50 \%$ al $60 \%$, en este indicador incide fuertemente la estructura espacial de la demanda.

Los costos del TAC han sido analizados en detalle en muchos países; donde se destaca claramente los costos de combustible ( $35 \%$ aproximadamente) y los de personal $(25 \%$ a $30 \%$ ). Dos factores generalmente subestimados son los costos financieros (los transportistas están expuestas a un desfasaje financiero entre sus cobranzas y el pago de sus obligaciones), y las condiciones de carga y descarga; debido a que, los cargadores suelen abusar del transportista, generándoles largos períodos de espera que reducen el uso productivo de sus equipos. Se destacan también el peso de la carga fiscal, el impacto de los robos (que puede alcanzar el $3 \%$ del costo total) y el costo de la corrupción, que se expresa en el pago de sobornos para conseguir contratos, el pago a entidades sindicales para reducir conflictos, y los pagos a agentes públicos al registrar los vehículos o durante la circulación. No se conoce que existan estimaciones de los costos externos del TAC en la región; por ejemplo, cálculos realizados en otros países (Canadá, Estados Unidos) los dimensionan entre el $10 \%$ y el $20 \%$ de los costos que enfrentan los operadores, pero la naturaleza de estos costos externos hace que no puedan ser fácilmente trasladado de un país a otro.

La relación de los fletes (los precios) con los costos resulta del proceso de negociación entre el transportista y el cargador. Es muy frecuente que exista una amplia asimetría en ese proceso a favor de este último, que está en mejor posición para imponer las condiciones, particularmente a los pequeños operadores. La combinación de esta asimetría con una visión incompleta de los costos lleva a los pequeños operadores a establecer frecuentemente precios por debajo de sus costos medios de corto y largo plazo, conformando un caso de competencia predatoria. Para protegerse, los pequeños operadores suelen requerirle al Estado una regulación tarifaria que establezca valores mínimos de flete, generalmente relacionados con la distancia del transporte. Las denominadas tablas de flete en algunos casos son sólo orientativas (valores de referencia para la negociación) y en otros son obligatorias, aun cuando su cumplimiento es parcial. El establecimiento de tarifas mínimas, de referencia u obligatorias, constituye un fenómeno de la mayor importancia en la región; ya que, la presión de los pequeños transportistas hacia las autoridades para forzar su implementación ha sido la causa de los principales disturbios generados alrededor del TAC; como por ejemplo, dos casos emblemáticos son los disturbios ocurridos en Colombia en el año 2015 y en Brasil en 2017.

Otros factores que afectan el desempeño del TAC son la extensión y calidad de la red vial, que ha mejorado en ALC en los últimos años, aunque aún presenta debilidades 
importantes, y el despliegue de la banda ancha móvil (BAM), que constituye un eslabón fundamental para poder disponer de la información que requieren enviar o recibir los actores de las cadenas de suministro en cualquier ubicación. La cobertura y la velocidad de la BAM en ALC es considerablemente menor que en las economías desarrolladas, especialmente en servicios $4 G$; dado que, la mayor debilidad se encuentra en la cobertura fuera de las áreas urbanas, a lo largo de las carreteras donde transitan los camiones con servicios interurbanos e internacionales.

EI TAC es un sector que se rige básicamente por la competencia, sin regulación económica (entrada, salida, precios), sea por opciones de política pública o por falta de capacidad de control. La mayor presión regulatoria proviene de regulaciones técnicas destinadas a la seguridad y la protección ambiental, cubriendo aspectos referidos a los vehículos, su circulación, sus conductores y las prácticas operativas. Las normas suelen expresarse en códigos que en muchos casos no son específicos del TAC, como son las normas de circulación y seguridad vial (que abarcan a todo tipo de vehículo), y en reglamentaciones ambientales de orden general. Los temas centrales son los pesos y dimensiones de los vehículos, las modalidades de estiba, la relación entre la potencia y el peso, la antigüedad máxima de los vehículos, los límites establecidos para las emisiones, y las condiciones de trabajo de los conductores. Esta perspectiva de "menor regulación económica y mayor regulación técnica" se ha visto desafiada recientemente, ante las presiones ejercidas por los pequeños operadores para imponer tablas de fletes. Por otra parte, el TAC no solo es regulado por las leyes y disposiciones propias del sector, emanadas de los organismos del estado específicos (ministerios de transporte o similares); sino también, por otros organismos, como los relacionados con las cargas (sanidad de los alimentos, regulación de mercancías peligrosas, etc.), con gestión vial, o con aduanas. Además, en los países con organización federal como Argentina, Brasil o México, a las disposiciones federales se suman las de las provincias o estados y las de distritos 0 municipios, que a veces son distintas y hasta contradictorias entre sí.

Cabe destacar la emergencia de programas tendientes a que el TAC sea más amigable con el ambiente, consuma menos recursos y sea más eficiente en esos aspectos. Suelen ser programas en los que el Estado otorga algún tipo de bonus a las empresas que se adhieren a prácticas del transporte limpio y seguro. Los temas centrales en estos programas son las mayores dimensiones admitidas en los equipos, una limitación creciente de las emisiones y el consumo energético, mayor seguridad para minimizar los accidentes (como requisitos de equipos telemáticos, y exigencia de sistemas activos y pasivos en las unidades nuevas), y la generación de mecanismos participativos (del tipo de mesas de acuerdo, nucleando a los numerosos actores vinculados al TAC). Otros temas que han ingresado con mayor fuerza en la normativa están relacionados con las condiciones de trabajo de los conductores y su control, debido a su relevancia social y a su relación con la seguridad.

La incorporación de vehículos a las flotas (nuevos o usados) han acompañado el crecimiento de la demanda, con valores que fluctúan entre el $5 \%$ y el $7 \%$ anual, con la excepción de las economías que sufrieron estancamiento o retroceso; por ejemplo, Argentina y Brasil. Así como se incorporan nuevos vehículos en los registros, es de esperar que algunos - particularmente los más antiguos - dejen de operar o lo hagan en forma ocasional, aunque se mantengan registrados. La incorporación de vehículos del TAC es 
más intensa en las empresas de mayores dimensiones, y muestra una tendencia hacia los tractocamiones con semirremolques, más que hacia camiones rígidos con remolques.

La estructura del mercado del TA, caracterizada por la atomización y presencia de numerosos operadores individuales, es un obstáculo para la renovación de la flota. Los transportistas individuales difícilmente pueden acceder a financiamiento, razón por la cual los Estados han impulsado programas de apoyo. Los motivos tradicionales de estos programas eran la incorporación de unidades más eficientes, seguras y limpias. En los últimos años se ha sumado como componente el desguace (chatarrización); siendo esto, programas de renovación que apuntan no sólo a incorporar nuevos vehículos; sino también, a retirar del mercado los más antiguos, tanto por razones de seguridad vial como porque son los más contaminantes y de menor eficiencia energética. Los resultados de estos programas en varios países muestran la dificultad de lograr llegar a los operadores más pequeños (ya que no son sujetos de financiamiento); asimismo, las enseñanzas dentro de la región muestran programas que han resultado relativamente exitosos, al permitir incorporar vehículos nuevos y desguazar los más antiguos.

EI TAC presenta desempeños diferenciados en distintas subregiones del ALC. Siguiendo la clasificación adoptada en estudios anteriores, se reconocen cuatro áreas en las que el TAC presenta una cierta homogeneidad: Centroamérica, los países Andinos, el Cono Sur y México. El análisis de su desempeño desde esta perspectiva permite apreciar algunos comportamientos específicos a cada subregión y otros comunes a todas ellas. Entre las primeras, el TAC en Centroamérica se destaca por la alta participación de los servicios internacionales, un desempeño operativo débil, una facilitación comercial en el tránsito entre países que va mejorando, alta siniestralidad, y un avance relativamente lento en normativas de seguridad y protección ambiental. En los Países Andinos el desempeño operativo es también débil, ha habido mejoras importantes en la infraestructura vial y pocos avances en la facilitación de los tráficos internacionales. En el Cono Sur el desempeño operativo es relativamente mejor, los avances en la infraestructura vial han sido moderados, la siniestralidad es menos pronunciada, y ha habido algunos avances en las regulaciones ambientales y de seguridad. En México el transporte internacional es muy relevante, el desempeño operativo es satisfactorio, los programas de apoyo en la renovación de flotas han sido efectivos, y ha habido avances importantes en las normativas ambientales $y$ de seguridad.

El análisis del TAC en América Latina sugiere que, en su conjunto, el sector presenta un desempeño relativamente débil si se lo compara con el de las economías desarrolladas. Esto parece confirmar que el TAC se modela a imagen de sus dadores de carga y del ambiente socio económicos en el que se desempeña, ya que las economías de América Latina se presentan más débiles e informales que las desarrolladas. A su vez, muestran que en adición a esa "brecha externa", existe una notable "brecha interna" la que separa el desempeño de los distintos segmentos del TAC en cada país. En toda la región aparecen segmentos con baja productividad que contrastan con operadores (generalmente nacionales) que exhiben un desempeño de clase mundial. Esta brecha es creciente, incentivada por la adopción de nuevas tecnologías, equipos de mayores dimensiones, expansión vertical de las empresas hacia las actividades logísticas y concentración empresarial que está ocurriendo en todas las cadenas de abastecimiento (la concentración en los dadores de carga impulsa la concentración de los transportistas). 
En lo referente a la distancia recorrida por las unidades del TAC, en ALC equivale al $60 \%$ de la que recorren en las economías más desarrolladas y similar al promedio mundial. En cuanto a la ocupación, los valores en la región se ubican, en un gran promedio en el rango del $40 \%$ de los vehículos-km vacíos, que contrastan con el aproximadamente $25 \%$ de los países europeos y $20 / 25 \%$ en América del Norte. Respecto a los niveles de fletes, el rango es muy amplio, considerando en términos generales que en ALC los valores son similares a los valores medios observados en países desarrollados. La conclusión, aún con las limitaciones que tienen los indicadores disponibles, es que el desempeño operativo de $A L C$ en promedio es claramente menor que en los países desarrollados, con diferencias entre segmentos de actividad muy pronunciadas dentro de un mismo país, y que los fletes cobrados no son más altos. Diversos factores contribuyen a estas brechas, tanto externas como internas, que se encuentran entrelazados. Se los puede agrupar de acuerdo con el impacto que generan:

(i) Factores que reducen la productividad del sector, como: la organización empresarial atomizada, la informalidad, la calidad y antigüedad de los equipos, las relaciones con los dadores de carga, el estado de la infraestructura vial y de telecomunicaciones, y la escasa incorporación de nuevas tecnologías.

(ii) Factores que incrementan el valor de los fletes, como: la carga impositiva, los costos laborales y las demandas sindicales, el precio de los combustibles, la calidad de las infraestructuras, la falta de competencia en algunos casos excepcionales, las modalidades de contratación de servicios, la seguridad de la carga respecto del hurto o robo, la calidad y antigüedad de los equipos, las relaciones con los dadores de carga y la baja incorporación de nuevas tecnologías.

(iii) Factores que atentan contra la calidad del servicio, como: las limitaciones de la infraestructura de telecomunicaciones, la escasa incorporación de sistemas tecnológicos de asignación de cargas y rutas, y la inestabilidad de las economías.

(iv) Factores que incrementan las externalidades negativas, como: la falta cumplimiento de reglas, la debilidad de los controles, la edad de las flotas y la calidad de los combustibles.

La búsqueda de buenas prácticas muestra que, en términos generales, la atención de las entidades públicas está centrada primariamente en disminuir las externalidades negativas que genera el TAC y en segundo término en mejorar la eficiencia. En el ámbito privado las empresas transportistas, al igual que otros actores de la cadena de abastecimiento, también han impulsado transformaciones, aunque con distintas prioridades; por ejemplo, un mayor énfasis en la productividad y en la eficiencia a través de mejoras operativas; como también un interés creciente en la sostenibilidad ambiental, incorporando la logística verde en sus políticas de responsabilidad social.

La revisión de experiencias recientes permitió identificar cinco casos que reflejan las tendencias en materia de buenas prácticas en el TAC en el mundo: (i) programas para mejorar la seguridad vial mediante la certificación de los procesos clave de las empresas transportistas; (ii) programas para descarbonizar el TAC y avanzar hacia una logística verde; (iii) conjuntos de buenas prácticas impulsadas por los actores de la cadena de suministros; (iv) regulaciones para mejorar la seguridad controlando las horas de trabajo 
de los conductores; e ( $v$ ) iniciativas para promover la utilización de vehículos más limpios mediante cargos por uso de infraestructura.

Mirando hacia el futuro, se presentan ante el TAC numerosas tendencias que van a incidir en su desempeño, aunque con una considerable incertidumbre. En el informe se tratan dos tendencias clave: las referidas a los mercados del TAC y los impactos que tendrán en el sector las tecnologías propias de la Cuarta Revolución Industrial. En los mercados se destaca el crecimiento de los volúmenes, y la expansión de los nuevos canales de venta y distribución, particularmente en el ámbito urbano, debido al impacto del crecimiento del e-commerce, los nuevos modelos de negocio (las bolsas de carga), la informalidad, y el control de las reglas de carga y descarga. En cuanto a los cambios tecnológicos, estos ya están generando un impacto en el TAC que indudablemente será mayor en los próximos años. Estos cambios se producirán tanto a nivel de los vehículos como de la organización comercial y operativa de las flotas, en tres grandes áreas: (i) la digitalización e interconexión de los vehículos, haciendo uso de la telemetría para mejorar la eficiencia, la seguridad y la calidad de servicio, (ii) el desarrollo de vehículos autónomos, y (iii) los nuevos sistemas de propulsión.

\section{Orientaciones para la política públicas}

Atendiendo a la situación actual del sector, las tendencias internas y externas que afectarán su desempeño, las aspiraciones de política pública respecto al TAC y los obstáculos existentes para avanzar en su concreción, se propone un conjunto de áreas de acción prioritarias para orientar las políticas referidas al TAC en los países de la región con un horizonte de mediano plazo:

1. Mejorar la eficiencia y la calidad del servicio

2. Descarbonizar la actividad y reducir otros impactos ambientales

3. Minimizar los siniestros

4. Fortalecer las instituciones y la coordinación entre los actores

5. Mejorar la infraestructura y los nodos operativos

Para cada una de estas áreas de actuación se proponen iniciativas específicas, que se resumen en la tabla a continuación. Estas iniciativas pueden considerarse como un "menú" potencial de medidas, que pueden adaptarse con diversa conveniencia a las necesidades de cada país.

Para reconocer el impacto de las políticas nacionales de apoyo al TAC es conveniente desarrollar mecanismos de monitoreo, identificando indicadores clave (KPI) que permitan evaluar el desempeño y los avances, superando la debilidad que tienen los sistemas estadísticos nacionales al respecto. A título de ejemplo, se proponen algunos indicadores, como los $\mathrm{km}$ recorridos por año por los camiones, en promedio, los viajes vacíos como \% de los viajes totales, el \% de bodega ocupada en viajes con carga, la edad promedio de la flota, las emisiones de GEl, la participación en siniestros viales y los tiempos de carga/descarga. 


\begin{tabular}{|c|c|}
\hline $\begin{array}{l}\text { Áreas de } \\
\text { actuación }\end{array}$ & Acciones de política \\
\hline \multirow{5}{*}{$\begin{array}{l}\text { Mejorar la } \\
\text { eficiencia y la } \\
\text { calidad del } \\
\text { servicio }\end{array}$} & Promover digitalización \\
\hline & Habilitar vehículos de mayores dimensiones \\
\hline & Controlar volatilidad de precios de combustibles \\
\hline & Apoyo a Pymes, cambio cultural de pequeños operadores, asociatividad \\
\hline & Mejorar condiciones de seguridad (vigilancia) \\
\hline \multirow{4}{*}{$\begin{array}{l}\text { Descarbonizar } \\
\text { el TAC y } \\
\text { reducir otros } \\
\text { impactos } \\
\text { ambientales }\end{array}$} & Programas de renovación de flotas y desguace de unidades viejas \\
\hline & Adecuar tasas a las emisiones \\
\hline & Impulsar programas autorregulados tipo SmartWay \\
\hline & Control sobre importación de vehículos usados \\
\hline \multirow{3}{*}{$\begin{array}{l}\text { Minimizar los } \\
\text { siniestros }\end{array}$} & Limitaciones de velocidad de los equipos \\
\hline & Condiciones de trabajo, horarios de conducción y fiscalización \\
\hline & Incentivar certificación de empresas seguras \\
\hline \multirow{7}{*}{$\begin{array}{l}\text { Fortalecer las } \\
\text { capacidades } \\
\text { públicas y la } \\
\text { coordinación }\end{array}$} & Organización y capacidades de las entidades del sector público \\
\hline & Iniciativa de generación de datos \\
\hline & Apoyo a la formalización y el uso de contratos \\
\hline & Desarrollo de capital humano (formación de conductores y empresarios) \\
\hline & Coordinación intersectorial y nacional-subnacional \\
\hline & Coordinación entre actores (mesas de trabajo) \\
\hline & Armonización normativa y facilitación comercial \\
\hline \multirow{5}{*}{$\begin{array}{l}\text { Mejorar la } \\
\text { infraestructura } \\
\text { y los nodos } \\
\text { operativos }\end{array}$} & Mejoras en la red vial en todos sus niveles \\
\hline & Mejoras en los accesos a los grandes nodos de carga/descarga \\
\hline & Rediseño de los sistemas de distribución urbana \\
\hline & Mayor cobertura de la banda ancha móvil \\
\hline & Desarrollo de redes de nodos logísticos \\
\hline
\end{tabular}

Las orientaciones propuestas no difieren mayormente de las que se sugerían en el estudio publicado en 2017. Sin embargo, si bien los temas son similares, se observa un importante cambio de énfasis en algunos de ellos, particularmente en lo referente al cambio climático y la seguridad vial, y se resalta notablemente el cambio que pueden producir (y que ya están produciendo) las nuevas tecnologías. Otro aspecto que ha ganado importancia en este nuevo análisis es la necesidad de una mayor atención a la coordinación institucional (entre áreas responsables de políticas públicas) y con los dadores de carga, que constituyen actores clave para que el TAC mejore su desempeño. 


\section{OBJETIVOS Y ORgANIZACIÓN DEL INFORME}

\subsection{Motivación y propósito}

El concepto de "supply chain" o "cadena de abastecimiento" se desarrolló hace alrededor de cuarenta años, como una forma de entender la administración de flujos de bienes en las cadenas de valor y su gerenciamiento evolucionó hasta convertirse, en la actualidad, en la disciplina fundamental para cualquier industria o sistema comercial, al tratarse de un concepto unificador y comprensivo de todos los procesos que generan riqueza. Las redes de transporte son parte esencial de la cadena de abastecimiento, y son la base de la economía de cualquier país. Permiten que los bienes se distribuyan de manera eficiente y que las personas viajen. Hacen accesibles los lugares, nos unen y nos permiten una alta calidad de vida (European Commission, Directorate-General for Communication Citizens information, 2014). Como el transporte de la carga ha crecido exponencialmente en las últimas décadas, los responsables de la configuración de las políticas públicas ahora deben incluir los flujos de carga en las evaluaciones cuantitativas de los sistemas de transporte. En tanto que las modelizaciones tempranas para el movimiento de cargas se inspiraron en los modelos de transporte de pasajeros, ahora los modelos se deben basar en métodos y técnicas inspiradas en la geografía económica y la gestión de la cadena de suministro (Tavasszy y De Jong, 2013).

Los gobiernos han ido tomando nota de este nuevo escenario y, en su búsqueda de mejorar la competitividad de sus economías, procuran elevar la calidad del desempeño logístico. Sin embargo, hacerlo implica actuar sobre sus múltiples determinantes, en principio el énfasis se centra en proveer infraestructura, pero un análisis más profundo pone al descubierto la relevancia que tienen las regulaciones de los servicios de transporte, el desempeño del sector privado (generadores de carga, intermediarios y operadores), y los procedimientos y trámites propios del comercio y el transporte internacional. En particular, en América Latina el TAC es el modo de transporte interno más importante, ya que le corresponde la movilización de más del $70 \%$ de las cargas nacionales de la región, y su participación en el comercio entre los países de la región es creciente. No obstante su relevancia, el nivel de conocimiento sobre su desempeño es escaso, notablemente menor que el registrado en otros modos (Barbero, J., \& Guerrero, P. (2017). Con el objeto contribuir al avance del conocimiento del TAC en la región, el Banco Interamericano de Desarrollo (BID) llevó a cabo diversos estudios sectoriales de alcance nacional y subregional en 14 países entre 2013 y 2015, cuyos resultados se publicaron en 2017, bajo el título El transporte automotor de cargas en América Latina, aportando una mirada general, reconociendo las principales características y tendencias del sector, así como los retos que enfrentaba en aquel momento.

El objetivo del presente informe es actualizar esa mirada, analizando la evolución reciente del TAC, las principales tendencias (particularmente en las regulaciones, la tecnología y los mercados) y las enseñanzas de las buenas prácticas de otras regiones, concluyendo con lineamientos de política pública que pueden contribuir a un mejor desempeño del TAC en la región. 


\subsection{Contenidos del informe}

La organización: comienza con una sección introductoria, que destaca los objetivos, organización del informe, resumen la relevancia y los desafíos que enfrenta el TAC en América Latina. Luego continúa con la caracterización del sector de transporte automotor de cargas en la región, las tendencias en el desempeño, los avances en los marcos regulatorios y la dinámica de la renovación de flotas. Seguidamente se hace una descripción del sector por subregiones de Latinoamérica, se evalúa la productividad entre países y segmentos de actividad, se describen las buenas prácticas internacionales, se analiza la perspectiva de los mercados y la tecnología a futuro y se finaliza con los retos del TAC en la región y las opciones de políticas públicas propuestas. 


\section{CARACTERIZACIÓN Del TRANSPORTE Automotor de CARGAS}

\subsection{El rol del TAC en el movimiento de bienes}

El transporte automotor es uno de los modos de transporte terrestre clave en la moderna logística de cargas, que constituye, a su vez, uno de los pilares de la gestión de las cadenas de abastecimiento. El concepto de cadena de abastecimiento, o de suministro, se tornó relevante en las tres últimas décadas del siglo XX, como una forma de comprender el movimiento de bienes dentro de las cadenas de valor, que en esos años se fueron globalizando. La gestión de las cadenas de abastecimiento fue evolucionando, hasta convertirse en la actualidad en una disciplina fundamental para cualquier actividad vinculada a la producción y comercialización de bienes. Dentro de ella, la logística de cargas es un componente clave, que centra su acción en la organización de los flujos físicos de mercadería y de información.

La logística abarca más que el transporte, también contempla los desplazamientos de los bienes en el espacio (transporte) y en el tiempo (almacenamiento); mencionando que, ambos movimientos se encuentran estrechamente relacionados y su organización debe ser programada en forma integrada. La gestión de la logística, no procura minimizar el costo de transporte de manera aislada, sino el costo conjunto del transporte y del almacenamiento (tanto por lo que representa el valor físico de almacenar los bienes como por el costo financiero del inventario inmovilizado). Quienes generan las cargas típicamente, firmas que producen y comercializan bienes - buscan gestionar eficientemente sus cadenas de abastecimiento minimizando los costos bajo el concepto de "costo logístico total" y asegurando la calidad del servicio a lo largo de sus eslabones.

Aun cuando la actividad del transporte es sólo un componente de la logística, es uno fundamental. La globalización ha incrementado su relevancia, al extender el rango geográfico de las cadenas de valor, significando un fuerte desafío para la logística y un considerable incremento para el nivel de actividad de los transportes en todos sus modos. Los flujos de transporte en el mundo han crecido considerablemente más que el producto bruto, atento a la forma en que se organizó la actividad económica a través de la expansión del outsourcing y del offshoring. Esos flujos articulan los distintos eslabones de las cadenas de valor, combinando usualmente modos de transporte; los camiones - en ese esquema - constituyen por lejos el principal modo de transporte terrestre, en el planeta y en la región. EI TAC brinda conectividad local, regional e internacional en las cadenas de valor y no sólo cubre movimientos de larga distancia, domésticos e internacionales; sino también, que tiene una función clave en la distribución de bienes en las ciudades. Estos fenómenos se ilustran en las siguientes secciones. 


\subsection{La diversidad de segmentos de actividad}

EI TAC presenta características específicas que dependen especialmente del tipo de carga y nivel de servicio que pretende quien la genera, de tal manera que puede afirmarse que existen casi tantas posibilidades de configuraciones técnicas, operativas y empresariales como clases de productos y clientes hay en el mercado. La gran heterogeneidad que caracteriza al sector, en sus diversas dimensiones, puede agruparse fundamentalmente en:

- las características técnicas de los vehículos

- los tipos de carga que pueden transportar

- el ámbito geográfico de sus prestaciones

- la modalidad de la organización empresarial

- las relaciones contractuales con el generador de cargas

Esta diversidad tiene como corolario que muchos datos agregados, que representan promedios generales del sector, encubren varianzas muy significativas.

Las características técnicas de los vehículos (considerando como vehículos tanto a las unidades motrices como a las remolcadas) condicionan los tipos de carga que tienen aptitud para transportar, de acuerdo no sólo con las características de su bodega sino también de su configuración general (dimensiones, potencia, número de ejes). La variación en los tipos de vehículos es enorme y la tendencia a su diversidad es creciente, desarrollándose cada vez más equipos con configuraciones a la medida de los requerimientos de los clientes en aspectos tales como: la motorización, la relación de diferencial, las características de la caja de cambios, los equipamientos especializados, el tipo de neumáticos, etc.

Entre los tipos de carga a las que se orientan las unidades, suele distinguirse la carga general (particionada, en pallets, paquetería, documentación, pequeños bultos), el transporte de contenedores, los graneles sólidos (como los cereales, oleaginosas, piedras, minerales, movimientos de tierra), los graneles líquidos (combustibles, leche, productos químicos), las cargas peligrosas (definidas como tales por los riesgos que implican su transporte), las cargas refrigeradas y las cargas especiales (hormigón, automóviles, caudales, etc.). Estos tipos de carga se combinan generando subtipos; por ejemplo, hay cargas peligrosas sólidas y líquidas, que pueden ir a granel o no, que pueden necesitar refrigeración $\circ$ no. Además, cada tipo de carga puede requerir disímiles niveles de calidad de servicio, y de precio que el dador de la carga esté dispuesto a pagar, lo que redunda en distintos requisitos para las unidades de transporte y la organización empresarial. Cabe también destacar que una parte significativa de los camiones que circulan no apuntan primariamente a transportar carga, sino que están preparados para brindar servicios específicos: flotas de apoyo al mantenimiento de servicios públicos (redes eléctricas, de telecomunicaciones o de agua y saneamiento), camiones-grúa, mezcladores de hormigón, camiones con tanques atmosféricos para aguas servidas, camiones de bomberos, etc.

En referencia al alcance geográfico de los servicios del TAC, las modalidades operativas varían en cuanto a la escala de la actividad: 
- el transporte interurbano de cargas entre centros urbanos, áreas rurales y centros de carga y descarga; representa el típico tráfico cabotaje nacional.

- el transporte internacional, con origen en un país y destino en otro, cruzando fronteras

- la distribución urbana, centrada en los tráficos de carga internos de las ciudades, asociada generalmente a operaciones logísticas. Los flujos urbanos también incluyen movimientos tales como recolección de residuos, procesamiento de concreto, distribución de caudales o entrega de paquetes a domicilio.

Los tipos de organización empresarial del TAC son muy diversos, abarcando desde el dueño de un camión que lo opera y explota comercialmente por sí ${ }^{\text {, }}$, hasta grandes operadores logísticos que realizan tareas de transporte gestionando grandes flotas, 0 eventualmente subcontratando el servicio y sin poseer vehículo alguno. Cabe destacar la relevancia que tienen el denominado transporte propio, que se refiere a actividades del TAC llevadas a cabo por el mismo dador de carga gestionando sus propios vehículos (tema que se desarrolla en la sección 0 ).

Las firmas de autotransporte de cargas en América Latina son usualmente propiedad de empresarios del mismo país en el que operan. La principal excepción son los servicios tipo courier y los grandes operadores logísticos, segmentos en los que operan empresas globales y nacionales, dependiendo del país. Además, desde hace aproximadamente diez años se está observando un proceso incipiente de empresas de la región que se están expandiendo desde su país de origen hacia países limítrofes.

La estructura societaria puede fluctuar desde el operador individual hasta sociedades anónimas que cuentan con una organización corporativa completa. En general, las formas societarias más sofisticadas corresponden a las empresas más grandes, mientras que las firmas menores son operadores independientes: microempresas, que presentan una mayor tendencia a la informalidad. Tradicionalmente las empresas suelen ser familiares y con escasa profesionalización hasta que superan un determinado umbral; esta última característica está cambiando, evidenciándose un mayor grado de profesionalismo. La TABLA 1 resume los modelos de organización empresarial más frecuentes del TAC en América Latina.

\footnotetext{
1 Denominado también, según el país: fletero, hombre-camión, one man/one truck, driver/owner.
} 


\begin{tabular}{|c|c|c|c|c|}
\hline Tipo de transportista & $\begin{array}{l}\text { Características } \\
\text { empresariales }\end{array}$ & $\begin{array}{c}\text { Características de los } \\
\text { vehículos }\end{array}$ & Mercado & Modos de Asociatividad \\
\hline $\begin{array}{l}\text { Individuos asociados } \\
\text { con pocas unidades } \\
\text { (hasta } 5 \circ 6 \text { ) }\end{array}$ & $\begin{array}{l}\text { Mínima formación } \\
\text { empresarial; gestión de } \\
\text { subsistencia. } \\
\text { Generalmente con lazos } \\
\text { familiares; similar al anterior. }\end{array}$ & $\begin{array}{l}\text { Unidades viejas, con baja } \\
\text { potencia, alto consumo de } \\
\text { combustible y de generación } \\
\text { de emisiones. Propensas a } \\
\text { accidentes viales. }\end{array}$ & $\begin{array}{l}\text { Dadores de carga, o } \\
\text { transportistas más grandes. } \\
\text { Generalmente en mercado } \\
\text { spot. }\end{array}$ & $\begin{array}{l}\text { Mínima. Eso reduce su } \\
\text { capacidad de negociación } \\
\text { con los clientes, que suelen } \\
\text { abusar (en precios y } \\
\text { condiciones). }\end{array}$ \\
\hline $\begin{array}{l}\text { Transportistas } \\
\text { medianos con varias } \\
\text { unidades propias } \\
\text { (entre } 6 \text { y } 10 \text { ) }\end{array}$ & $\begin{array}{l}\text { Micro Pymes. Baja formación } \\
\text { empresarial; buen control de } \\
\text { costos. Con personal } \\
\text { asalariado. }\end{array}$ & $\begin{array}{l}\text { Unidades viejas o nuevas, } \\
\text { según el cliente al que } \\
\text { atiendan y a su propia } \\
\text { disponibilidad financiera,y } \\
\text { criterios técnicos para su flota. }\end{array}$ & $\begin{array}{l}\text { Dadores de carga, o } \\
\text { transportistas más grandes. } \\
\text { Suelen tener clientes fijos que } \\
\text { les requieren características } \\
\text { especiales. }\end{array}$ & $\begin{array}{l}\text { Pueden llegar a agruparse en } \\
\text { asociaciones empresariales } \\
\text { locales. Los trabajadores } \\
\text { pertenecen a los sindicatos. }\end{array}$ \\
\hline $\begin{array}{l}\text { Cooperativas de } \\
\text { transportistas }\end{array}$ & $\begin{array}{l}\text { Asociación de operadores } \\
\text { individuales, que suman sus } \\
\text { unidades para tener mayor } \\
\text { escala. }\end{array}$ & $\begin{array}{l}\text { Unidades viejas o nuevas, } \\
\text { dependiendo del cliente al } \\
\text { que atiendan. Los recursos } \\
\text { técnicos y financieros } \\
\text { dependen de cada asociado. }\end{array}$ & $\begin{array}{l}\text { En general grandes clientes } \\
\text { de graneles agrícolas. }\end{array}$ & $\begin{array}{l}\text { Los socios de la cooperativa } \\
\text { pueden llegar a agruparse en } \\
\text { agremiaciones empresariales. } \\
\text { Los empleados pertenecen a } \\
\text { los sindicatos. }\end{array}$ \\
\hline $\begin{array}{l}\text { Transportistas } \\
\text { grandes con múltiples } \\
\text { unidades propias o } \\
\text { tercerizadas }\end{array}$ & $\begin{array}{l}\text { Pymes, con estructura } \\
\text { empresarial completa, que } \\
\text { operan unidades propias o } \\
\text { contratadas. }\end{array}$ & \multirow{2}{*}{$\begin{array}{l}\text { Unidades adaptadas al tipo } \\
\text { de cliente al que atiendan, a } \\
\text { su propia disponibilidad } \\
\text { financiera y criterios técnicos } \\
\text { para su flota. }\end{array}$} & \multirow{2}{*}{$\begin{array}{l}\text { En general, grandes dadores } \\
\text { de cargas, con contratos de } \\
\text { largo plazo y condiciones de } \\
\text { servicio estrictas. Servicios } \\
\text { expreso atienden cargas } \\
\text { fragmentadas. }\end{array}$} & \multirow{2}{*}{$\begin{array}{l}\text { Agremiación empresaria en } \\
\text { una o varias cámaras. Los } \\
\text { trabajadores pertenecen a los } \\
\text { sindicatos. }\end{array}$} \\
\hline Operadores Logísticos & $\begin{array}{l}\text { Transportistas grandes, que } \\
\text { han ampliado su ámbito, } \\
\text { prestando servicios logísticos } \\
\text { (almacenamiento, gestión de } \\
\text { órdenes). Operan unidades } \\
\text { propias y contratadas. }\end{array}$ & & & \\
\hline
\end{tabular}

- Al transportista Individual en México se les denomina "hombre camión". En Argentina, si posee un camión tractor sin bodega se le llama "tractorista", y si posee bodega 0 un remolque, se le denomina "fletero".

- En Argentina, los individuos asociados con pocas unidades son llamados "flotilleros" o "flotillas" si posee camiones tractores sin bodega se le llama "tractorista", y si poseen bodega o remolques, se les denomina "fleteros".

Fuente: Fiadone, R. (2018)

Aunque el sector presenta las características de un mercado ampliamente competitivo, homogéneo y atomizado, se observa que la cantidad de oferentes se reduce a medida que aumenta la complejidad de las operatorias demandadas. Por ejemplo, es común observar una muy amplia la oferta de transportistas para los productos indiferenciados, y una mucho más reducida para cargas especiales o para operaciones logísticas.

Los operadores (tanto las empresas mayores como los operadores individuales, e incluso los informales) se agrupan en cámaras empresariales a través de las cuales buscan defender sus intereses como sector. Estas asociaciones reflejan la alta asociatividad que predomina en el sector en todos los países, promovida por la necesidad de defender los intereses comunes frente a los dadores de carga (en general, empresas con mayor poder económico que buscan fraccionar la oferta de transportistas) para así mejorar su propia posición negociadora. Las entidades agrupan a las empresas por su ubicación geográfica, o por su especialización de oferta, o a veces por ambos factores, generando multiplicidad de cámaras, asociaciones y federaciones, lo que refleja la complejidad del sector. Además, las empresas más formales se agrupan en cámaras que están a favor de mayores regulaciones técnicas. Esto suele constituir una barrera de entrada que puede 
dejar fuera de mercado a los transportistas más informales. Por otro lado, la atomización de la oferta hace que no haya posiciones dominantes, salvo excepciones, y en general es el dador de carga el que pone las condiciones operativas.

Las relaciones contractuales entre dadores de carga y transportistas, y de los transportistas entre sí, asumen formas muy diversas y combinadas. El generador de carga puede contratar servicios con transportistas pequeños y medianos (de hasta diez equipos, con escasa organización), con grandes transportistas, que cuentan con estructuras técnicas y administrativas, $\circ$ con operadores logísticos. Los grandes operadores suelen subcontratar servicios, al menos parcialmente, de transportistas más pequeños. El Gráfico 1 resume los principales aspectos de la contratación. Generalmente son acuerdos y presupuestos que pocas veces se plasman en documentos contractuales, salvo en los acuerdos de largo alcance (por ejemplo, con un operador logístico). Los acuerdos pueden ser formales o informales (como se verá en la sección 2.4, la informalidad es muy frecuente en el TAC de América Latina), con una dedicación total o parcial, y demandando un equipo completo, parte de su bodega o exclusivamente la unidad tractora (por ejemplo, cuando el generador de carga tiene sus propias unidades remolcadas).

\section{Gráfico 1 - Aspectos ClaVe de LA CONTRATACIÓn Del TAC}

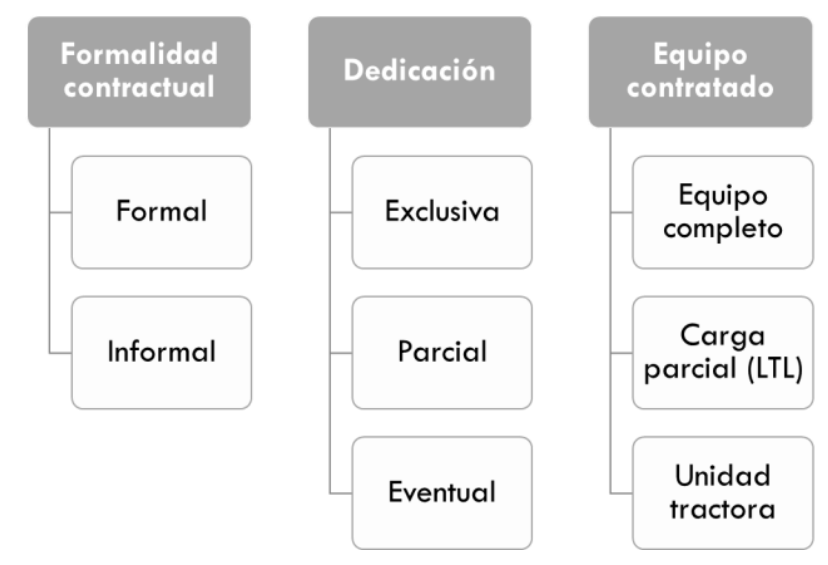

Fuente: Fiadone (2018)

Un aspecto para destacar es la gran influencia que tienen las características del dador de carga sobre los operadores del TAC. Algunas actividades productivas y comerciales imponen una alta disciplina y profesionalidad a los transportistas (por ejemplo, la distribución de combustibles o movimientos de cargas peligrosas), en tanto otras se limitan a requerir al transportista el menor valor de flete posible; por ejemplo, este caso es frecuente en el transporte de granos o de productos de la construcción.

\subsection{Las limitaciones de los datos básicos}

Un análisis realizado por el BID sobre la logística en la región en el año 2010 advertía sobre la escasez de fuentes de información y de análisis del TAC, no obstante mencionaba ser el modo de transporte interno de mayor relevancia en el transporte de cargas (Barbero, 2010). Estudios posteriores referidos a la disponibilidad y calidad de los datos 
del transporte en América Latina señalaban al TAC como uno de los modos que presentaba la mayor debilidad (Barbero \& Uechi, 2012), destacando la escasez y heterogeneidad de las fuentes de información (Barbero \& Guerrero, 2017). Las principales falencias son la falta de estadísticas básicas en el nivel de actividad (las ton$\mathrm{km}$ transportadas por camión) ${ }^{2}$, la baja desagregación (al no contemplar los segmentos) y algunas dudas sobre la calidad de los datos disponibles. La falta de armonización en las definiciones que adoptan los países de la región dificulta los análisis comparados. Más allá de las fuertes falencias que presenta en la región, la debilidad de la información sobre el TAC es un problema general (Recuadro 1).

\section{RECUADRO 1 - LA BAJA DISPONIBILIDAD DE DATOS EN EL TAC}

La baja disponibilidad de datos en el TAC es fenómeno general. Uno de los principales estudiosos del tema lo refleja así: "El transporte de carga generalmente se caracteriza por ser la sangre vital de un país y vital para su desarrollo económico, pero el reconocimiento político de su importancia a menudo no se extiende hasta la oficina de estadísticas."

McKinnon, 2015: Performance measurement in freight transport: Its contribution to the design, implementation and monitoring of public policy

En algunos países de la región existen anuarios que resumen datos estadísticos: cantidades de vehículos, toneladas transportadas, toneladas-kilómetro producidas, distancias medias y otros similares ${ }^{3}$, aunque con escaso grado de desagregación en cuanto a las cargas transportadas, tipos y tasas de ocupación de las unidades, el consumo de combustible $\circ$ las tarifas. En otras regiones del mundo ha habido avances importantes en la armonización de la información, adoptando glosarios comunes y generando bases de datos con criterios comparables (como es el caso de OECD Data y del ITF Transport Statistics, que ya abarcan 50 países, de los cuales sólo dos - México y Chile - pertenecen a América Latina).

Los esfuerzos más destacados para estimar y proyectar el nivel de actividad del TAC son los realizados por la comunidad profesional energética-ambiental, atenta al consumo de combustibles y generación de gases de efecto invernadero (GEI) del sector. Un ejemplo es el Modelo de Movilidad (MoMo) desarrollado por la International Energy Agency (IEA, 2017). El MoMo es un modelo de simulación diseñado para estimar y calibrar el consumo de energía y las emisiones de GEl de los vehículos de transporte, basado en datos de panel que se extienden desde 1990 hasta 2015 . Considera las ventas de vehículos y las dimensiones de las flotas (stock), y estima los consumos de combustible, el kilometraje recorrido y los factores de ocupación/carga de los camiones. Contempla también los costos de los vehículos, de los combustibles y de otros insumos de la actividad, y los requisitos de infraestructura. Los valores estimados presentan diferencias considerables con los que reportan los países; por ejemplo, son menores que los que informa China y mayores que los que reporta la Unión Europea. MoMo es un modelo descriptivo, que permite la creación de escenarios hipotéticos. Permite modelar los impactos de las políticas utilizando elasticidades (e.g., la elasticidad de la demanda al precio del combustible) y

\footnotetext{
2 Países como Brasil o Argentina, por ejemplo, no disponen de esa información.

3 Por ejemplo: Brasil, Chile, Costa Rica, Paraguay, Perú y Uruguay.
} 
estudios de casos (e.g., el impacto de la congestión o los precios de estacionamiento sobre la carga) (Mulholland, 2017).

Las nuevas modalidades de captura de datos (big data) abren una perspectiva promisoria para mejorar la disponibilidad de información y una mayor desagregación. La digitalización de los documentos comerciales (mediante tecnología blockchain) y de la gestión operativa del TAC brindan fuentes potenciales que pueden desarrollarse en los próximos años, contribuyendo a superar las actuales carencias y a permitir la toma de decisiones de política pública basada en datos (ITF, 2018).

\subsection{El peso de la informalidad}

La informalidad, que significa el no cumplimiento de las normas, ha tenido tradicionalmente una fuerte impronta en el TAC en América Latina, pero, por su propia naturaleza, se encuentra muy poco documentada. A título de ejemplo, en Colombia, la Oficina de Regulación Económica estima que sólo se registran el $40 \%$ de los viajes realizados; en Perú las estimaciones muestran proporciones similares (que se incrementan sustancialmente cuando incluyen al transporte de pasajeros). En México el nivel de informalidad sería aproximadamente la mitad $(20 \%)$, según declaraciones de las cámaras empresarias.

La informalidad genera diversos impactos negativos: competencia desleal, distorsión de los costos y tarifas, reducción de ingresos para el sector y para el fisco, riesgos en la seguridad vial, falta de respuesta ante incidentes, menor calidad de servicio y falta de protección social para los trabajadores. Los transportistas informales tienen costos menores (debido a que no tributan impuestos y cargas del Estado), con lo cual pueden establecer tarifas que los operadores formales no pueden lograr, perjudicando al mercado en su conjunto.

La informalidad en LAC debe entenderse en el contexto de la informalidad de los negocios que es habitual en la región, ya que los transportistas reflejan las prácticas empresariales de los dadores de carga. Si estos tienen una calidad de productos, niveles de servicio y formalidad altas, buscarán que su proveedor de transporte cumpla con esas características. Por el contrario, si la calidad, nivel de servicio y grado de formalidad es bajo, incluyendo facturación, compras y empleados en "negro", el transporte replicará esa situación ya que el costo de la formalidad que podría tener no le será recompensado por el dador de carga. El elevado nivel de informalidad interpela la pertinencia de las normas y la eficacia de los organismos de regulación y control.

\subsection{La relevancia del sector en el mundo y en la región}

\section{La participación del TAC en el PIB}

La relevancia del sector puede medirse de diversas formas. Tradicionalmente se hace referencia a su participación en el PIB, tal como lo registran las cuentas nacionales. En 2016 el transporte carretero de cargas representaba - en promedio - el 5,7\% del PIB 
en América Latina, alcanzando valores más elevados en algunos países como Panamá, donde representaba el $12,6 \%$. Pero se trata de un indicador que tiende a subestimar el peso económico del TAC: se limita a registrar el valor agregado por la actividad de los camiones que prestan servicios comerciales de carga, excluyendo el denominado transporte propio, que refleja la actividad de transporte que realizan las firmas con sus propios equipos. Por ejemplo, empresas industriales que distribuyen sus productos con sus propias unidades, $\circ$ firmas mineras $\circ$ petroleras que tienen flotas propias, $\circ$ supermercados o empresas de servicios que realizan sus movimientos de bienes y de equipos con vehículos de su propiedad. Se estima que el transporte propio puede constituir aproximadamente un tercio de la actividad total del TAC. Las estadísticas de la OECD muestran que en el año 2017 representaba el 18\% de las ton-km en los países asociados, llegando a valores del 23\%, por ejemplo, en Francia. Los datos parciales que existen para América Latina sugieren una participación elevada: el $29 \%$ de las ton-km en Argentina, $018 \%$ de la flota en Perú.

En términos generales, se observa que el nivel de actividad del TAC acompaña la evolución del PIB. En algunos países creció más, por diversas razones; por ejemplo, porque disminuyó el PIB por la baja de precios de los commodities, porque afloró algún tipo de carga masiva, o porque se desarrolló considerablemente la red vial facilitando al TAC (como puede ser el caso de los países de Centroamérica, Perú o Colombia).

\section{Participación del TAC en la matriz modal de los países}

El transporte por camión participa en tres alcances geográficos diferentes: en el transporte interurbano (doméstico, de cabotaje), en el transporte internacional y en los movimientos dentro de las ciudades. El indicador que probablemente mejor ilustra la relevancia del TAC es la participación de este modo de transporte en la matriz de carga de los países, computando el porcentaje de las toneladas-kilómetro movilizadas por camión en viajes interurbanos y comparándolo con el de otros modos, básicamente el ferrocarril, la navegación fluvial y marítima, el transporte aerocomercial y las tuberías. Los datos disponibles (IEA, 2017) muestran que el TAC constituye el principal modo de trasporte interno de cargas en el mundo, y que ha tenido un crecimiento muy acentuado en las últimas décadas. Entre los años 1990 y 2015 en las economías más desarrolladas su crecimiento fue moderado: 2,3\% anual acumulado en Estados Unidos y 1,5\% en los países de EU28; en Japón se redujo ligeramente. Pero en países de ingresos medios y bajos el crecimiento fue sustancialmente mayor, de entre $5 \%$ y $6 \%$ anual acumulativo en la India, Rusia o México. Y en el caso de China el crecimiento fue formidable: 9,5\% anual acumulativo. El Gráfico 2 muestra las estimaciones de la IEA, que incluye camiones livianos, medianos y pesados, de acuerdo con el Modelo de Movilidad de la IEA. 


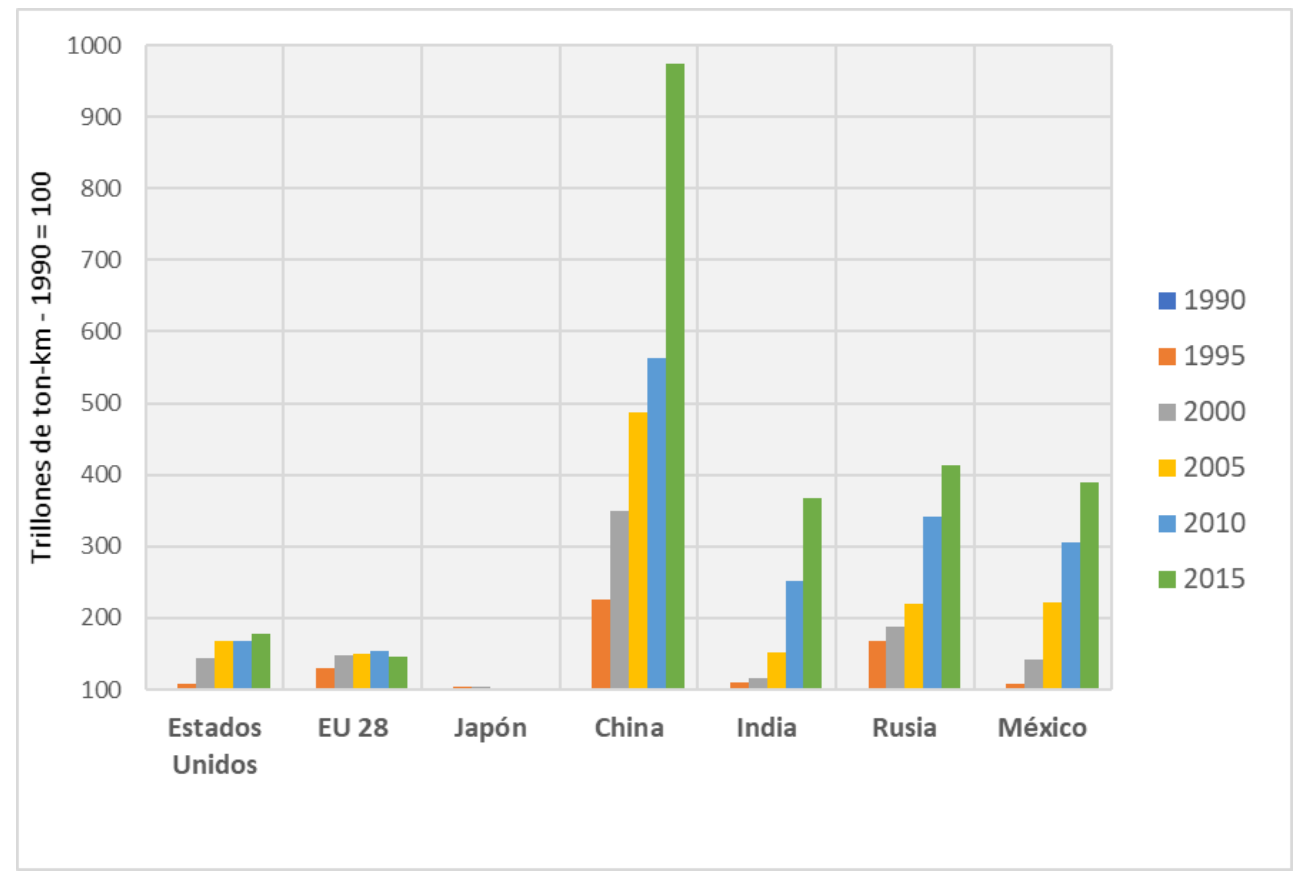

Fuente: IEA - International Energy Agency, 2017

La participación del camión en la matriz de carga depende en gran medida del desarrollo que hayan alcanzado otros modos de transporte. Por ejemplo, en los grandes países de América del Norte, Asia u Oceanía, que movilizan masivamente cargas a granel, su participación (medida en las ton-km transportadas) es inferior al 50\%; es el caso de Estados Unidos, Canadá, China, Rusia o Australia, donde los ferrocarriles, las tuberías y la navegación interior - donde es viable - tienen un rol relevante. En Estados Unidos y Canadá la participación del TAC es del orden del $40 / 45 \%$ de las ton-km, debido al importante desempeño de los ferrocarriles, particularmente en el transporte de graneles (carbón, granos, minerales, productos químicos). El caso de China pasó del $22 \%$ en el año 2007 al 48\% en el año 2016 (medida en ton-km): en valores absolutos creció más de 5 veces en 10 años, período en el que el ferrocarril mantuvo el mismo nivel de actividad. En Rusia el TAC ha tenido una penetración menor, probablemente por las largas distancias y el escaso desarrollo de la red vial; los ferrocarriles y las tuberías tienen una presencia dominante.

En países menores, como es el caso típico de los países europeos, la participación del TAC es decididamente mayor, generalmente superior a los dos tercios de los volúmenes de carga totales, a pesar de la existencia de modos alternativos que brindan servicios de calidad. Es el caso de países como Alemania, Francia o España. En Europa, en promedio, alcanza el $71 \%$. La Tabla 2 resume la matriz de carga de economías desarrolladas, calculada sobre la base de las ton-km transportadas. 
TABLA 2 - MATRIZ DE CARGA EN OTRAS REGIONES DEL MUNDO

Participación porcentual de las ton-km transportadas

\begin{tabular}{|l|c|c|c|c|}
\hline \multicolumn{1}{|c|}{ País } & Carretero & Ferroviario & Por agua & Tuberías \\
\hline Canadá & $40 \%$ & $25 \%$ & $4 \%$ & $31 \%$ \\
\hline China & $43 \%$ & $18 \%$ & $31 \%$ & $33 \%$ \\
\hline Rusia & $5 \%$ & $45 \%$ & $2 \%$ & $48 \%$ \\
\hline Estados Unidos & $45 \%$ & $35 \%$ & $7 \%$ & $13 \%$ \\
\hline Australia & $42 \%$ & $40 \%$ & $4 \%$ & - \\
\hline Alemania & $63 \%$ & $22 \%$ & $11 \%$ & $4 \%$ \\
\hline España & $91 \%$ & $4 \%$ & 0 & $4 \%$ \\
\hline Francia & $76 \%$ & $16 \%$ & $3 \%$ & $5 \%$ \\
\hline
\end{tabular}

Fuente: OECDStat; Russian Railways.

La relevancia del TAC en la matriz modal puede ser sustancialmente mayor si la unidad de comparación es el valor de la mercadería transportada. Por ejemplo, en Estados Unidos la participación del TAC alcanza el $85 \%$, poniendo en evidencia el mayor valor unitario de la carga, conformada en una buena proporción por productos terminados. Cabe destacar el peso de las tuberías en los países de mayor extensión. Su participación en la matriz de cargas es computada en los países más desarrollados (de acuerdo con la organización de las estadísticas de OECDStat); en los restantes países del mundo incluidos los de América Latina - muy pocas veces son incluidos.

En los países de América Latina el rol del TAC es fuertemente dominante, dando cuenta de aproximadamente las tres cuartas partes del movimiento interno de cargas (medido en ton-km). Esta elevada participación probablemente obedezca al escaso desarrollo que han tenido los modos alternativos, con algunas excepciones. Sólo en los países donde el transporte ferroviario es relevante (México y Brasil) el TAC presenta una participación inferior al $90 \%$ de las ton-km domésticas. La Tabla 3 presenta la composición de la matriz de cargas de varios países de la región para los que la información se encuentra disponible.

TABLA 3 - MATRIZ de CARGA en PAíses de AmÉRICA LATINA

Participación porcentual de las ton-km transportadas

\begin{tabular}{|l|c|c|c|c|}
\hline \multicolumn{1}{|c|}{ País } & Carretero & Ferroviario & Por agua & Otros \\
\hline Argentina & $93 \%$ & $4 \%$ & $3 \%$ & \\
\hline Brasil & $61 \%$ & $21 \%$ & $14 \%$ & $4 \%$ \\
\hline Chile & $95 \%$ & $4 \%$ & & $1 \%$ \\
\hline Colombia & $98 \%$ & $2 \%$ & & \\
\hline México & $56 \%$ & $13 \%$ & $31 \%$ & \\
\hline Perú & $99 \%$ & $1 \%$ & & \\
\hline Uruguay & $97 \%$ & $3 \%$ & & \\
\hline
\end{tabular}

Fuente: Elaboración propia sobre la base de anuarios de los diversos países y datos del BID y el Banco Mundial. Valores redondeados. 
Analizando a nivel de país, en la Argentina la participación del TAC es fuertemente dominante, alcanzando el $93 \%$ de la carga interurbana; el ferrocarril da cuenta de sólo el $4 \%$ de las ton-km, a pesar de las largas distancias y de la importancia del transporte de agrograneles (aproximadamente el $20 \%$ del total del movimiento de bienes, medido en toneladas), lo cual se justifica en que dos tercios de los granos se mueven hacia puertos ubicados a una distancia media inferior a los $500 \mathrm{~km}$, para la cual el camión es eficiente y evita la necesidad de acopios. En México el TAC es el principal modo de transporte, aunque el ferrocarril tiene una presencia considerable $(13 \%$, en su mayor parte transportando cargas de alto valor unitario), al igual que el transporte marítimo, centrado en el transporte de combustibles. La distancia media de las cargas transportadas por camión es de $470 \mathrm{~km}$. La participación se ha mantenido en los flujos interurbanos; en los tráficos internacionales ha crecido: medida en valor, pasó del 58,1\% en 2010 al $62,2 \%$ en 2017. En Brasil el camión es responsable por el $61 \%$ de las ton-km, el ferrocarril por el $21 \%$, el transporte fluvial por el $14 \%$ y las tuberías por el $4 \%$ tuberías La distancia media de las cargas es de $690 \mathrm{~km}$. En Chile la participación del camión es del 95\%, con distancias medias de $550 \mathrm{~km}$. En Colombia la participación del camión es del $98 \%$ con distancias medias de $400 \mathrm{~km}$.

Más allá del transporte doméstico, el TAC tiene un rol relevante en el comercio internacional, compitiendo principalmente con el transporte por agua. En el caso de América del Sur, los camiones transportan aproximadamente el $30 \%$ del volumen del comercio intraregional, y el $40 \%$ del valor. En el caso de México, el TAC da cuenta del $62 \%$ de las exportaciones, medidas por el valor de la mercadería (inciden en este porcentaje los movimientos desde y hacia las maquiladoras mexicanas ubicadas cerca de la frontera con los Estados Unidos). En América Central la exportación de servicios de transporte representa el $33 \%$ del total de exportación de servicios. El transporte internacional de cargas ha tenido tasas de crecimiento muy elevadas en las últimas dos décadas, mayores al crecimiento de la economía. Las elasticidades respecto al incremento PIB, estimadas a nivel global desde el comienzo del siglo hasta la crisis de los años 2007/08, han sido del orden del 2,4\%, bajando posteriormente a 1,4\% (Kauppila, 2015).

Cabe destacar que los procesos de integración regional obligan a reconsiderar las matrices modales: al incrementarse el comercio entre los países que integran sus economías, las modalidades de transporte de carga pueden ir cambiando. El caso emblemático es el de la Unión Europea, donde el transporte ferroviario internacional muestra un nivel de actividad similar al de la suma del transporte doméstico de todos los países (Eurostat, 2018). Las tendencias del mundo - incluyendo los nuevos proyectos de integración entre Asia y Europa - realzan la importancia creciente del transporte terrestre internacional (tanto carretero como ferroviario).

El tercer nicho de participación del TAC es en el movimiento dentro de las ciudades. En la logística urbana, el TAC es el modo de trasporte excluyente, con muy escasas excepciones. La actividad de las cargas urbanas ha crecido notablemente, en el mundo y también en América Latina. Ello obedece en parte al incremento de la producción y el consumo de bienes (ambos concentrados en ciudades), resultado de que América Latina es la región con mayor nivel de urbanización a nivel mundial. Otros factores que han contribuido al incremento de la logística urbana de cargas son: (i) la expansión de las 
áreas metropolitanas y el crecimiento de los suburbios, caracterizados por la dispersión de las actividades y la baja densidad de la población (ii) la preferencia de los comercios por ocupar el suelo para la exposición y venta, limitando los inventarios y por lo tanto recurriendo a una mayor frecuencia de las reposiciones (iii) el desarrollo de nuevos canales de comercialización impulsados por el comercio electrónico, en los que la distribución al consumidor final constituye un nuevo ámbito de operación comercial (entrega de paquetes); (iv) el crecimiento de la logística reversa (devoluciones, retorno de envases y embalajes).

Los datos sobre los volúmenes de carga movilizados en las ciudades son escasos; las estimaciones disponibles indican que para el año 2010 alcanzaban los 9,5 trillones de ton-km a nivel global, creciendo a una tasa de 3,1\% anual (Arthur D. Little, 2015). Estimaciones en la Unión Europea muestran que la logística urbana es responsable del $25 \%$ de las emisiones de GEl originada por el transporte en las ciudades, significando entre el $10 \%$ y el $15 \%$ de los vehículos-km que circulan, generalmente con bajos factores de ocupación (las unidades livianas en Londres: 38\%) ${ }^{4}$. En América Latina no se tiene conocimiento de volúmenes agregados, aunque existen estudios realizados en varias ciudades. Cabe destacar que los motores diésel son responsables de la contaminación ambiental originada por el material particulado (PM) (también llamado humo negro), las moléculas de monóxido de carbono, los óxidos de nitrógeno (NOx) y los óxidos de azufre (SOx), que producen daños neurológicos y en el ambiente, con efectos económicos para la salud pública.

\section{Camiones, consumo de energía y emisiones de GEI}

El transporte de cargas por carretera es un demandante de primer orden de energía, en particular de combustibles fósiles, en los que basa casi exclusivamente su funcionamiento. El Gráfico 3, basado en IEA (2017), muestra que los camiones constituyen la segunda fuente de demanda mundial de derivados del petróleo, después de los automóviles.

\footnotetext{
${ }^{4}$ Estimaciones realizadas por el programa ALICE (Alliance for Logistics Innovation through Collaboration in Europe), en el marco del ERTRAC (European Road Transport Research Advisory Council).
} 




Fuente: IEA, 2017

Los camiones por sí solos representan el 3\% de las emisiones de GEl en el mundo: un $21 \%$ del transporte en todas sus formas, que a su vez constituye un $14 \%$ del total (SLoCaT, 2018). Y las tendencias de estas emisiones son particularmente preocupantes: entre 2000 y 2015 las correspondientes al transporte de pasajeros crecieron un 36\%, y las de carga (segmento en el que TAC es dominante), un $75 \%$ (ibidem). El TAC consume aproximadamente la mitad de la demanda mundial de diésel. Además de la emisión de GEl, la combustión del diésel es el principal responsable de la contaminación originada por el material particulado y por los óxidos de nitrógeno y azufre, constituyendo una de las mayores causas del deterioro de la calidad del aire en las áreas urbanas.

\subsection{La debilidad institucional para la gestión del TAC}

Un factor recurrente en los países de Latinoamérica es la debilidad institucional para la gestión del transporte automotor de cargas. Si bien cada país tiene una secretaría o subsecretaría que se encarga de los temas básicos a nivel de gobierno nacional, en general lo que se observa es que se dedican a la regulación en cuanto a pesos y dimensiones, requisitos para la obtención de la licencia de conducir y regulaciones respecto del uso de las carreteras. La debilidad institucional se refleja en la escasez de métricas de productividad, siendo la excepción las agencias que tienen datos de toneladas/km transportadas por año, o recorrido medio en $\mathrm{km}$ de cada camión entre otros. Generalmente se encuentran estadísticas simples de total de toneladas transportadas. Los entes gubernamentales parecen poner mucho más énfasis en el transporte de pasajeros. Un aspecto positivo por mencionar es la importancia creciente que se está dando a la seguridad vial, que se refleja en cursos de capacitación, o requisitos concretos regulatorios en cuanto a trabajo y descanso de los choferes.

La debilidad institucional para gestionar el transporte automotor de cargas se ve reflejada también en la dificultad de establecer políticas públicas específicas para el 
sector. Como se presenta en el informe, las políticas de renovación de flotas tienen un grado intermedio de éxito. Los trabajos analíticos referidos al TAC son escasos. Cabe también citar la debilidad para la fiscalización y ejecución de sanciones en caso de faltas o incumplimientos, ambas actividades atravesadas, además, por aspectos de corrupción e informalidad. 


\section{3 - TENDENCIAS EN EL DESEMPEÑo DEL TAC EN LA REGIÓN}

El desempeño del sector se expresa básicamente por su productividad y por la calidad del servicio que brinda a los usuarios. En esta sección se analizan cinco aspectos que reflejan el desempeño del TAC desde distintas perspectivas:

i. las características de las flotas (incluyendo sus configuraciones y edad)

ii. la organización empresarial

iii. el desempeño operativo de las unidades (distancias recorridas, coeficientes de ocupación)

iv. los costos y precios (determinantes, estructura de costos, valores promedio de los fletes)

v. la calidad del servicio según la perciben los usuarios.

Posteriormente se analizan varios factores externos al sector que pueden favorecer $u$ obstaculizar su desempeño. En los países de América Latina no se conoce que haya estudios sistemáticos de productividad del TAC, como sí los hay en algunas economías avanzadas. En Canadá, por ejemplo, se han realizado estudios revisando la productividad, general y de los principales factores que participan en la producción de los servicios (McKellips \& Calver, 2016); en Corea, donde se ha aplicado un modelo DEA para evaluar la eficiencia de los operadores (Hahn J. \&., 2015).

\subsection{Características de las flotas}

\section{Clasificación y dimensiones máximas de los equipos}

En América Latina no hay un nomenclador unificado de los distintos tipos de camiones; cada país de la región adopta su propia clasificación, de acuerdo con las características de los vehículos que circulan en su territorio. En general, atendiendo a la configuración (equipo tractor, remolque) se establece un listado de vehículos en el que para cada categoría se precisan una longitud y pesos máximos. Por ejemplo:

- En México se reconocen dos tipos de camiones unitarios (sin remolque), cuatro tipos de camiones con remolque, seis tipos de tractocamión articulado simple (unidad tractora y semirremolque) y once tipos de tractocamión articulado (unidad tractora con semirremolque y remolque). La categorización se basa en el número de ejes y de llantas por tipo de equipo y establece el peso máximo admitido para distintos tipos de camino (de acuerdo con una clasificación de la red vial del país).

- En Chile se reconocen ocho categorías de camiones, de acuerdo con sus combinaciones de tipo de rodado (simple, doble) y los tipos de ejes (simple, doble o triple), estableciendo límites de peso bruto para cada uno, que varía de acuerdo con la distancia entre ejes extremos. El peso máximo admitido es de 45 ton. En el año 2018 se actualizaron las tolerancias, para cada tipo de camión.

- En Brasil se reconocen cuatro tipos de vehículos de carga: no articulados (camiones), articulados con dos unidades (tractor más semi remolque), articulados 
con dos unidades (camión más acoplado), y articulados con más de dos unidades ("bitrenes")

- En Argentina se reconocen 29 tipos de vehículos de carga ${ }^{5}$ : siete de camiones (de acuerdo con la cantidad de ejes delanteros y traseros), ocho de tractores con semirremolques, seis de camión con acoplado, cuatro de "bitrenes" y cuatro de camiones especiales. El peso máximo va creciendo de acuerdo con la cantidad y disposición de los ejes. La reglamentación también establece las dimensiones máximas y valores mínimos de relación potencia/peso, y los pesos máximos permitidos por eje (o conjunto de ejes).

- En Uruguay se reconocen dos tipos de camiones, uno de remolques, tres de camión con remolque, ocho de tractocamiones con semirremolques, y uno de bitren. Para cada categoría se establece un peso y una longitud máxima, y se establecen pesos máximos por ejes y conjuntos de ejes.

- En Colombia se reconocen tres tipos de camiones (uno de largo máximo 10,80, dos de 12,20 metros), cinco de camión con semirremolque y quince de tractor con acoplado (todas las combinaciones combinadas de largo máximo 18,50 metros). Cada categoría tiene un peso total combinado admitido diferente, en tanto que altura y ancho son iguales para todos los casos.

La Tabla 4 muestra las dimensiones máximas de los equipos en varios países de la región (que no necesariamente corresponden a una misma configuración). Se observa que, dentro de la heterogeneidad de las normas de cada país, hay una mayor varianza en lo referente al largo y al peso total de los equipos, y una varianza menor en el ancho, alto y peso máximo por eje.

TABla 4 - Dimensiones máximas de los equipos en diferentes Países ${ }^{6}$

\begin{tabular}{|l|c|c|c|c|c|c|}
\hline \multicolumn{1}{|c|}{ País } & $\begin{array}{c}\text { Largo } \\
\mathrm{m}\end{array}$ & $\begin{array}{c}\text { Ancho } \\
\mathrm{m}\end{array}$ & $\begin{array}{c}\text { Alto } \\
\mathrm{m}\end{array}$ & $\begin{array}{c}\text { Cantidad } \\
\text { de ejes } \\
\#\end{array}$ & $\begin{array}{c}\text { Peso total } \\
\text { ton }\end{array}$ & $\begin{array}{c}\text { Peso } \mathrm{p} / \text { eje } \\
\text { individual } \\
\text { ton }\end{array}$ \\
\hline Argentina & 30,25 & 2,60 & 4,30 & 9 & 75,00 & 10,50 \\
\hline Brasil & 19,80 & 2,60 & 4,40 & & 57,00 & 10,00 \\
\hline Chile & 22,40 & & & & & \\
\hline Colombia & 18,50 & 2,60 & 4,40 & 8 & 52 & \\
\hline México & 60,50 & & & 9 & 66,50 & 11,00 \\
\hline Uruguay & $>18,6$ & 2,60 & & 7 & 57,00 & 10,50 \\
\hline
\end{tabular}

Fuente: Elaboración propia

\section{Estructura de las flotas por tipo de equipo y dimensiones}

Usualmente se reconocen tres categorías en la flota de camiones, de acuerdo con sus dimensiones: livianos, medianos y pesados. A nivel global, las estimaciones para el año

\footnotetext{
5 Las configuraciones admitidas fueron modificadas incrementando sus dimensiones y pesos recientemente, según el Decreto №32/2018

${ }^{6}$ Las dimensiones máximas en cada línea de la tabla no necesariamente corresponden a la misma configuración)
} 
2015 (IEA, 2017) muestran que el tipo de equipo dominante era el de los camiones livianos, que con 130 millones de vehículos representan el $70 \%$ de la flota mundial. Los camiones medianos daban cuenta del 17\%, con 32 millones de unidades, y los pesados el $13 \%$ restante (24 millones). En América Latina las proporciones son similares: $72 \%, 16 \%$ y $12 \%$ respectivamente. En cuanto a la dimensión de la flota, la mayor es la de la Unión Europea (casi 28 millones de unidades), seguida por China (27 millones). América Latina, de acuerdo con estas estimaciones, tiene una flota conjunta de 20,2 millones de vehículos.

Las unidades del transporte incluyen tanto vehículos tractores como remolcados (de arrastre). Dentro de los primeros se reconocen dos categorías: los camiones rígidos, que consisten en una unidad motriz que lleva incorporada su caja de carga (a la que además puede eventualmente engancharse un acoplado), y los tractocamiones (conocidos en la región también como tractores, tractomulas o cabezales), que consisten en una unidad tractora que no posee caja de carga sino que se le acopla un semirremolque, que se apoya en su parte posterior. Entre los equipos remolcados las dos principales categorías son los remolques (o acoplados) convencionales, que se enganchan a camiones rígidos, y los semirremolques (o plataformas), que se acoplan al tractocamión. También existen configuraciones en las cuales a un primer remolque $o$ a un primer semirremolque se le acopla otro remolque $y$, más recientemente, se combina el arrastre de más de un semirremolque en las configuraciones denominadas B-Dobles o bitrenes (Brasil, México, Uruguay, Argentina) Cada una de estas unidades puede tener diversas características que constituyen la base para su clasificación, siendo el número de ejes la más utilizada.

No se cuenta con estadísticas como para procesar todas las unidades de la región, pero sí para varios países, que constituyen una muestra altamente representativa, que se presenta en la Tabla 5.

Tabla 5 - Estructura de la flota en países de América latina

\begin{tabular}{|l|c|c|c|c|c|c|}
\hline \multicolumn{1}{|c|}{ País } & Año & $\begin{array}{c}\text { Camión } \\
\text { rígido }\end{array}$ & Tractocamión & Remolque & Semirremolque & Total \\
\hline Argentina & 2017 & 196,9 & 86,5 & 94,9 & 106,5 & 484,8 \\
\hline Brasil & 2018 & 561,6 & 437,9 & 35,8 & 566,5 & $1.601,8$ \\
\hline Colombia & & & & & & \\
\hline Chile & & 67,6 & 54,1 & 13,3 & 69,0 & 210,6 \\
\hline México & & 158,1 & 304,1 & 3,7 & 450,2 & 916,1 \\
\hline Perú & 2013 & 91,5 & 32,9 & 35,0 & 6,0 & 165,4 \\
\hline Uruguay & 2017 & 13,2 & 6,7 & 6,7 & 7,9 & 34,5 \\
\hline
\end{tabular}

Fuente: Elaboración propia en base a anuarios y estadísticas diversas fuentes de los distintos países

A continuación se analizan las principales características estas flotas en diversos países de la región, de acuerdo con estas categorías.

- En Argentina hay casi medio millón de unidades, de los que 283.000 corresponden a vehículos camiones y tractocamiones. La combinación de camión rígido/acoplado supera a la de tractor/semirremolque en una proporción de 
60/40. En los últimos años el proceso de renovación de unidades puede pensarse en función de quienes tuvieron o no tuvieron capacidad financiera para afrontar la renovación. En el caso de empresas más grandes y con poder económico, se valieron de financiación propia o a través de líneas de crédito de las empresas de camiones, incorporando vehículos más potentes y con mayor cantidad de tecnología a bordo. En el caso de empresas más pequeñas o con menor capacidad financiera, el crédito bancario ha sido muy caro y se valieron de planes del Estado, pero adquirieron unidades de menor potencia y tecnología. La relación entre el número de semirremolques y el de tractocamiones es de 1,23

- Brasil cuenta con más de 1,6 millones de vehículos de carga, de los que 1 millón son camiones y tractocamiones. Los tractocamiones y sus semirremolques son dominantes ( $62 \%$ de las unidades) respecto a los camiones rígidos y sus acoplados (38\%). La relación semirremolque / tractocamión es de 1,29.

- En Chile hay 210.000 unidades, de las cuales 122.000 son camiones y tractocamiones; dentro de ellas: $55 \%$ camiones y $45 \%$ tractocamiones. En los últimos años (2013 a 2017) el parque de camiones convencionales creció al 8,2\%, en tanto el de tractocamiones creció el doble: $17,7 \%$. La relación semirremolque / tractocamión es de 1,28.

- En México hay 910.000 unidades, de las cuales 462.000 son camiones y tractocamiones. De ellos 304.100 son tractocamiones, con lo cual la relación semirremolque / tractocamión es de 1,50, la más elevada de la región, posiblemente influenciada por la mayor eficiencia exigida en los viajes internacionales a Estados Unidos. Entre 2012 y 2017 el parque de camiones convencionales creció un $12 \%$ mientras que los tractocamiones crecieron a más del doble, en un $28 \%$.

- En Uruguay hay 34.500 unidades, de las cuales 19.900 corresponden a camiones y tractocamiones. La relación entre semirremolque y tractocamión es de 1,17 . La evolución del parque se mantiene pareja: todos los tipos crecen de manera pareja, aunque con altibajos en el tiempo: en 2010 superó el 11\%, en 2016 apenas superó el $1 \%$ y en 2017 fue del 10\%

- En Perú hay 165.000 unidades, de las cuales casi 33.000 son tractocamiones. La relación semirremolque/tractocamión es de 1,18

En conclusión, puede apreciarse que las flotas de vehículos del TAC han venido creciendo en forma sostenida en la región (la tasa anual en Chile ha sido del 5,7\% anual, y en México del $5,4 \%)$, aunque menos que en los países de Asia. Hay una tendencia hacia un mayor uso de tractocamiones y semirremolques, en detrimento del camión rígido y su acoplado, aunque con excepciones: en Argentina estos últimos mantienen una alta participación, probablemente por el tipo de carga (del agro) y el mal estado de los caminos rurales, donde los semirremolques son menos maniobrables. Similar es la situación en Uruguay. La relación entre semirremolques y tractocamiones es relativamente baja, por debajo de 1,3; en las economías desarrolladas esa relación es del orden de 3 para Estados Unidos y Canadá, y 1,4 para Europa, lo que permite una mayor productividad de las unidades tractoras (International Council of Clean Transportation, 2018). Respecto a la tendencia en el porte de los vehículos, las estimaciones disponibles sugieren un mayor crecimiento en los vehículos pesados (orientados al transporte interurbano e internacional) 
y en los livianos (orientados a la logística urbana); el segmento de camiones medianos estaría teniendo un crecimiento ligeramente menor.

\section{Edad de las flotas}

La antigüedad del parque es un dato importante, ya que se vincula con factores como la calidad de servicio, la seguridad vial, el consumo energético y las emisiones de GEl. En Argentina la edad media del parque es ligeramente superior a los 14 años. Las edades de los diferentes tipos de equipos muestran los mayores valores en los acoplados (remolques), en lenta retirada del mercado, seguidos por los camiones, los semirremolques y los tractores. Las unidades afectadas al transporte propio muestran en casi todos los casos (salvo en semirremolques) una edad media menor a los equipos de las empresas transportistas. En Brasil la edad promedio de la flota es mayor para el transportista autónomo (16,9 años) respecto a la empresa cooperativa $(12,9)$ y a la empresa de transporte (9,9). En Chile la edad promedio es de 17 años en los camiones y 12 en los tractocamiones; es mayor en las regiones más remotas y en los operadores individuales. En México la edad promedio es de 15 años. En Uruguay la flota tiene una antigüedad promedio de 17 años, los camiones son los vehículos más antiguos, con 18 años en promedio, seguidos por los remolques con 16 años, los tractores con 15 años y los semirremolques con 14 años. Cabe señalar que la edad promedio en la Unión Europea es de 11,7 años.

\section{La relevancia de las flotas propias}

En secciones anteriores se hacía referencia a que una parte relevante de la flota de camiones no opera para terceros, sino que se dedica a transportar mercadería propia, generalmente de empresas que vende o comercializan bienes. En los Estados Unidos, por ejemplo, el $45 \%$ del movimiento de cargas por camión (medido por el valor de los bienes) lo realizan flotas propias. En 2017 los países de la OECD tuvieron una participación del transporte automotor propio del $18 \%$ sobre el total de las ton-km transportadas, variando sensiblemente entre países: en Alemania fue del 13\%, en Francia del $23 \%$ y en España del $4 \%$.

En los países de América Latina la participación de estas flotas es muy relevante. En la Argentina los vehículos de carga dedicados al transporte propio son el $29 \%$ del total (alcanzando el $60 \%$ en los vehículos livianos). La relevancia del transporte propio se pone en evidencia al analizar las 16 mayores flotas registradas en el país (flotas que cuentan con más de 400 unidades): 3 de ellas corresponden a empresas de transporte para terceros, en tanto 13 flotas se dedican al transporte de carga propia. De esas 13 flotas, 6 son de firmas de servicios petroleros, 3 de servicios públicos (telefonía, correo, agua), 2 de constructoras, 1 de gestión de caudales, y 1 de auxilio mecánico. Las 3 grandes flotas de empresas dedicadas al transporte se dedican al transporte de automóviles, de combustibles, y al movimiento de cargas en la Patagonia. Cabe destacar también el peso que tienen las flotas de transporte de residuos en ese país. En el caso de Perú, de las cinco empresas con flotas mayores a 400 vehículos en el año 2013 (CIDATT, 2014), solo una corresponde a un operador logístico; las otras cuatro son propiedad de grupos empresarios dedicados principalmente a la producción de lácteos, cemento, aves y alimentos balanceados y cerveza. 


\subsection{Organización empresarial}

En secciones anteriores se hace referencia a la diversidad de modelos de organización para la prestación de servicios del TAC. A continuación, se presenta una breve caracterización de la organización empresarial en varios países de la región, limitada por la disponibilidad de información, para reconocer luego varios patrones comunes, característicos del TAC en la región.

En Argentina el sector se encuentra altamente atomizado: el $82,4 \%$ de transportistas tiene menos de 5 camiones, y el $94,8 \%$ menos de 10 . Los contratos con los dadores de carga son específicos por viaje, y solo los grandes dadores de cargas y las empresas más organizadas establecen los contratos son anuales ${ }^{7}$. Se destaca la organización en numerosas cámaras empresarias. EI TAC genera 142 mil puestos de trabajo en el país.

En Brasil el servicio de transporte es prestado por transportistas autónomos, empresas y cooperativas. El análisis de los datos arroja que las empresas han incrementado su participación sobre el total del tipo de prestador. En 2013 las empresas representaban el $54,2 \%$ de los prestadores, los autónomos el $45 \%$ y las cooperativas $0,8 \%$ sobre un total de 2,06 millones de prestadores. Estos valores habían variado en 2016 a 59,6\% para empresa, $39,4 \%$ y $1 \%$ respectivamente para autónomos y cooperativas, sobre un total de 1,98 millones de prestadores. Es decir que desde 2013 a 2016 cayó el número total de prestadores, y creció la participación de las empresas. Estos datos tenderían a reflejar una mayor concentración del sector. La recesión económica de los años 2016 y 2017 afectó el sector transporte, con una cantidad menor de empresas prestando el servicio en todas las categorías, ya sea transportistas, camioneros autónomos, o cooperativas: los transportistas vieron su cantidad reducida en un 22,8\% entre 2015 y 2017 , los autónomos en un $47,3 \%$ y las cooperativas en un $24,7 \%$. Se ha incrementado el número de unidades promedio de cada una de estas categorías); para los transportistas, las unidades promedio pasaron de 6,7 a 7,5, para los autónomos de 1,2 a 1,4 y para las cooperativas, de 43 a 70 unidades. Esto indicaría una creciente concentración del mercado (Confederação Nacional do Transporte, 2018).

En Chile las empresas de mayor facturación (las mayores) cuentan con flotas más modernas, con el $86 \%$ de los vehículos con una antigüedad máxima de 10 años y el $48 \%$ máxima de 5 años. Para las empresas más pequeñas, sin embargo, el $72 \%$ de la flota tiene menos de 10 años y el $30 \%$ menos de 5 . El sector de carga terrestre ocupa más de 121.500 personas (Instituto Nacional de Estadísticas). Los conductores en los siete años que van de 2009 a 2016 prácticamente se duplicaron, pasando de 84 mil a 161 mil.

El perfil empresarial en Perú está dominado por empresas de 1 a 4 vehículos de flota. Esta categoría representa el $89 \%$ de las empresas de transporte de cargas. En 2013, el total de empresas era de 56.131 , con un $0,5 \%$ con flotas superiores a 50 vehículos. Entre 2012 y 2013 ese segmento creció en $17 \%$, pasando de 217 empresas a 257 empresas, concentrando el $18 \%$ de los vehículos totales en circulación, con un promedio de 119 vehículos por empresa. Las empresas con flotas de 1 a 4 vehículos concentran el $63 \%$ del

\footnotetext{
7 En rigor tampoco son contratos sino presupuestos, órdenes de compra o cartas de intención firmadas por las partes, con valor legal equivalente pero con menores costos fiscales.
} 
parque vehicular. Estas mismas empresas son las que tienen las flotas más antiguas, con 10 años para 2013, versus 9 para las empresas que tienen de 5 a 9 vehículos, 6 años para las empresas con 31 a 50 vehículos y 6 años para las que tienen más de 50 vehículos (CIDATT, 2014).

En México la categoría dominante corresponde al "hombre camión" con el $81 \%$ de las empresas, seguida por la pequeña empresa, que representa el $16,3 \%$ del total de las firmas. Las medianas son sólo el $2 \%$ y las grandes menos del $1 \%$. Sin embargo, como es de esperar en cuanto a tamaño de flota la participación es más equilibrada. Los hombrecamión tienen el $24 \%$ de las unidades, con un promedio de 1,9 vehículos por titular, las empresas pequeñas el $29,7 \%$, con un promedio de 11,5 vehículos, las medianas el $16,5 \%$ de la participación de las unidades, con un promedio de 50 vehículos y las grandes, el $29,6 \%$ con un promedio de 280 unidades cada empresa. Puede observarse que las grandes empresas están ganando participación de mercado, puesto que su flota promedio era de 247 unidades en 2010 y fue creciendo año tras año hasta las 280 unidades promedio en 2017. Los demás tipos de empresa tuvieron igual número de vehículos promedio a través de los años.

En Uruguay las empresas que tienen un solo vehículo participan en el 32,6\% del total, las empresas que tienen entre 2 y 5 vehículos son el $50,7 \%$, las de entre 6 y 10 vehículos son el $10,8 \%$ y las de más de 10 vehículos el $5,9 \%$ del total. Los vehículos promedio por categoría responden a 1 vehículo para las empresas unipersonales, 3 para las pequeñas, 7 para las medianas y 20 vehículos para las grandes. Esto arroja que las empresas pequeñas participan del $8,6 \%$ del total de vehículos, las pequeñas, del $39,8 \%$, las medianas del $21 \%$ y las grandes del $30,6 \% 8$

El análisis de la organización empresarial en diversos países permite encontrar algunos factores comunes:

- La elevada atomización, reflejada en la alta proporción de operadores individuales (la atomización del TAC es una característica mundial). Como se verá más adelante, la productividad de los equipos en esos operadores suele ser considerablemente menor.

- Una tendencia leve hacia la concentración de los mercados (seguramente más intensa en mercados especializados), respondiendo en parte a la concentración empresarial de los dadores de carga.

- Las empresas mayores cuentan con flotas más modernas

- El transporte propio tiene un rol muy relevante

\footnotetext{
8 Datos del Ministerio de Transporte y Obras Públicas 2018.
} 


\subsection{Desempeño operacional}

\section{Distancia recorrida anualmente por los camiones}

La distancia recorrida anualmente por los vehículos constituye uno de los indicadores básicos del desempeño operacional en el TAC. Pero los resultados deben ser analizados con cautela; los valores medios que surgen de las estimaciones en los países esconden fuerte varianza interna, ya que diferentes segmentos del sector presentan valores muy diversos. Por ejemplo, estimaciones realizadas en la Argentina muestran que la distancia recorrida por año es muy reducida en las unidades afectadas a la logística urbana $(15.000 \mathrm{~km})$ o en las que prestan servicios en puerto $9(18.000 \mathrm{~km})$, en tanto alcanza los 120.000 en los servicios expresos interurbanos, y $144.000 \mathrm{~km}$ en los servicios especializados (i.e., los que transportan vehículos, o combustibles). Esta dispersión pone en evidencia que la relación entre los tiempos de marcha y los tiempos muertos es un factor determinante para este indicador de productividad. Y esa relación depende no tanto del transportista como del cargador y de la forma en que éste organiza la carga y descarga de las unidades. En este ejemplo, las unidades menos productivas - de logística urbana y los camiones que prestan servicios en puerto - pertenecen en forma predominante a operadores autónomos; la preminencia de los tiempos muertos resulta de los procedimientos de carga y descarga que les impone el cargador.

En el caso de México, para el año 2014 la distancia media recorrida por camión era de $73.000 \mathrm{~km}^{10}$. En Brasil una encuesta que realizó la Confederación Nacional de Transporte arrojó que la distancia media recorrida en promedio por los camiones estuvo entre 125 mil km/año y hasta un máximo de 156 mil km/año para 2011 y 2013. En Chile los camiones de carga interurbana presentan distancias medias recorridas de entre 120.000 y 144.000 kilómetros al año. Respecto de servicios de carga urbana, se estima en promedio entre 22.800 y $28.800 \mathrm{~km}$-año. En Colombia la productividad de los vehículos de transporte de carga es mayor en recorridos nacionales que urbanos, recorriendo distancias medias superiores para el primer caso, con un promedio de $65.000 \mathrm{~km}$ versus 22.500 para el recorrido urbano' ${ }^{1}$.

\section{Coeficientes de ocupación y los viajes vacíos}

La ocupación efectiva de los vehículos de carga, sea por la proporción de viajes vacíos que realizan como por la ocupación efectiva de su capacidad cuando transportan cargas, es otro de los indicadores típicos de desempeño operativo. La información disponible al respecto es muy escasa; no existen estadísticas, y sólo pueden lograrse algunas estimaciones como resultado de entrevistas con referentes calificados. Cabe destacar que estos indicadores de ocupación no dependen sólo de la gestión del operador sino también de la estructura espacial de la demanda de cargas. En muchos países de América Latina suele haber fuertes asimetrías regionales, que se traducen en desbalances en los mercados

\footnotetext{
9 Se trata de camiones que movilizan contenedores entre las terminales portuarias y las plazoletas fiscales ubicadas fuera del área portuaria. Se trata de viaje cortos, para los que los transportistas esperan en cola su turno para cargar y descargar.

10 Anuario Estadístico de Cargas y Logística. BID 2014.

11 Encuesta Nacional de Logística 2018. Departamento de Planificación, Gobierno de Colombia.
} 
de transporte. Por ejemplo, en un país puede haber regiones que generan altos volúmenes de graneles y otras que producen bienes de alto valor agregado; el desbalance no se reflejará solo en el diferencial de los volúmenes transportados en una u otra dirección, sino también en el tipo de bodega necesaria para cada tipo de carga y en el nivel de servicio requerido.

En el caso de Argentina las estimaciones de operadores del mercado de cargas apuntan a que el nivel de ocupación media de las bodegas se encuentra en el rango del $50 \%$ al $60 \%$. En el caso de Chile el coeficiente de ocupación estuvo entre $60 \%$ y $65 \%$. Para México la ocupación media de bodega estuvo cerca del $62 \%$, mientras que para Brasil, algo más baja con 55\%. En Costa Rica hubo una sorprendente ocupación media del $90 \%$. Para Uruguay la ocupación media de bodega se estimó en $53 \%$.

\subsection{Costos y precios}

Los costos del TAC pueden verse en dos perspectivas: los que enfrenta el operador, (entendiendo por tal a la entidad legal y económica que llevará las cargas por carretera desde el sitio del remitente hasta el del receptor), y desde la perspectiva general de la sociedad. En esta segunda pueden agregarse algunos factores no considerados por el operador, que se denominan costos externos (como las emisiones de GEl, los accidentes, la congestión u otras externalidades negativas).

\section{Los costos de los operadores}

EI TAC genera diversos costos variables, asociados a un servicio, y costos fijos. Al igual que en otros modos de transporte, son frecuentes los costos comunes y conjuntos, difíciles de asignar en las empresas que ofrecen diversos servicios (varios tipos de carga, múltiples orígenes/destinos, etc.). La Tabla 6 presenta los costos típicos que enfrenta un operador de TAC. 


\begin{tabular}{|c|c|}
\hline jos & oles \\
\hline $\begin{array}{l}\text { - Salarios } \\
\text { - Amortización del capital } \\
\text { invertido y mantenimiento de } \\
\text { máquinas e instalaciones } \\
\text { - Administración } \\
\text { - Tecnologías de información y } \\
\text { comunicación (TICs) } \\
\text { - Alquiler de instalaciones y } \\
\text { - } \text { equipos } \\
\text { - Seguro de instalaciones, } \\
\text { - Patentes y licencias de vehículos } \\
\text { - y personas } \\
\text { - Mantenimientos programados } \\
\text { - activos } \\
\text { - Servicios de seguridad frente al } \\
\text { crimen }\end{array}$ & $\begin{array}{l}\text { - Combustibles, lubricantes, neumáticos } \\
\text { - Adicionales de salarios (horas extras, } \\
\text { - Tervicios especiales) } \\
\text { - (TICs) } \\
\text { - Peajes carreteros } \\
\text { - Alquiler de instalaciones y equipos } \\
\text { - } \text { adicionales } \\
\text { - Seguros para servicios especiales } \\
\text { - } \text { Licencias de vehículos y personas para } \\
\text { - Mantenimientos a rotura y reparaciones } \\
\text { - Sosto financiero del capital de trabajo } \\
\text { - Tabcontratación de otros transportistas } \\
\text { - de actividad y de la renta } \\
\text { - Servicios de seguridad frente al crimen }\end{array}$ \\
\hline
\end{tabular}

Fuente: Elaboración propia

La apropiación de los costos a cada uno de los servicios de transporte prestado por un operador (diversos tipos de carga, entre distintos orígenes y destino, con o sin carga de retorno, etc.) depende de diversos factores. Esa diversidad es muy relevante, ya que dificulta sensiblemente la posibilidad de establecer tarifas genéricas que sean representativas. Entre estos factores se destacan:

- Las economías de escala; por ejemplo, economías a las dimensiones de los vehículos o de las flotas

- La posibilidad de operar con un camión completo o con carga parcial

- La magnitud del contrato: desde contratos plurianuales a viajes "spot"

- La disponibilidad de carga de retorno

- La naturaleza de la carga, por las condiciones de servicio requeridas por el cliente. Por ejemplo, el transporte de combustibles, de cargas peligrosas o de cargas refrigeradas puede implicar costos mayores que los del transporte de agrograneles o materiales de construcción

- Las demoras en las operaciones de carga y descarga

- La demora en hacer efectivo el cobro

En informes anteriores se afirmaba que "los niveles de costo presentan una gran variación, dependiendo de la eficiencia de los operadores, de los precios de los insumos y de las características de la demanda. El primer aspecto está vinculado con la tecnología que se utilice (por ejemplo, el tipo y la edad de los vehículos) y con la eficiencia con que se organicen las operaciones (por ejemplo, la gestión comercial, y la programación y el monitoreo de las 
operaciones), que a su vez responde a múltiples factores, entre ellos, el marco regulatorio en que se desempeña el sector y la cultura empresarial de los operadores" (Barbero \& Guerrero, 2017). Ante la tendencia de muchos operadores de pasar de empresas de transporte a operadores logísticas, agregando servicios, las estructuras de costos se tornan más complejas.

Dos de los factores mencionados merecen una especial consideración, ya que suelen ser subestimados: los costos financieros y las condiciones de carga y descarga. En referencia a los costos financieros, el TAC requiere capital de trabajo en forma intensiva. Las empresas de servicio no disponen de bienes de cambio para ejecutar en caso de necesidad de financiación; están expuestas al giro financiero entre sus cobranzas y el pago de sus obligaciones. Los transportistas generalmente deben pagar a proveedores y al estado antes de haber percibido ingresos por los servicios realizados; si el cliente demora el pago, el costo financiero es absorbido por el transportista quien, finalmente, termina agregándolo a su tarifa, estimándolo con menor o mayor precisión dependiendo de la capacidad de cálculo de su estructura administrativa. Las estructuras de costos no suelen computar adecuadamente este factor, excepto en el caso de Chile donde es del orden del 10\%. En otros casos debe suponerse que está contemplado dentro del costo administrativo; en países con inflación su incidencia puede ser considerable. En cuanto a las condiciones de carga y descarga, su incidencia se presenta en el Recuadro 2, ilustrando cómo inciden en la productividad de los equipos.

\section{RECUADRO 2 - LA RELEVANCIA DE LAS CONDICIONES DE CARGA Y DESCARGA}

Los tiempos de espera en las operaciones de carga inciden en la productividad de los equipos. Dependen fundamentalmente del cargador, no del transportista. Ocasionalmente el transportista puede cargar el costo de espera en la tarifa, pero la asimetría en las posiciones negociadoras hace que generalmente lo deba absorber. Los tiempos dependen de la programación y su cumplimiento, de la tecnología utilizada para cargar/descargar, de la modalidad de utilizar los equipos (por ejemplo, una unidad tractora dejando un semirremolque para descarga y enganchar otro para el retorno). Estudios de la ANDI en Colombia para un viaje entre Bogotá y Buenaventura muestran que adoptando mejores prácticas de carga y descarga se puede incrementar en $20 \%$ los viajes mensuales por unidad, reduciendo los costos para el cargador y para el transportista.

En algunos casos el cargador utiliza al equipo de transporte como almacenamiento transitorio mediante largos períodos de espera antes de la descarga, lo que genera externalidades negativas (impactos sociales de numerosas unidades esperando en la vía pública); por ejemplo, en el transporte de agrograneles en Argentina. Para evitar estos desvíos en este país se ha implementado en 2018 un Sistema de Turnos Obligatorios para Descarga en Puertos (STOP), que establece los horarios de arribo de las unidades de transporte a las terminales de descarga o de acopio de acuerdo con un turnos previamente asignados, disminuyendo así el tiempo de espera de los camiones y los impactos negativos que acarrean sobre la gestión del transportista. Aun no se han realizado evaluaciones sobre la eficacia del sistema.

La composición de los costos es objeto de análisis en los diversos países de la región; a continuación se muestran varios resultados. En el caso de la Argentina la Tabla 7 resume los resultados de las estimaciones de su principal federación de cámaras empresariales 
(Federación Argentina de Entidades Empresarias de Autotransporte de Cargas, FADEEAC), para 2017. La estructura de costos de Chile vigente en 2018, figura en la Tabla 8, y la de Colombia en la Tabla 9, basada en estudios de ANDI del año 2016. En esta última se observa que, en el caso del tractocamión destinado a largas distancias, el mayor componente de costo no es el combustible, sino los "costos de administración". En el modelo de cálculo, desarrollado para la ruta Buenaventura a Bogotá, se valorizaron específicamente los tiempos de espera para cargar y descargar y para maniobras específicas de la carga y descarga; así "el impulsor de costo más predominante para la configuración es el tiempo, que eleva el costo fijo de administración del activo dado su alto costo de capital y es el más alto de todos con un promedio de $36 \%$ ". La TABLA 10 muestra estimaciones realizadas en México, considerando un vehículo articulado de carga general que recorre $120.000 \mathrm{~km}$ por año, en un $85 \%$ con carga.

\section{TAbla 7 - Estructura de costos del tAC en Argentina}

\begin{tabular}{|l|c|}
\hline \multicolumn{1}{|c|}{ Componente } & Participación \\
\hline Impuestos (incluyendo los de los insumos y los peajes) & $39,7 \%$ \\
\hline Combustibles & $9,5 \%$ \\
\hline Salarios & $23,8 \%$ \\
\hline Costos operativos y de estructura & $17,5 \%$ \\
\hline Amortización & $5,7 \%$ \\
\hline Renta & $3,9 \%$ \\
\hline
\end{tabular}

Fuente: FADEEAC

TABla 8 - Estructura de costos del tAC en Chile

\begin{tabular}{|l|c|}
\hline \multicolumn{1}{|c|}{ Grupo } & Ponderación \\
\hline Combustibles & $36,8 \%$ \\
\hline Recursos humanos & $29,8 \%$ \\
\hline Otros servicios a los equipos & $7,7 \%$ \\
\hline Servicios financieros & $10,6 \%$ \\
\hline Repuestos y accesorios para el mantenimiento & $15,1 \%$ \\
\hline
\end{tabular}

Fuente: Santana, 2018

\section{TABla 9 - Estructura de costos del TAC en Colombia}

\begin{tabular}{|l|c|c|}
\hline \multicolumn{1}{|c|}{ Componente } & Tractocamión & Camión simple \\
\hline Combustibles & $25 \%$ & $34 \%$ \\
\hline Peajes & $12 \%$ & $10 \%$ \\
\hline Mantenimiento & $8 \%$ & $15 \%$ \\
\hline Maniobras & $5 \%$ & $4 \%$ \\
\hline Salario conductor & $10 \%$ & $11 \%$ \\
\hline Gastos de viaje (alimentación, hospedaje) & $4 \%$ & $7 \%$ \\
\hline Costos de administración & $36 \%$ & $19 \%$ \\
\hline
\end{tabular}

Fuente: ANDI, 2016 
TABla 10 - Estructura de costos del TAC en MÉxico

\begin{tabular}{|c|c|}
\hline \multicolumn{1}{|c|}{ Rubro } & Participación \\
\hline Costos por tiempo & $\mathbf{5 1 , 6 \%}$ \\
\hline Amortización del vehículo & $10,7 \%$ \\
\hline Financiación del vehículo & $1,0 \%$ \\
\hline Personal de conducción & $22,7 \%$ \\
\hline Seguros & $5,3 \%$ \\
\hline Costos fiscales & $0,7 \%$ \\
\hline Dietas & $11,2 \%$ \\
\hline Costos por kilómetro & $\mathbf{4 8 , 4} \%$ \\
\hline Combustibles & $38,5 \%$ \\
\hline Neumáticos & $5,3 \%$ \\
\hline Mantenimiento & $1,7 \%$ \\
\hline Reparaciones & $2,9 \%$ \\
\hline
\end{tabular}

Fuente: Robles Linares, 2018

La revisión de estos ejemplos permite extraer algunas conclusiones sobre los costos que enfrentan los operadores de TAC en los países de la región.

- Las comparaciones de las estructuras entre diferentes países se tornan dificultosas, ya que los cálculos contemplan distintos componentes, o los agrupan de maneras diferentes.

- El combustible es el rubro de mayor incidencia, del orden del 35\% (menor en Argentina, porque no consideran los impuestos dentro de su costo en la estructura adoptada).

- El personal es el otro componente de fuerte incidencia. En algunas ocasiones se computa sólo el de conducción, y en otras todo el personal de la empresa (administrativo, talleres, etc.). Su incidencia fluctúa entre el $25 \%$ y el $30 \%$

- Los peajes carreteros tienen un peso considerable; en Colombia, por ejemplo, pueden llegar al 10\% a 12\%. En Perú, han sido uno de los detonantes de una semana de huelga en febrero de 2019.

Algunas tendencias relevantes, que surgen de las entrevistas con operadores, señalan que la incidencia de los costos de combustible y de personal tiende a incentivarse, y que la carga fiscal - que no suele aparecer discriminada en las estructuras de costos tradicionales - constituye un rubro de peso. Existen algunos rubros que no suelen computarse, que también han ido ganando en relevancia. Uno de ellos es la denominada "piratería del asfalto", que consiste en el robo de la mercadería en ruta, ejercida particularmente sobre productos fácilmente comercializables. En Argentina, por ejemplo, se registran 3,5 hechos por día, de los cuales un $40 \%$ corresponde a comestibles, un $18 \%$ a productos electrónicos y electrodomésticos, y un $14 \%$ a productos textiles e indumentaria. Estos robos generan costos adicionales en materia de personal de custodia, sistemas de rastreo adicionales, elección de rutas seguras más extensas y alteración de la programación de los viajes para que varios camiones circulen juntos. En el caso de Argentina, su peso ha sido estimado en torno al $3 \%$. Otro rubro de importancia y generalmente no computado es la corrupción, que se expresa en el pago de sobornos para conseguir contratos, pago a 
entidades sindicales para reducir conflictos, pagos a agentes públicos al registrar los vehículos en su circulación, o pagos a agentes de control durante la circulación.

\section{Los valores de fletes en la región}

Al comentar los factores que inciden en el costo de los servicios de TAC se hacía notar la dificultad de establecer valores genéricos de fletes, no sólo por la distancia, sino también por otros numerosos factores que inciden en el costo, tales como la disponibilidad de carga de retorno, el volumen a transportar, la frecuencia del servicio, el tipo de mercadería, las condiciones de carga y descarga, etc. Los fletes a cobrar por un operador para recuperar sus costos dependerán, entonces, de un amplio abanico de factores.

En la práctica, la relación de los fletes con los costos resulta del proceso de negociación entre el transportista y el cargador. Es muy frecuente que exista una amplia asimetría en ese proceso a favor de este último, que está en mejor posición para imponer las condiciones, particularmente a los pequeños operadores. Adicionalmente, éstos suelen carecer de una visión integral de sus costos; por ejemplo, omitiendo valorizar las amortizaciones, los costos de reposición y los costos financieros, tendiendo a cobrar un flete que sólo les permite cubrir el costo operativo. Esta combinación de asimetría en la negociación y visión incompleta de los costos lleva a que los pequeños operadores frecuentemente establezcan precios por debajo de sus costos medios de corto y largo plazo. Esa práctica no es sostenible: el transportista consume su capital, y si a raíz de eso sale del mercado, ingresa otro pequeño operador que procederá de igual manera. Este fenómeno suele describirse como "competencia predatoria", e incluirse entre los ejemplos de falla de mercado" ${ }^{12}$. Un ejemplo típico en el TAC es el del del transporte de agrograneles en países como Argentina, Paraguay, Brasil o Uruguay.

La necesidad de protegerse de la competencia predatoria ha llevado a los pequeños operadores a requerirle al Estado regulación tarifaria, estableciendo valores mínimos de flete, generalmente de acuerdo con la distancia del transporte. Las denominadas tablas de flete en algunos casos constituyen valores de referencia para la negociación, orientativos, y en otros se pueden tornar obligatorios. Las tablas de flete deben reflejar situaciones promedio que - como se destaca más arriba - pueden tener una enorme varianza, ya que el costo de la prestación depende de numerosas variables, no solo de la distancia a recorrer. Estas tablas, que se basan en la definición de una estructura de costos, son actualizadas periódicamente, de manera de incorporar la variación de los precios de los insumos. El Recuadro 3 presenta con detalle las experiencias de tablas de flete en Argentina, Brasil, Colombia y Uruguay.

El establecimiento de tarifas mínimas, de referencia u obligatorias, constituye un fenómeno de la mayor importancia en la región; la presión de los pequeños transportistas hacia las autoridades ha sido la causa de los principales disturbios generados alrededor del TAC. Dos casos emblemáticos son los ocurridos en Colombia en el año 2015 y en Brasil en 2017, así como un tercero en Perú en febrero de 2019; su emergencia no es ajena a la volatilidad que tuvo en esos años el precio del petróleo, que se reflejó en el de los

\footnotetext{
12 The Economics of Regulation - Principles and Institutions, libro pionero de Alfred Kahn sobre el tema, dedica un capítulo (Cap. 5, Vol. II) a la competencia destructiva, poniendo como ejemplo al transporte automotor de cargas (Kahn, 1988).
} 
combustibles, que los operadores no podrían trasladar a las tarifas. En el caso de Brasil, la huelga de camiones duró 10 días, paralizando la actividad y bloqueando carreteras, alterando las cadenas de abastecimiento de todo el país. El movimiento forzó al gobierno nacional a otorgar subsidios en el precio del diésel, reducciones tributarias y el establecimiento de una tabla de fletes mínimos de carácter obligatorio para diversos tipos de servicio. Las tablas de fletes normalmente son elaboradas por organismos consultivos permanentes entre las autoridades y los operadores.

Cabe preguntarse en qué medida se cumplen los valores propuestos por las tablas de fletes. En términos generales, los valores de los fletes tienden a seguir siendo pactados en el mercado, habitualmente por debajo de los montos de referencia. Sólo la obligatoriedad, acompañada de una fuerte presión de las autoridades de control, logra imponer los valores. 


\section{Argentina}

La Resolución 8/2016 de la Secretaría de Gestión del Transporte establece una Tarifa de Referencia para el servicio del TAC de jurisdicción nacional de cereales, oleaginosas, afines, productos, subproductos y derivados (mejorando el mecanismo ya existente desde 2012). Establece también una mesa para elaborar estos valores periódicamente, aunando a las tres grandes federaciones de transportistas, así como cinco grandes federaciones de productores agrícolas, el Ministerio de Transporte y el de Agroindustria. Existe un mecanismo similar en las provincias de Buenos Aires y de Santa Fe. En la práctica, las partes fijan valores acordados que pueden oscilar hasta un $15 \circ 20 \%$ por encima o por debajo, dependiendo de la oferta de carga y la oferta de camiones del momento, por lo que estas tarifas de referencia tienen un valor más político que práctico a la hora de negociar el valor concreto del flete.

Brasil

En el Brasil se dictó en 2018 la Ley $N^{\circ} 13.703$ que instituye la política nacional de pisos mínimos del transporte carretero (rodoviario) de cargas. A efectos de su aplicación, la Ley determina cinco tipologías de TAC: general, a granel, refrigerada, peligrosa y neo-granel. Las tarifas mínimas deben ajustarse periódicamente y cuando el costo del combustible varíe más del 10\%. Está expresamente prohibida en la Ley "la celebración de cualquier acuerdo o convención, individual o colectivamente, o incluso por cualquier entidad o representación de cualquier naturaleza, que representen la práctica de fletes en valores inferiores a los pisos mínimos establecidos en la forma de esta Ley". Los valores son determinados por la Agencia Nacional de transporte Terrestre (ANTT)

\section{Colombia}

Em Ministerio de Transportes ha desarrollado una herramienta interactiva en la internet, denominada "Sistema de Información para el Transporte Automotor de Carga - SICE TAC", que está en su versión 2.0, que permite calcular los costos para 24 configuraciones distintas. La herramienta fue desarrollada por una "Mesa Técnica del Observatorio del Transporte de Carga - OTCC", formada por organismos del estado y cámaras empresariales representativas de los sectores transportistas y dadores de cargas.

\section{Uruguay}

De acuerdo con la ley 349 del año 2001 de "Normas relativas a las Empresas de Transporte Terrestre Profesional de Carga", el Ministerio de Transporte y Obras Públicas "publicará periódicamente precios de referencia de los distintos tipos de transporte de carga. Estos precios de referencia se fijarán por parte del Ministerio de Transporte y Obras Públicas con la participación de la Mesa Intergremial de Transporte Profesional de Carga".

En la Tabla 11 se muestran los valores típicos de una tabla de fletes, correspondiente a Argentina, en noviembre de 2018 , expresando los montos en centavos de dólar corrientes por ton-km para el transporte de cereales y oleaginosas. Los precios reales en el mercado son ligeramente menores; la brecha se incrementa en la temporada baja. 
TABLA 11 - VALORES DE UNA TABLA DE FLETES

Argentina: tabla de fletes de CATAC, valores de noviembre de 2018

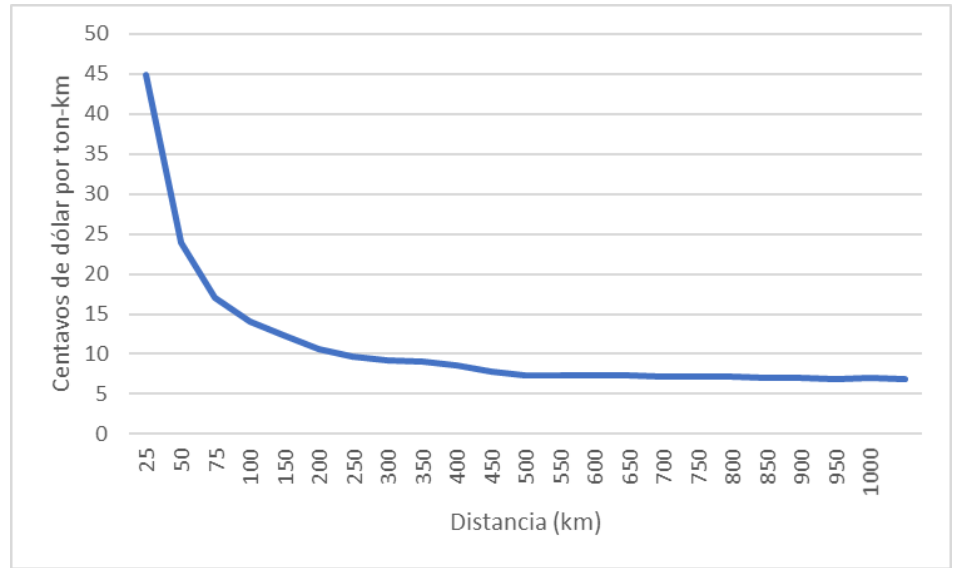

Fuente: tabla de fletes de CATAC

\section{Los costos externos}

Los costos totales del TAC incluyen los recursos que la sociedad debe disponer para la prestación de los servicios y las externalidades negativas que éstos generan. Se trata de un cálculo económico complejo, ya que a los costos que enfrenta el operador (los costos financieros) deben agregarse otros costos que suelen denominarse costos externos (Proost, 2011 ), que son valuados con criterio social: por el costo de oportunidad para la sociedad, que puede diferir de los precios de mercado, o no tener valor de mercado. Ello requiere establecer criterios sobre numerosos factores, que incluyen desde el valor de la tierra asignada a la red vial, el valor del capital, el de la vida (por los siniestros y las muertes que generan), el de la congestión, el de la contaminación del aire, el ruido o la emisión de GEl. Estudios realizados en Canadá, por ejemplo, sitúan a los costos totales entre un $10 \%$ y un $20 \%$ por encima de los costos financieros (Transport Canada, 2008). Estudios en Estados Unidos muestran que los costos de congestión, el deterioro de la calidad del aire y los accidentes son los costos externos de mayor magnitud (Delucchi, 2011).

La naturaleza de estos costos externos hace que no puedan ser fácilmente trasladados de un país a otro, ya que los temas a considerar, la forma de asignarles valor y las magnitudes pueden ser muy diferentes. No se tiene conocimiento de estudios que abarquen los costos totales del transporte carretero de cargas en América Latina.

\subsection{La calidad del servicio}

La calidad del servicio presenta dificultades para ser medida. La forma más frecuente de hacerlo es mediante encuestas de percepción a los usuarios. Un ejemplo es el Índice de Desempeño Logístico 2018, elaborado por el Banco Mundial sobre la base de encuestas a operadores de comercio exterior. La región de Latinoamérica y el Caribe ante la pregunta de cómo considera los niveles de los precios del transporte terrestre, responde en un $69 \%$ diciendo que son altos o muy altos. Sólo el Sur de Asia tiene una tasa de 
respuesta similar, con el $63 \%$ opinando que los fletes son altos o muy altos. Luego cuando se pregunta por la calidad de la infraestructura terrestre, LAC responde en un $50 \%$ que las condiciones son malas o muy malas. Finalmente, ante la pregunta de calidad y competencia del servicio, asociado al transporte de mercaderías de comercio exterior, en LAC el $27 \%$ considera que es baja o muy baja, y el $21 \%$ que es alta o muy alta.

En Colombia, el Departamento Nacional de Planeación efectuó la Encuesta Nacional Logística 2018 que, entre numerosos aspectos, relevó la percepción respecto de la calidad de los servicios. Dos resultados que se vinculan con la calidad del servicio son los prolongados tiempos de espera en la carga y la descarga (en ambos casos se demora más en la espera que la operación propiamente dicha), y el índice de pedido perfecto, que surge de combinar el porcentaje de pedidos entregados a tiempo, el de pedidos completos, el de pedidos sin daños y el de pedidos con documentación precisa. Esta métrica arroja un valor de $75 \%$, menor que el $90 \%$ característico de las economías desarrolladas; las principales problemáticas que se generan en la entrega de pedidos son los daños de la mercancía, los problemas del TAC y los de entrega causados por el cliente. Al ser consultados sobre las barreras a la operación logística, el $44,9 \%$ de las empresas respondieron la principal era el alto costo de transporte, siguiendo en orden los robos, la delincuencia y las actividades criminales (42,4\%). Las dos barreras que siguen en orden de importancia son la complejidad en la distribución urbana $(21,9 \%)$ y la disponibilidad del cliente para recibir mercancías $(14,1 \%) .{ }^{13}$

\subsection{Infraestructuras que afectan el desempeño del TAC}

Tres redes de infraestructura afectan el desempeño del transporte automotor de cargas: la red vial, la de telecomunicaciones y la de aprovisionamiento de energía (hasta el presente, combustibles). Su mayor o menor disponibilidad y calidad de servicio pueden incidir sensiblemente sobre la actividad del TAC.

\section{La red vial}

Entre los años 2005 y 2015 América Latina llevó a cabo un esfuerzo de inversión en la red de carreteras que hace presumir una mejora considerable en sus condiciones. En varios países la inversión alcanzó hasta $5 \%$ del PIB. Destacan los casos de Bolivia y de Colombia (este último caso es especialmente relevante por las dimensiones del PIB y por la fuerte participación privada). Como lo muestra el Gráfico 4, en varios países como Costa Rica, Panamá, Paraguay o Perú, la inversión anual en carreteras se ubicó en el rango del $1 \%$ al $2 \%$ del PIB (destacándose Perú por la participación privada). En los países con economías de mayores dimensiones, como es el caso de México y Brasil, la inversión se ubicó en umbrales sensiblemente menores, llegando en los mejores años al $0,7 \%$ y $0,6 \%$ respectivamente. La proporción de red pavimentada en Brasil pasó del $9.8 \%$ en 2001 al $12,4 \%$ en 2017 , lo que implica $42.500 \mathrm{~km}$ adicionales, fundamentalmente en las redes subnacionales. La red vial total en estado óptimo y bueno pasó del $26 \%$ en el año 2007 al $38 \%$ en 2017. (Fuente: Anuario CNT de Transporte, 2018). La mejora en las redes

\footnotetext{
13 Encuensta Nacional de Logística 2018. Departamento Nacional de Planeación. Gobierno de Colombia.
} 
indudablemente debe haber impactado en la gestión del TAC al facilitar su circulación y reducir los costos, en particular en aquellos países en los que el cambio fue mayor.

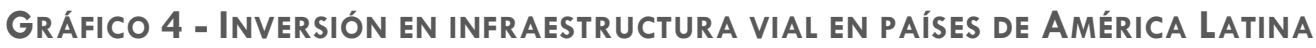
Expresada en \% del PIB

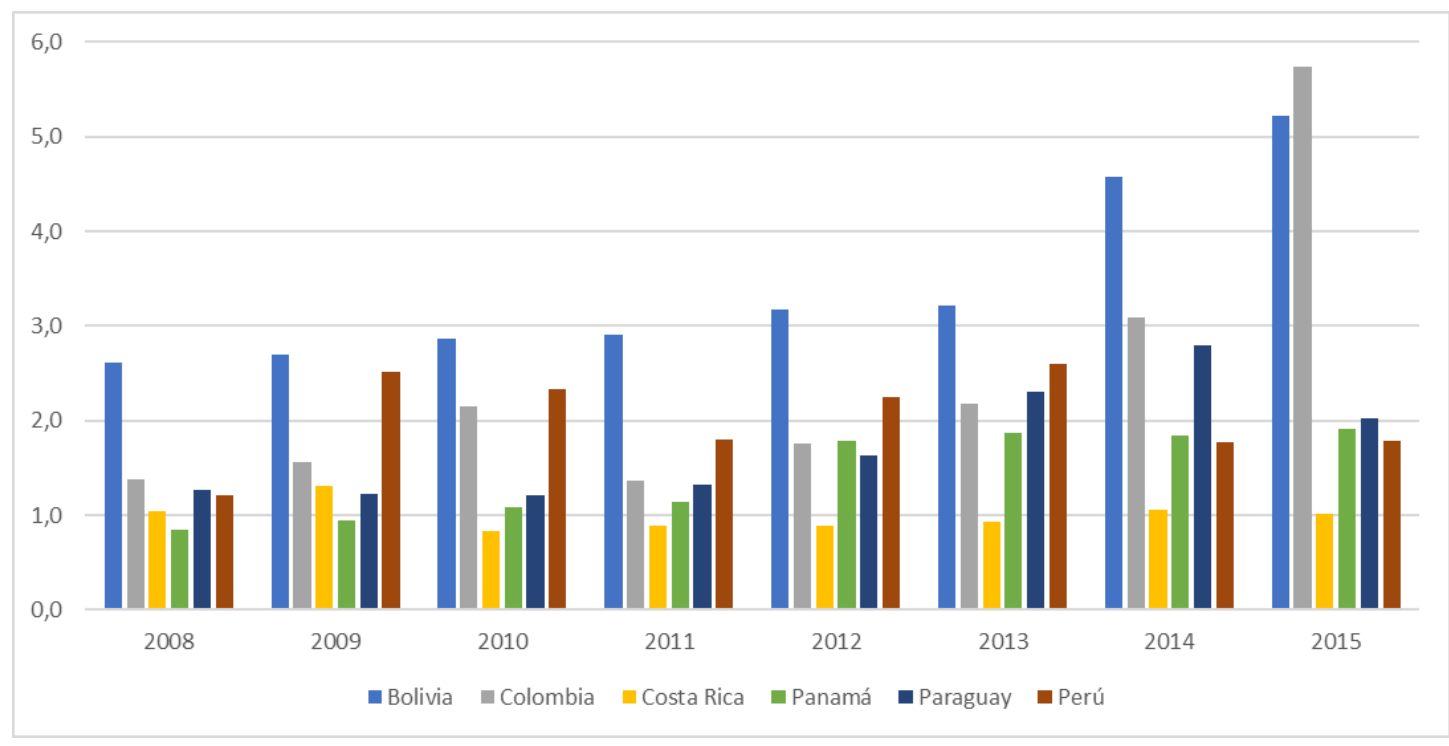

Fuente: elaborado con datos de Infralatam

\section{La cobertura de la banda ancha móvil}

La banda ancha proporciona la infraestructura básica para los procesos digitales de apoyo a la logística, dentro de la que el TAC es un eslabón fundamental, para poder disponer de la información que requieren enviar o recibir los actores de las cadenas de suministro en cualquier ubicación (WEF-IDB, 2018). Ello requiere de una red que tenga adecuada cobertura y velocidad, crítica para subir o bajar información. La cobertura generalmente es medida con respecto a la población; siendo América Latina una región altamente urbanizada, no es llamativo que - desde esa perspectiva -la cobertura sea relativamente satisfactoria: en varios países la banda ancha fija y la banda ancha móvil de $3 G$ tienen índices de cobertura de la población superiores al 95\%; la cobertura con servicios $4 G$ - que proveen mayor velocidad - es considerablemente menor, de alrededor de $80 \%$ en muchos países de la región, pero con varios casos de rezago (particularmente en Centroamérica) (Katz, 2018). Respecto a la velocidad, particularmente la de la banda ancha móvil, si bien ha aumentado, se encuentra claramente por debajo de la de las economías desarrolladas; la expansión de la conexión 4G (Katz, 2018).

La mayor debilidad se encuentra en la cobertura fuera de las áreas urbanas, a lo largo de las carreteras donde transitan los camiones: si bien no se tiene conocimiento de índices que lo cuantifiquen, la observación de los mapas (como por ejemplo el del Gráfico 5) muestra que, salvo las rutas troncales, en muchas otras la cobertura es intermitente o bien inexistente, y limitada a servicios de bajas velocidades. Esta debilidad - mucho más acentuada en Sudamérica que en México y Centroamérica - dificulta la digitalización de los servicios en el TAC, para el seguimiento y control de vehículos, cargas y conductores, 
generando un obstáculo a la digitalización integral de las cadenas de abastecimiento. (WEF-IDB, 2018).

Gráfico 5 - Ejemplo de mapa de cobertura de Redes 2G/3G y 4 G

Oeste de Argentina y centro de Chile



Noroeste de Argentina, Norte de Chile, Sur de Bolivia

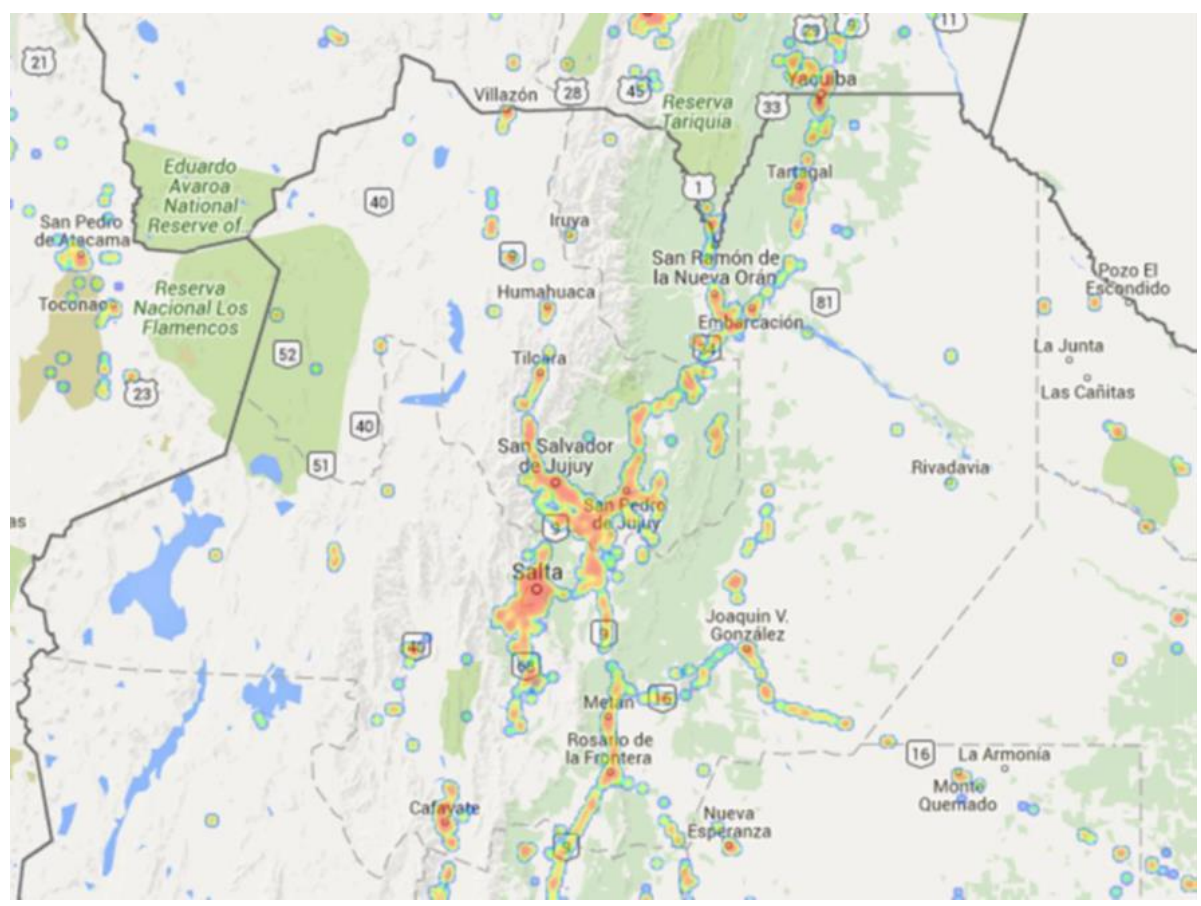

Fuente: Opensignal. Consulta realizada en febrero 2018 en https://opensignal.com/networks 


\section{Aprovisionamiento de energía}

Hasta el presente, el aprovisionamiento de energía para el TAC se reducía a los combustibles líquidos distribuidos por las estaciones de servicio o aprovisionamiento, $\circ$ bien entregados por las propias petroleras a los tanques de reserva en las terminales de las empresas de transportes. La distribución de estos combustibles está bien desarrollada en todos los países y los conflictos de aprovisionamiento no tienen que ver con la red sino con los costos y precios. Esta situación cambiará radicalmente en los próximos años, debido a la incorporación de combustibles alternativos, procedentes de diversas fuentes limpias y/o renovables cuyos estándares definitivos aun no son del todo claros, y mucho menos sus redes de distribución. Pueden citarse:

- Biocombustibles (bioetanol y biodiésel): estos ya se están utilizando en varios países (especialmente Brasil, con más de 15 años de experiencia) y Argentina en forma de mezclas (el biodiesel con el diésel convencional) y puro el bioetanol (en el caso de Brasil). La red de distribución es la misma y con iguales características que la de combustibles fósiles.

- Gas Natural Comprimido (GNC): no se utiliza en camiones, pero sí en utilitarios, para distribución urbana especialmente debido a la baja autonomía que implica. Su distribución se hace ampliando la capacidad de la misma red urbana de gas natural de uso corriente en hogares e industrias, e instalando los correspondientes surtidores en las estaciones de servicio. Argentina, por ejemplo, cuenta con este combustible en casi todas sus ciudades medianas y grandes.

- Gas Natural Licuado (GNL): esta versión de gas se está empezando a experimentar con éxito en camiones pesados en países europeas, agregando escaso peso adicional a los camiones, pero otorgándoles gran autonomía, similar al diésel. Las motorizaciones cambian (se usa el ciclo Otto en vez del Diésel, aunque Volvo está haciendo experiencias con ciclo Diésel), y si bien se puede usar el gas de red corriente, la compresión y licuefacción significan procesos complejos que implican maquinaria específica en los puntos de aprovisionamiento.

- Electricidad: si bien en Europa y Estados Unidos se están haciendo algunas pruebas para camiones pesados en circuitos específicos de alta densidad de carga, la electricidad es especialmente indicada para las distribuciones urbanas $\circ$ para circuitos entre industrias de distancias acotadas. Aún existen dudas de los estándares futuros en el mundo, ya que existen diversas variantes en cuanto a la autonomía, tiempo de recarga, formato de enchufes, etc. Su uso podría repercutir en el dimensionamiento de las redes eléctricas, equipos de transformación, etc. 


\section{AVANCES EN LOS MARCOS REGULATORIOS}

\subsection{La regulación del TAC}

El transporte automotor por carretera se caracteriza por las bajas barreras de entrada y salida, lo que facilita la competencia en el mercado. No obstante, históricamente, y en especial tras la crisis de 1930, la actividad fue objeto de una considerable regulación económica (entrada, precios), seguramente influenciada por la presión de los actores vinculados al transporte ferroviario, dominante hasta esa época, que se vieron desafiados ante la irrupción del TAC. A partir de los años 80 hubo una tendencia hacia la desregulación de los servicios del autotransporte de cargas en las economías desarrolladas (OECD, 1997), y también en la región, que fue objeto de fuertes controversias por el temor que generaba en relación con la posible caída de la calidad de servicio, la seguridad y la desatención de las localidades más pequeñas. A partir de los años 90 se estableció un consenso generalizado de que el TAC es un sector que no requiere regulación económica; sea por opciones de política pública $\circ$ por falta de capacidad de control, el TAC se ha comportado básicamente como un mercado regido por la competencia.

A partir del nuevo siglo se renovó el interés en la regulación del TAC, pero impulsado por los aspectos ambientales y de seguridad, y también por la búsqueda de una mayor productividad en un sector que se iba tornando cada vez más como el actor clave en el movimiento terrestre de cargas en el mundo. Ello se reflejó en numerosas reglas técnicas que establecieron las condiciones que debían prestar vehículos y conductores. Las nuevas tecnologías aparecieron también como una posible fuente de mejora, tanto en la reducción de externalidades negativas como en la productividad. El RECUADRO 4 resume las recomendaciones de la OECD al respecto.

\section{RECUADRO 4 - LOS IMPULSORES DE LA REgulACIÓN EN EL TAC}

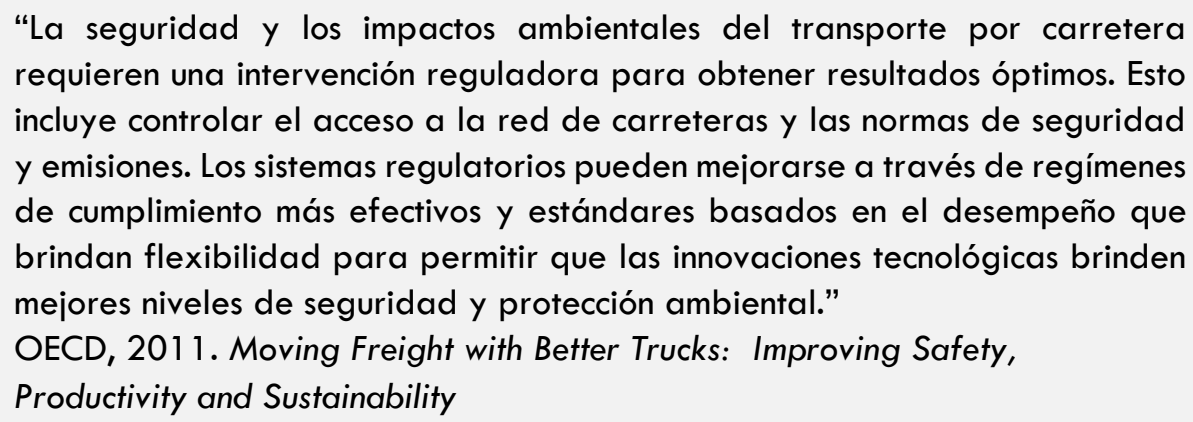

En América Latina, estudios recientes (Barbero \& Guerrero, 2017) muestran que en la región hubo un comportamiento similar al de las tendencias globales: un avance hacia la desregulación económica, pero simultáneamente una creciente regulación de orden técnico, vinculada con la seguridad y la protección ambiental, cubriendo aspectos referidos a los vehículos, su circulación, sus conductores y las prácticas operativas. Los temas centrales son los pesos y dimensiones de los vehículos, las modalidades de estiba, la relación entre la potencia y el peso, la antigüedad máxima de los vehículos, los límites establecidos para las emisiones, y las condiciones de trabajo de los conductores. Las 
normas suelen expresarse en códigos que en muchos casos no son específicos del TAC, como son las normas de circulación y seguridad vial (que abarcan a todo tipo de vehículo) y en reglamentaciones ambientales. Esta perspectiva de "menor regulación económica y mayor regulación técnica" se ha visto desafiada recientemente, ante las presiones ejercidas por los pequeños operadores para imponer tablas de fletes que buscan defenderse de la asimetría en la negociación con los grandes dadores de cargas, especialmente en los graneles agrícolas, como se comenta en el Capítulo 3.

Por otra parte, el TAC no solo es regulado por las leyes y disposiciones propias del sector, emanadas de los organismos del estado específicos (ministerios de transporte o similares), sino también por otros organismos relacionados con la carga (sanidad de los alimentos, regulación de mercancías peligrosas, etc.), con el estado de los caminos, con el tipo de viaje y las aduanas (cabotaje, internacional, tránsito internacional), y muchos otros. Además, en los países con organización federal como Argentina o Brasil, a las disposiciones federales se suman las de las provincias o estados, y distritos o municipios, que a veces son distintas y hasta contradictorias entre sí.

A continuación se revisan los cambios ocurridos recientemente en cuatro países de la región, representativos de las tendencias generales, ensayándose posteriormente una síntesis.

\subsection{Los cambios en la región en los últimos años}

En México, el Programa Sectorial 2013/2018, en lo que se refiere al TAC, enfatiza como objetivos de política la seguridad vial, la modernización del autotransporte y la formalización de las unidades económicas, la integración de la logística mediante una red de plataformas, el impulso a la multimodalidad y a los contratos de largo plazo, la facilitación del financiamiento, el apoyo al desarrollo de recursos humanos y la prioridad al transporte puerta-a-puerta. Las normas más relevantes que fueron promulgadas en los últimos años muestran claramente la orientación de la política regulatoria mexicana respecto al TAC. Se destacan: la referida al transporte de sustancias peligrosas (2003); las especificaciones de pesos, dimensiones y capacidad máxima (2008); la estrategia de seguridad vial 2011-2020 (2010); el reglamento de paquetería y mensajería que define las condiciones que regulan el servicio de paquetería y mensajería que se presta a terceros; el Programa de Modernización del Autotransporte Federal (2015) que establece un estímulo fiscal; el Programa de Transporte Limpio (que es de adopción voluntaria) para reducir el consumo de combustible y las emisiones; y la creación del Comité Consultivo Nacional de Normalización de Transporte Terrestre la elaboración de Normas Oficiales Mexicanas en materia de Transporte Terrestre, las cuales son competencia de la Secretaría de Comunicaciones y Transporte, en el cual se incluyen múltiples dependencias públicas, representantes de los transportistas (de cargas y pasajeros), representantes de los cargadores y pasajeros, y constructores de vehículos y entidades académicas. (Robles Linares, 2018).

En Chile, en los aspectos económicos (entrada, salida, precios), el mercado está desregulado, y no ha experimentado cambios recientes. En cuanto a la regulación técnica, sí se han aplicado reglamentaciones nuevas, vinculadas fundamentalmente con la 
seguridad (requisitos de los vehículos) y las emisiones (normas de emisiones máximas). Dos reglamentaciones se destacan (Santa Muñoz, 2018):

- Requisitos técnicos que deben cumplir los dispositivos y sistemas de seguridad de camiones y tractocamiones nuevos. El Decreto Supremo 45 de 2017 (publicado oficialmente en 2018) establece que los camiones y tractocamiones que se inscriban por primera vez a partir de fechas específicas (de 2020 a 2022) deberán estar dotados de sistemas o dispositivos de seguridad certificados que acrediten el cumplimiento de normas internacionales de seguridad. Los elementos considerados son vidrios, frenos, depósito de combustible, asientos y sus anclajes, cinturón de seguridad y sus anclajes, dispositivo antiproyección (guardabarros, faldillas) y dispositivo de protección lateral, que deben cumplir con normas determinadas, entregándose como opciones de certificación normas europeas, de Estados Unidos y de Brasil (y en algunos casos se establecen exigencias específicas).

- Normas de Emisión de Motores de Vehículos Pesados Nuevos. Abarca los vehículos con peso superior a $3860 \mathrm{~kg}$ ). Los valores se han ido actualizando progresivamente desde las primeras normas (que datan de 1994). A partir de septiembre de 2015 los motores de todos los camiones deben cumplir con norma europea Euro $\mathrm{V}$ o de Estados Unidos EPA 2007.

Otras dos regulaciones relevantes son la incorporación de simuladores de conducción para la obtención de licencias de conducir y el reintegro de un porcentaje del impuesto específico al diésel (porcentaje que es menor al incrementarse los ingresos anuales de las empresas).

En la Argentina el TAC opera en un mercado desregulado: no hay reserva de mercado, hay libertad de entrada y salida de la actividad, y libre fijación de fletes entre el dador de carga y el transportista. Si bien existen tarifas de referencia para el transporte de granos, aun así los fletes cobrados pueden ser hasta un 30/35\% menores a las tarifas de referencia, o pueden superarla cuando hay sobreoferta de carga y escasez de camiones disponibles. No hay posiciones dominantes por el lado de la oferta, salvo excepciones. En general es el dador de carga el que pone las condiciones operativas. Los contratos de largo plazo existen en los estratos de mayor escala de complejidad y facturación (grandes dadores de carga que contratan a grandes empresas transportistas) y es muy usual en los operadores logísticos. Las medidas recientes más destacadas son las siguientes (Fiadone, 2018):

- Limitación de velocidad para vehículos de más de $3.500 \mathrm{~kg}$. Los vehículos fabricados de 2017 en adelante deben tener un dispositivo limitador que no permita circular a más de $90 \mathrm{~km} /$ hora, para mejorar la seguridad vial, disminuir el consumo de combustible, las emisiones y los costos de mantenimiento.

- Mesa de Negociación Participativa, para determinar la tarifa de referencia en el transporte de ciertos productos del agro. La mesa incluye las federaciones de transportistas, las de productores agrícolas y las entidades del gobierno nacional responsables por el transporte y la agricultura. 
- Sistema de turnos obligatorios, que establece que sólo arriben a las terminales de descarga o de acopio las unidades de transporte que tengan asignado un turno de descarga, para disminuir el tiempo de espera de los camiones.

- Incremento en las dimensiones y carga admitida: el Decreto 32/2018 permite unidades de transporte más grandes que las utilizadas hasta su emisión (Ilamadas "escalables"), y los bitrenes, con nuevas y más exigentes disposiciones en materia de seguridad vial y de contaminación producida por los vehículos, y determina una nueva y mayor relación de potencia-peso.

- Creación de una "Mesa de Logística" en diciembre de 2018, convocada y por los Ministerios de Transporte y de Producción y Trabajo, formada por más de 60 cámaras empresarias y sindicales vinculadas con el sector logístico, como un ámbito de diálogo y participación entre el Estado y los sectores productivos y de transporte a través de las empresas, las cámaras y los sindicatos.

- Facilidades para importar vehículos propulsados por GNC y GNL: El Ente Nacional Regulador del Gas aprobó la Norma Argentina de Gas (NAG) 451 "Procedimiento para la habilitación de vehículos importados, propulsados mediante el uso de gas natural", para dotar de Gas Natural Comprimido y Licuado a vehículos importados de carga y pasajeros, reconociendo que la utilización eficiente del gas natural representa una transición de la matriz de energía secundaria, hacia patrones de uso de combustibles menos contaminantes y más eficaces.

- Reducción plazo para validar homologación de vehículos importados de Europa. Esta disposición de febrero de 2018 admite que las homologaciones europeas son más exigentes que las nacionales y reduce el trámite a una simple declaración jurada.

En Brasil se aprobó en 2018 la "Política Nacional de Pisos Mínimos del Transporte Rodoviario de Cargas 14", por la cual se fijan tarifas mínimas que deben ajustarse periódicamente, y especialmente cuando el costo del combustible varíe más del $10 \%$. Está expresamente prohibida en la Ley "la celebración de cualquier acuerdo o convención, individual o colectivamente, o incluso por cualquier entidad o representación de cualquier naturaleza, que representen la práctica de fletes en valores inferiores a los pisos mínimos establecidos en la forma de esta Ley". Los valores son determinados por la Agencia Nacional de transporte Terrestre (ANTT). Esta política fue la respuesta del Gobierno a los reclamos de los pequeños transportistas que, ante la negativa de los dadores de carga de pagar una mayor tarifa originada en los aumentos del combustible, generaron una huelga de casi diez días que paralizó el suministro de todo tipo de productos en el país. Otras normas son:

- El Programa Despoluir, desarrollado en 2007 por la Confederación Nacional de Transportes (CNT) que busca promover la mejora de la calidad de vida de los transportistas, comprometiéndolos en acciones de responsabilidad socio ambiental.

- La Ley n 13.103 entró en vigor en el año 2015 para disponer, de forma completa, sobre los derechos y las obligaciones de conductores autónomos, camioneros y empresas de transporte.

\footnotetext{
${ }^{14}$ Ley $\mathrm{N}^{\circ} 13.703$
} 
- Pesos máximos de vehículos de carga (2017). El Contran (Consejo Nacional de Tráfico), órgano máximo en el sistema nacional de tránsito, estableció límites legales para dimensiones, Peso Bruto Total (PBT) y peso por eje para todos los vehículos de cargas terrestres.

- La Ley no 12.619 de 2012, que dispone sobre el ejercicio de la profesión de conductor, para regular y disciplinar la jornada de trabajo y el tiempo de conducción del conductor profesional

En Uruguay, de acuerdo con la ley 349 del año 2001 de "Normas relativas a las Empresas de Transporte Terrestre Profesional de Carga", el Ministerio de Transporte y Obras Públicas publicará periódicamente precios de referencia de los distintos tipos de transporte de carga, en acuerdo con la Mesa Intergremial de Transporte Profesional de Carga.

En Colombia se creó a inicios de 2018 el SITRA (Sistema Integral de Tránsito y Transporte), orientado a la seguridad ante accidentes, atentados o agresiones a los transportistas, integrando las capacidades tecnológicas de las empresas con los sistemas de control y monitoreo de la Policía Nacional, permitiendo de manera inmediata que un conductor o los centros de monitoreo de las empresas reporten un evento de emergencia en las vías nacionales para que sea atendida en el centro de comando y control de la Dirección de Tránsito de la Policía. Este país es un caso especial en la región, ya que el TAC es considerado un servicio público regulado por el Estado. En efecto, la Ley 105 de 1993, establece que le corresponde al Estado la planeación, el control, la regulación y la vigilancia del transporte y de las actividades a él vinculadas; que la operación del transporte público en Colombia es un servicio público bajo la regulación del Estado, el cual ejercerá el control y la vigilancia necesarios para su adecuada prestación, en condiciones de calidad, oportunidad y seguridad; y dispone que corresponde a las autoridades competentes diseñar y ejecutar políticas dirigidas a fomentar el uso de los medios de transporte, racionalizando los equipos apropiados de acuerdo con la demanda. Por su parte la Ley 336 de 1996, prevé que el servicio de transporte prestado por las empresas de transporte es un servicio público esencial bajo la regulación del Estado, y que este deberá garantizar su prestación y la protección de los usuarios, mediante, entre otras medidas, la regulación del ingreso de vehículos por incremento al servicio público, y faculta al Gobierno Nacional para expedir los reglamentos correspondientes "a efectos de armonizar las relaciones equitativas entre los distintos elementos que interviene la contratación y prestación del servicio público de transporte, con criterios que impidan la competencia desleal y promuevan la racionalización del mercado de transporte".

En Perú, a efectos de mejorar la seguridad vial, se estableció la obligación de informar velocidad máxima a partir de 2017: las unidades vehiculares de transporte de carga y mercancías a nivel nacional deben enviar una señal GPS al Centro de Gestión y Monitoreo de la Superintendencia de Transporte Terrestre de Personas, Carga y Mercancías (SUTRAN). Se da así cumplimiento al Reglamento Nacional de Administración de Transporte - RENAT a fin de evitar que los camiones de carga excedan la velocidad en de $80 \mathrm{~km} / \mathrm{h}$ en las rutas (70 para cargas peligrosas). 
Los cambios hacia regulaciones técnicas más exigentes ponen en evidencia las diferencias crecientes entre las grandes empresas de transporte y la multitud de pequeñas empresas. En Argentina, por ejemplo, en enero de 2018 el Decreto 32/2018 estableció una mayor relación potencia/peso a efectos de mejorar la seguridad vial y la eficiencia energética, y disminuir las emisiones. Sin embargo, los parámetros establecidos dejarían fuera del mercado a una amplia cantidad de pequeños transportistas, por lo que sus reclamos canalizados a través de cámaras y asociaciones obligaron al gobierno a emitir en octubre 2018 la Resolución 884/2018, fijando plazos de implementación más extensos y condiciones menos estrictas. En Perú, la negativa de los transportistas a implementar los controles de velocidad a través de GPS (por su costo y las limitaciones operativas que significan), fue una de las causas de la huelga de una semana en febrero 2019.

\subsection{Programas de transporte limpio}

En los últimos años se han impulsado programas de tendientes a que el TAC sea más amigable con el ambiente, consuma menos recursos y sea más eficiente en esos aspectos. A continuación, se detallan varias iniciativas recientes.

El Programa Giro Limpio de Chile. En Chile se ha iniciado en 2018 el Programa GiroLimpio, un programa nacional voluntario, desarrollado por el Centro de Transporte y Logística de la Universidad Andrés Bello (UNAB), con financiamiento de Corfo, y cuenta con el apoyo de los Ministerios de Transportes, Energía, y Medio Ambiente; la Agencia Chilena de Eficiencia Energética (ACHEE) y la Agencia de Sustentabilidad y Cambio Climático. Busca certificar y reconocer los esfuerzos realizados por las empresas de transporte en el ámbito de la sustentabilidad y eficiencia energética. Además, se certifican a las empresas generadoras de carga que prefieren a los transportistas comprometidos por mejorar su desempeño energético y medioambiental. El objetivo de GiroLimpio es que el transporte de carga sea más eficiente, competitivo y amigable con el medio ambiente. Esto se logra con la adopción de tecnologías y estrategias para la reducción de consumo de combustible y las emisiones asociadas. En este Programa el adherente debe establecer un estado base y desarrollar un plan de acción para mejorar el desempeño ambiental, que debe reportar anualmente con los ahorros alcanzados y las emisiones reducidas. Ya hay alrededor de 20 empresas adheridas.

El Proyecto GFEl de Colombia. Colombia inició en 2017 su adhesión al proyecto Global Fuel Economy Initiative (GFEI), que surge de una asociación de la Agencia Internacional de Energía (IEA), el Programa de las Naciones Unidas para el Medio Ambiente (PNUMA), el Foro Internacional de Transporte de la OCDE (ITF), el Consejo Internacional de Transporte Limpio (ICCT), el Instituto de Estudios de Transporte de la UC Davis y la Fundación FIA, que trabaja para garantizar mejoras reales en el ahorro de combustible, y la máxima implementación de las tecnologías existentes de ahorro de combustible en vehículos en todo el mundo. El proyecto GFEl, a nivel mundial, tiene el objetivo de reducir el consumo de combustibles y las emisiones de gases de efecto invernadero y otros contaminantes a través de mejoras en la eficiencia del combustible de vehículos. El proyecto GFEl en Colombia se inició en enero de 2017 y las principales tareas iniciales son las siguientes: 
- Armar una base de datos de consumo de combustible con línea base y parámetros nacionales de la economía de combustible.

- Analizar los posibles resultados de las diferentes opciones de política con la herramienta del GFEl (Fuel Economy Policies Implementation Tool -FEPIT) en base a las características de la flota de vehículos en una serie de escenarios diferentes.

- Sensibilización de los tomadores de decisiones de los beneficios de una política de ahorro de combustibles en relación a la salud, el medio ambiente, económicos y globales.

- Recomendaciones sobre los próximos pasos para desarrollar una propuesta para política nacional la economía de combustible, incluyendo un programa nacional de combustibles y vehículos limpios, con un plan de acción y líneas de tiempo para poner en práctica una política de ahorro de combustible, preparado en colaboración con un grupo de trabajo de actores claves.

- Recomendaciones para la legislación para apoyar la reducción de azufre en los combustibles, la promoción de vehículos más limpios y mejorar la economía de combustible en Colombia.

El Programa de Transporte Inteligente de Argentina. En Argentina se han impulsado dos iniciativas de transporte limpio de cargas. Por un lado, la ya citada limitación de velocidad a $90 \mathrm{~km} /$ hora para vehículos de más de $3.500 \mathrm{~kg}$ fabricados de 2017 en adelante. Por otro lado, en octubre 2018 el gobierno impulsó el Programa de Transporte Inteligente a modo de prueba con aproximadamente una docena de empresas de transporte. El Programa, creado en 2016 y aprobado en 2017, tiene como objetivo mejorar la eficiencia energética, aumentar la competitividad mediante la disminución del costo logístico, disminuir las emisiones contaminantes y de GEl, y crear una comunidad de buenas prácticas y fomentar su uso en el transporte de cargas, estableciendo un sistema de información que permita concentrar la información de las acciones implementadas y volcar los resultados en una base de datos perteneciente al programa. Inspirado en el programa francés Objectif $\mathrm{CO}_{2}$ y el programa SmartWay de la EPA (EEUU) se centra en el compromiso de reducción de emisiones por parte del transportista en un lapso convenido, recomendando tecnologías y otras estrategias, pero sin realizar certificaciones $u$ homologaciones, limitándose a medir el logro del resultado comprometido. El programa se encuentra en una etapa experimental, con un número limitado de empresas. Cabe destacar que el sector privado propuso casi simultáneamente un programa denominado Rango Verde, creado por la Federación Argentina de Entidades Empresarias de Transporte de Cargas (FADEEAC).

\section{El Programa Transporte Limpio en México}

Es un programa voluntario y gratuito desarrollado en 2012 por la Secretaría de Medio Ambiente y Recursos Naturales (SEMARNAT) y la Secretaría de Comunicaciones y Transportes (SCT), ambas dependientes del gobierno central. Se trata de una adaptación del modelo Smartway desarrollado en Estados Unidos. Está dirigido, principalmente, a empresas transportistas de carga y pasajeros, tanto urbanas como de larga distancia, así como a dadores de carga y proveedores de tecnologías y/o 
estrategias. Estos deben adherir al Programa comprometiéndose a cumplir algunos requisitos establecidos en el Programa. Los objetivos generales del Programa son:

- Reducir el consumo de combustible.

- Reducir las emisiones de GEl y contaminantes criterio (NOx y PM10 y PM2.5).

- Reducir los costos de operación del transporte.

Para ello el Programa se compromete a proveer asistencia técnica, a difundir los resultados y a premiar a los socios por los logros alcanzados.

Perú: Obligación de informar velocidad máxima. La obligación de enviar una señal GPS al Centro de Gestión y Monitoreo de la SUTRAN, citada antes, está orientada a la seguridad vial, pero repercute positivamente en el consumo de combustible.

Uruguay: proyecto Transporte de Carga Sustentable. En 2018 se está llevando adelante el proyecto "Transporte de Carga Sustentable", propuesto por la Intergremial de Transporte Profesional de Carga (ITPC), en conjunto con el Centro de Innovación en Organización Industrial (CINOI) de la Universidad de Montevideo, apoyado por el Ministerio de Transporte y Obras Públicas y co-financiado por la Agencia Nacional de Desarrollo (ANDE). El proyecto terminó recientemente un informe de caracterización del TAC en el país.

\subsection{Las tendencias regulatorias y su impacto}

La revisión de los casos analizados permite observar que presentan algunos patrones comunes, que se repiten en los países de la región. Las tendencias apuntan fundamentalmente hacia la disminución de costos de los servicios de transporte, la eficiencia energética, la seguridad vial y, más recientemente, a la descarbonización y disminución de emisión de contaminantes. Pueden reconocerse los siguientes tipos de normas, de acuerdo con sus objetivos:

- Mayores dimensiones admitidas en los equipos

- Limitación creciente de las emisiones y el consumo

- Mayor seguridad para minimizar los accidentes, como requisitos de equipos telemáticos y exigencia de sistemas activos y pasivos en las unidades nuevas

- La generación de mecanismos participativos, de tipo de mesas de acuerdo, nucleando numerosos actores vinculados al TAC

- Otras normas: laborales, de paquetería y mensajería, de turnos en puerto, y normas para organizar/agilizar la carga y descarga.

Las tendencias normativas de América Latina se corresponden con las que tuvieron las economías desarrolladas en las dos décadas pasadas, particularmente en materia de reducción de emisiones y de seguridad, aun cuando estos temas siguen siendo centrales en su agenda (OECD, 2011; ITF, 2018). La búsqueda de mayor productividad (por ejemplo, mediante camiones de mayor porte) son objeto de especial atención en países como Australia, Canadá, los Estados Unidos o la UE. La presión por la regulación de los 
fletes se ha expresado ocasionalmente en países europeos, como por ejemplo en Francia en 2017.

Otros temas que han ingresado con mayor fuerza en la normativa están relacionados con las condiciones de trabajo de los conductores y su control, debido a su relevancia social y a su relación con la seguridad. A título de ejemplo, en los Estados Unidos las tres principales normas actualmente en discusión son los dispositivos de registro electrónico de la tarea del conductor (ELD), el régimen de horas máximas de conducción (HOS) y la admisión de algunos conductores de menos de 21 años en el transporte interurbano de cargas (que desde 1935 no podían conducir camiones pesados). Un efecto no deseado de la reglamentación de ELD y HOS es que reduce la productividad; los operadores estiman que el registro electrónico de horas trabajadas, al eliminar las frecuentes "trampas" en las declaraciones, redujo la productividad del sector en el orden del $3 \%$ al $8 \%)^{15}$.

El impacto que han tenido los cambios regulatorios es difícil de evaluar, pero sin duda ha sido relevante:

- En la reducción de siniestros involucrando camiones en América Latina, la Organización de las Naciones Unidas (ONU) ha propuesto que las víctimas de siniestros viales se reduzcan en 50\% para 2020. Para lograrlo deberían rediseñarse los caminos para que circulen los vehículos con las velocidades adecuadas por tipo de usuario, los vehículos deberían tener seguridad activa y pasiva $^{16}$, y debería existir un sistema eficaz de emergencias médica. Para que el sistema funcione es imprescindible tener instituciones sólidas que lideren todos sus componentes, información detallada acerca de los siniestros viales y de los riesgos que existen en las vías, así como legislación adecuada y controles para que se cumplan ${ }^{17}$. Uno de los hallazgos de la investigación realizada por IRU en 2018 es la importancia que las empresas de transporte dan a la tecnología como medio para mejorar la seguridad vial. Sin embargo, y aunque "los accidentes con camiones son cada vez menos frecuentes gracias a las mejoras tecnológicas, el $85 \%$ de ellos son causados por errores humanos" 18 . Es decir que, si bien las nuevas tecnologías pueden ayudar al conductor y ayudar a reducir la gravedad de los accidentes, es fundamental una mejor capacitación de los conductores y otros usuarios de la carretera, ya que sin un alto nivel de capacitación, el impacto beneficioso de la tecnología es limitado.

- En la descarbonización. Los distintos países han comenzado a tomar el asunto con responsabilidad a partir de sus compromisos con el Acuerdo de París sobre el Cambio Climático, ya que están obligados a calcular periódicamente las Emisiones Nacionalmente Determinadas (NDC). Sin embargo, dado que el Acuerdo de París es relativamente reciente (2015) y que las primeras mediciones se aportaron en 2016, sobre bases que cada país podía elegir de forma algo arbitraria (ya que

\footnotetext{
15 Supply Chain Management Review: Trucking Regulation Update: Winds of change? October, 2018.

16 Seguridad activa: se logra con dispositivos internos y externos del vehículo que prevengan los siniestros - ayuden a la maniobrabilidad para evitarlos. Seguridad pasiva: la que reduce los efectos del choque, como airbags, cinturones de seguridad, etc.

17 Banco de Desarrollo de América Latina (CAF) (2017)

18 IRU (2018)
} 
del Acuerdo no surgían con claridad los factores a evaluar ${ }^{19}$ ), resulta que aún es difícil establecer conclusiones.

- En la mayor productividad del TAC. Las regulaciones implementadas en los últimos años tienden a modificar el parque vehicular con unidades de mayor capacidad de carga y mejores motorizaciones, acompañadas de las innovaciones propias de la industria 4.0. Sin embargo, el acceso a este tipo de unidades implica inversiones iniciales mayores por parte de los transportistas, lo que limita la demanda a las empresas con mayor capacidad económico-financiera, dejando fuera de posibilidades de renovación y mejora a los transportistas más chicos. A su vez los dadores de carga buscan aprovechar las ventajas de las unidades de mayor tamaño y tecnología más moderna, favoreciendo a los transportistas que las posean. Todo esto probablemente incrementará la brecha entre los transportistas más grandes y con mayor capacidad económica y financiera, en detrimento de los más pequeños que no podrán salir de su estadio. En Chile, por ejemplo, la evolución de las normas de seguridad y de emisiones tienen un impacto en el segmento de transportistas que adquieren camiones nuevos, habitualmente las empresas medianas y grandes, pero no en los pequeños operadores. Al igual que otras normativas (como se verá en las que propician la renovación de flotas en el Capítulo siguiente, o en las tendencias a la incorporación de nuevas tecnologías), es probable que se esté reforzando la tendencia a la concentración en los operadores de mayores dimensiones.

19 El 15 de diciembre 2018 en Katowice (Polonia), en la reunión COP 24, los gobiernos de los países adoptaron un conjunto de directrices para hacer más operativo el Acuerdo de París, incluyendo la manera en que los países informarán sobre sus acciones climáticas en el marco de las respectivas contribuciones determinadas a nivel nacional (NDC) 


\section{LA DINÁMICA DE LA RENOVACIÓN DE FLOTAS}

\subsection{Las tasas de renovación}

Las tasas de renovación y expansión de las flotas en la región presentan valores que reflejan el crecimiento general de la actividad. En México la tasa de incorporación de camiones entre los años 2010 y 2017 fue del 5,4\% TACC., mayor en las unidades de arrastre $(6,5 \%)$ que en las motrices $(4.4 \%)$, y mayor aún en los semirremolques de dos ejes $(7 \%)$; estos guarismos reflejan el impacto de las políticas de facilitación de la renovación que se detallan más adelante.

En Chile anualmente se renueva el 5,7\% de la flota (unas 12.000 unidades, en promedio, sobre una flota de 210.000 vehículos de carga. En el año 2016 la incorporación de unidades - de acuerdo con la Asociación Nacional Automotriz de Chile (ANAC) - fue en un $14 \%$ de camiones livianos, $32 \%$ de camiones medianos y $54 \%$ de camiones pesados. En 2009 y 2013 se desarrolló el Programa "Cambia tu Camión", que se describe más abajo.

En Argentina el proceso de renovación de unidades en los últimos años estuvo condicionado por la capacidad financiera de los operadores. Las empresas más grandes se valieron de financiación propia o a través de líneas de crédito de proveedores, incorporando vehículos más potentes y con mayor cantidad de tecnología a bordo. Las empresas más pequeñas o con menor capacidad financiera, para las que el crédito bancario resultaba (y sigue resultando) muy caro, se valieron de planes del Estado (ver más abajo), pero adquirieron unidades de menor potencia y tecnología, más apropiados para cargas urbanas, pero que en muchos casos se aplicaron a viajes de ruta, donde su duración es menor. Los compradores priorizaron la baja inversión inicial por sobre el costo total de la vida útil de la unidad.

\section{Tabla 12 - Venta de Camiones nUevos en Argentina}

\begin{tabular}{|c|c|c|}
\hline Año & Ventas & $\begin{array}{c}\text { Variación } \\
\text { interanual }\end{array}$ \\
\hline 2006 & 19790 & - \\
\hline 2007 & 22968 & $16,06 \%$ \\
\hline 2008 & 22888 & $-0,35 \%$ \\
\hline 2009 & 13514 & $-40,96 \%$ \\
\hline 2010 & 18761 & $38,83 \%$ \\
\hline 2011 & 26225 & $39,78 \%$ \\
\hline 2012 & 23038 & $-12,15 \%$ \\
\hline 2013 & 26209 & $13,76 \%$ \\
\hline 2014 & 20479 & $-21,86 \%$ \\
\hline 2015 & 19550 & $-4,54 \%$ \\
\hline 2016 & 17173 & $-12,16 \%$ \\
\hline 2017 & 25794 & $50,20 \%$ \\
\hline
\end{tabular}


Las variaciones interanuales son muy disímiles, desde $-40,96 \%$ en 2009 hasta $+50,20 \%$ en 2017. La decisión de compra está influida por el ambiente político del país, el valor del dólar, las tasas de interés y los ciclos de expansión-detracción del comercio en general.

En Brasil ha habido considerables debates sobre las flotas del TAC ante la fuerte crisis experimentada en 2017. La recesión de los últimos años ha reducido la cantidad de operadores registrados. Ello no significa que se haya reducido la flota, que incluye vehículos de transporte propio y de usos especiales ${ }^{20}$. El tema ha sido objeto de polémica, ya que se habló de que el crecimiento del $288 \%$ de la flota de camiones fue una de las causas de los problemas de los transportistas autónomos, como consecuencia de los incentivos dados por el BNDES entre 2009 y 2016, lo que llevó al aumento de la oferta de transporte $y$, consecuentemente, el deterioro del valor del flete y las molestias de la categoría. Sin embargo, las dificultades de los autónomos con respecto al flete no son recientes: hubo huelgas por la misma causa desde 1959, por ejemplo en 1972, 1979, 1985,1999 y 2015 . Además, en la compra de los camiones no intervinieron solamente los autónomos, sino también los grandes transportistas y las empresas que realizan transporte por su cuenta, que representan el $40 \%$ de la flota total. Todas estas tienen mejor promedio de edad de sus camiones ( 10 años, contra 20 años de los de autónomos), por lo que se deduce que las grandes empresas transportistas y quienes hacen transporte propio son quienes han comprado más camiones.

Como consecuencia de la crisis económica iniciada en 2014, la oferta de transporte viene disminuyendo desde 2015, como muestran los números de RNTRC (Registro Nacional de Transportadores de Cargas) de la ANTT (Agencia Nacional de Transporte Terrestre). Considerando que la renovación anual del RNTRC es obligatoria para la prestación de servicio de transporte, se puede suponer que 22,85\% de transportadoras cerraron las puertas. En el caso de los autónomos, el abandono es aún mayor, de 47,34\%. Sin embargo, muchos autónomos tuvieron que convertirse en persona jurídica por exigencia de clientes o para ingresar en cooperativas existentes, siendo difícil saber correctamente el número exacto de los que dejaron el sector. La reducción de registros de cooperativas fue de $25 \%$. Como parte de las causas para la reducción de la flota activa, debe recordarse que miles de camiones fueron incautados por los bancos por dificultades de los transportistas en cumplir con sus prestaciones de las financiaciones. Se estima además que hay cerca de 200 mil unidades paradas por falta de mantenimiento debido a la crisis o que fueron "canibalizados", o sea, tuvieron sus piezas retiradas para el mantenimiento de otro vehículo de la misma flota. Se suma a eso, los camiones que fueron accidentados y retirados de circulación.

En Uruguay la tasa de crecimiento de la flota entre 2010 y 2017 fue del $7 \%$ TACC. La variación interanual fluctúa fuertemente, acompañando los ciclos económicos. En ese período hubo años en los que los registros oficiales muestran un incremento de la flota de vehículos a tasas superiores al 10\% (al inicio y al final) y otros con aumentos muchos menores ( $1 \%$ en 2016). Las ventas de vehículos declaradas por los concesionarios son

\footnotetext{
20 A verdade sobre o tamanho da frota e da oferta de transporte. Transporte Mundial, junio de 2018.
} 
sustancialmente mayores, lo que permite estimar las bajas que se producen anualmente junto con la incorporación de nuevos vehículos (Tanco, 2018).

En Perú el crecimiento anual de la flota de camiones entre 2013 y 2017 fue del $7,8 \%$ TACC. (Ministerio de Transporte y Comunicaciones, Boletín Estadístico I Semestre de 2017).

La incorporación de vehículos a las flotas (nuevos o usados) han acompañado el crecimiento de la demanda, con valores que fluctúan entre el $5 \%$ y el $7 \%$ anual, con la excepción de las economías que sufrieron estancamiento o retroceso, como fue el caso de Argentina y Brasil. Así como se incorporan nuevos vehículos en los registros, es de esperar que algunos, particularmente los más antiguos, dejen de operar o sólo lo hagan en forma ocasional, aunque se mantengan registrados.

\subsection{Los mecanismos de apoyo gubernamental y sus resultados}

La estructura del mercado del TAC, caracterizada por la atomización y presencia de numerosos operadores individuales, es un obstáculo para la renovación de la flota. Los transportistas individuales difícilmente pueden acceder a financiamiento, razón por la cual los Estados han impulsado programas de apoyo a la renovación de flotas. Los motivos tradicionales de estos programas han sido la incorporación de unidades más eficientes, más seguras y más limpias. En los últimos años se ha sumado como componente el desguace (chatarrización): los programas de renovación apuntan no sólo a incorporar nuevos vehículos sino también a retirar del mercado a los más antiguos, tanto por razones de seguridad vial como porque son los más contaminantes y de menor eficiencia energética.

México es el caso emblemático en la región con un programa de renovación implementado hace 15 años, con diversas variantes, que se expone a continuación. ${ }^{21} \mathrm{~A}$ finales del año 2003 el Gobierno Federal de México impulsó un novedoso programa para motivar la renovación del parque vehicular del país. La premisa era que la renovación vehicular aumentaría la competitividad, empleando unidades que cumplan las normativas de seguridad, calidad y confort, además de cumplir con los alineamientos en materia de reducción contaminante al medio ambiente. El Programa consistió en la aplicación de un estímulo fiscal para la adquisición de un vehículo nuevo, siempre y cuando éste sustituya a un vehículo obsoleto en operación. En 2004, Nacional Financiera (NAFIN) creó el Programa de Financiamiento para la Renovación de la Flota Vehicular del Autotransporte Federal para modernizar el parque vehicular del autotransporte federal (de carga, pasajeros y turismo) a través de financiamiento, chatarrización y registro (denominado emplacamiento) realizado en forma expedita.

Pese a que el objetivo del Programa era impulsar la renovación del parque vehicular del autotransporte federal de carga, en especial las unidades de los operadores individuales (hombre-camión) y pequeños transportistas, el acceso al beneficio fiscal para ese segmento fue limitado. Los principales obstáculos encontrados fueron los siguientes:

\footnotetext{
${ }^{21}$ La descripción de este Programa se basa en Robles Linares, 2018.
} 
- Los operadores individuales no eran sujetos de crédito para los distribuidores vehiculares, dado que no podían comprobar sus ingresos de manera formal.

- El monto del estímulo fiscal solo podía cubrir una parte del valor del vehículo nuevo, generalmente el pago inicial (5-30\% del valor del vehículo nuevo).

- Las tasas de interés para la adquisición del vehículo nuevo eran demasiado altas para ser absorbidas por los operadores individuales.

Para romper la barrera de acceso al crédito de los pequeños operadores, la Secretaría de Comunicaciones y Transporte desarrolló mecanismos de otorgamiento de permisos y garantías que permitieron imponer a los intermediarios financieros una serie de reglas en beneficio de los pequeños operadores. Principalmente la reducción de las tasas y la cesión de la placa como garantía (el distribuidor es propietario de las placas por la duración del crédito). Mediante la ejecución de los nuevos mecanismos financieros en el período 2010-2011, se pudo observar un repunte en el número de vehículos destruidos bajo el Programa de Renovación Vehicular. De 2004 a 2011 se inscribieron al Programa 24.746 vehículos, de los cuales $21.214(85,7 \%)$ cumplieron con los requisitos y fueron destruidos aplicándose su estímulo fiscal.

En el año 2015 se promulgó una nueva norma, con estímulos para destruir hasta 6.000 vehículos por año en 2016 y 2017, apuntando a que la mitad al menos pertenecieran a operadores individuales (personas físicas dedicadas al TAC). El mecanismo confiere una activa participación al vendedor del vehículo nuevo (la armadora-distribuidora): debe verificar las características del vehículo a desguazar, confirmar el estímulo fiscal correspondiente, verificar la documentación del transportista, solicitar la destrucción del vehículo antiguo, estar presente en su destrucción en un centro de destrucción autorizado, y tramitar la baja de ese vehículo y el alta del nuevo. El cumplimiento de estas tareas le permite acceder al estímulo fiscal, que alcanza hasta aproximadamente US\$15.000 para un tractocamión pesado. Comparando el volumen de las ventas anuales de vehículos de TAC respecto a número de vehículos destruidos mediante el Programa de Renovación Vehicular, se observa que la proporción ha oscilado entre un $6,3 \%$ y un $18,2 \%$. No obstante, se debe considerar que el Programa permitía la adquisición de vehículos seminuevos de hasta 5 años de antigüedad, así como la destrucción de 2 vehículos por la adquisición de 1 nuevo (lo que puede variar estos porcentajes en un cálculo más detallado). 


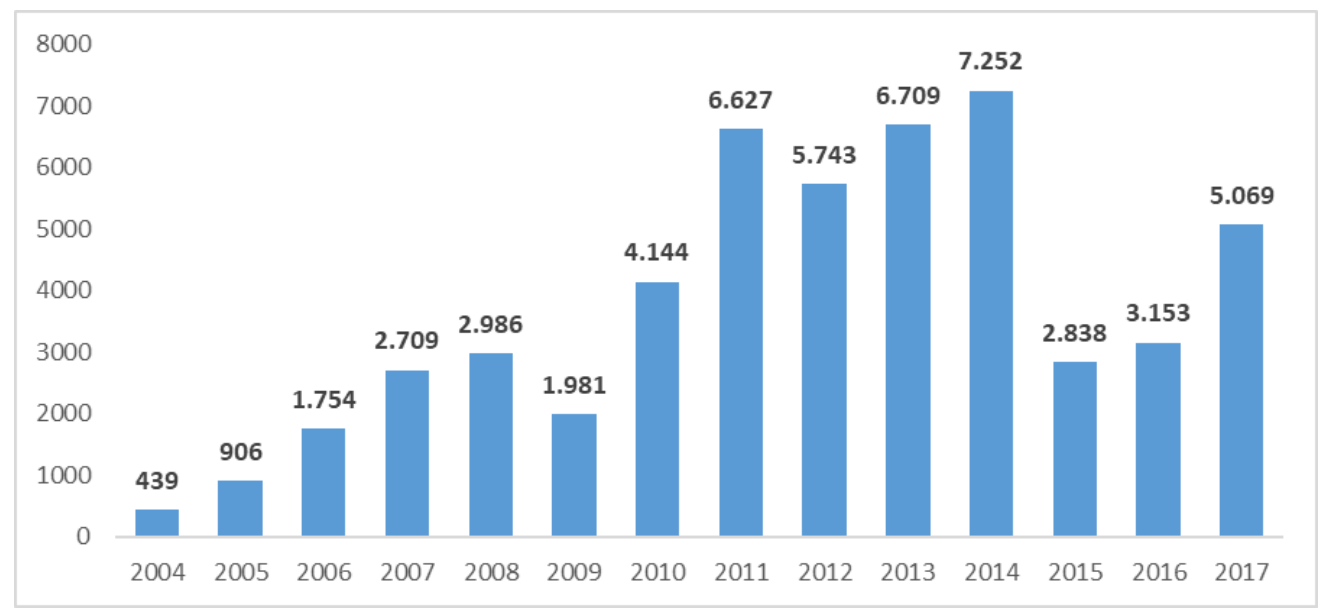

Fuente: Robles Linares, 2018

La operativa de este programa incluye: (i) al transportista, que elige la nueva unidad a adquirir y la vieja a desguazar; (ii) una entidad pública (la SCT) que evalúa y aprueba la operación; (iii) el fabricante, ensamblador o distribuidor de vehículos, que gestiona la destrucción del vehículo viejo en un centro autorizado, y (iv) el centro de destrucción, que desguaza las unidades. Los pasos sucesivos para realizar estas operaciones han sido cuidadosamente elaborados (Robles Linares, 2018).

Chile: Entre 2009 y 2013 se desarrolló el Programa "Cambia tu Camión", destinado a financiar y subsidiar la modernización del parque camionero de los micro y pequeños empresarios del país, buscando que renovaran su antiguo vehículo de carga por uno nuevo, más eficiente en el uso de energía y más amigable con el ambiente. La iniciativa, consistió en la entrega de un aporte en dinero para la renovación de camiones de más de 10 toneladas y más de 25 años de antigüedad, como parte del Programa País Eficiencia Energética de la Comisión Nacional de Energía (CNE).

En Argentina en los últimos años hubo diversos programas:

- Plan REFLOTA, creado en 2012 y desactivado en 2016, para ampliación y renovación de la flota del transporte de cargas por carretera, bonificaba en 4 puntos la tasa vigente para las líneas de crédito del Banco de la Nación Argentina. A fin de 2016 y después de 53 meses permitió la adquisición de: 7.411 camiones nuevos) ( $2,6 \%$ del parque total); 3.204 semirremolques y acoplados (1,6\% del parque total); y 248 camiones usados. Puede observarse que el Plan no produjo grandes efectos en la renovación, en parte porque los transportistas más chicos, que podrían haberlo usado, no poseen la "cartera de crédito" suficiente que exigen los bancos. Por otra parte, como se explicó más arriba, fueron adquiridas unidades de menor potencia y tecnología, de menor duración, ya que los compradores priorizaron la baja inversión inicial por sobre el costo total de la vida útil de la unidad 
- Líneas financieras del Banco de Inversión y Comercio Exterior (BICE), lanzadas a fines de 2018, incluyen: Acoplados, Semirremolques y Bitrenes de determinadas marcas adheridas, con garantía prendaria. Por su lanzamiento reciente, no se pueden establecer resultados.

- Resolución 519/2018 de la Secretaría de Emprendedores y de la Pequeña y Mediana Empresa del Ministerio de Producción (SEPyME) incluyó al "Servicio de Transporte y Almacenamiento" como "industria", lo cual permite a las empresas adoptar importantes beneficios impositivos, entre ellos computar 10\% de las inversiones como pago a cuenta del impuesto a las Ganancias y acceder a préstamos el BICE. La resolución es casi desconocida por los transportistas, ya que el Gobierno no ha hecho una difusión adecuada.

- Sistema de financiamiento con chatarrización: es un proyecto de la Dirección de Transporte de Carga del Ministerio de Transporte, e implica que quien compra camión $0 \mathrm{~km}$, si aporta otro a chatarrizar, obtiene una serie de beneficios inmediatos (públicos y privados) y en el tiempo, cuyo valor actual es superior a lo que pagó por el camión que va a desguace. El sistema tiene asuntos por resolver: ambientales relacionados con la destrucción de la unidad, y el financiamiento de las soluciones a los mismos; certeza de que la unidad será destruida y que no ingresará en un mercado negro; y el principal problema: que no hay fondos en el estado para desarrollar el esquema.

Colombia tiene una larga historia con programas de chatarrización, iniciados en 2005. El programa ha sufrido diversas modificaciones $y$, si bien ha logrado eliminar unidades viejas del mercado, no lo ha sido con el éxito que las sucesivas autoridades esperaban, especialmente por causa abusos y corrupción por parte de diversas autoridades de aplicación, y también porque no se ha establecido una edad máxima para que sea posible la operación de los camiones, lo que ha convertido la chatarrización en una opción voluntaria. El sistema de chatarrización se ha basado, además, en que no puede incorporarse un camión nuevo si no se desguaza uno viejo (llamado "sistema uno a uno"), lo cual ha disgustado no solo a transportistas que no pudieron ampliar sus flotas, sino a los proveedores de camiones (todos de Estados Unidos), quienes acusan una violación al libre comercio.

A la fecha de este informe se está revisando una vez más el sistema, que buscará eliminar el sistema "uno a uno". En el nuevo sistema los propietarios de vehículos podrán entregar su camión y financiar la compra de un modelo nuevo con el apoyo de una línea de crédito que está reestructurando Bancoldex, con el apoyo del Ministerio de Transporte, para ampliar los recursos disponibles y mejorar las condiciones ofrecidas, y el I Fondo Nacional de Garantías del Ministerio de Comercio trabaja en diseñar un producto de garantía a la medida dirigido al sector, que respalde estos créditos. Estas ayudas se alinearán con incentivos tributarios (exenciones) a la transición energética para quienes adquieran vehículos con nuevas tecnologías en materia de sostenibilidad ambiental.

Como conclusión, puede apreciarse que: 
- La adquisición de unidades nuevas para la renovación/ampliación de flota es más accesible a las empresas de mayor porte, especialmente porque están más organizadas y son más eficientes en los aspectos económico-financieros, y porque los pequeños transportistas no tienen acceso a las líneas de financiamiento ya que no son sujetos de crédito según los parámetros habituales del negocio bancario. $Y$ adicionalmente porque los más pequeños suelen estar obligados a manejar sus finanzas con criterio de flujo de caja que les impide generar reservas para realizar inversiones.

- Las dificultades para acceder a los créditos bancarios son menores para las empresas no transportistas, capaces de tener carpetas crediticias basadas en su actividad principal, lo que hace posible que renueven con más frecuencia sus unidades.

- Los Estados se encuentran ante la situación de que la obligación de destruir unidades más antiguas puede generar problemas sociales causados por la eliminación de la fuente de trabajo de los sectores del TAC más vulnerables. Sin embargo, los sistemas de desguace (chatarrización) son pasibles corrupción en distintas instancias, ya sea en las de aprobación de los canjes como especialmente en la real y verificable destrucción del vehículo a desguazar, ya que existe el riesgo de que se lo reacondicione para volver a introducirlo en el mercado, así como que se lo canibalice para vender las partes. Otro tema no menor es el tratamiento y disposición final de elementos contaminantes de los vehículos: combustible remanente, lubricantes, líquido de frenos, ácido de las baterías, plásticos, etc.

Por último, se observa una tendencia hacia la incorporación de tractocamiones con semirremolques, relegando a los camiones rígidos con remolques, ya que los primeros son más eficientes y adaptables a las necesidades de las modernas cadenas de abastecimiento. 


\section{UNA MIRADA AL TAC EN DISTINTAS SUBREGIONES}

Como lo sugieren los capítulos anteriores, el comportamiento del transporte automotor de cargas presenta características diferentes en las distintas subregiones que conforman América Latina. Siguiendo la clasificación adoptada en estudios anteriores (Barbero \& Guerrero, 2017), se reconocen cuatro en las que el TAC presenta una cierta homogeneidad: Centroamérica, los países Andinos, el Cono Sur y México ${ }^{22}$. A continuación se presenta una caracterización del TAC en cada una de ellas, y un análisis comparativo de sus comportamientos. ${ }^{23}$

\subsection{Centroamérica}

El TAC es el modo de transporte terrestre clave para los países de América Central (incluyendo a estos efectos a Guatemala, Honduras, El Salvador, Nicaragua, Costa Rica y Panamá ${ }^{4}$ ); el rol del ferrocarril para el transporte de cargas es muy reducido, al igual que el del cabotaje marítimo. La dimensión de los países y su integración económica hacen que el TAC no solo sea relevante en el cabotaje de cada país, sino también en el comercio de los países entre sí y con México. ${ }^{25}$

En Centroamérica la Secretaría de Integración Económica Centroamericana (SIECA) tiene bajo su mandato el funcionamiento del Consejo Sectorial de Ministros de Transporte de Centroamérica, (COMITRAN), integrado por los Ministros de Infraestructura de cada país miembro, con la responsabilidad de coordinar y armonizar las acciones en materia de transporte, movilidad y logística. El Directorio del COMITRAN está integrado por los países de Costa Rica, El Salvador, Guatemala, Honduras, Nicaragua y Panamá. COMITRAN ha priorizado la gestión integral de los activos viales en una agenda de planificación de alcance regional. EI TAC tienen una Importancia superlativa en el transporte internacional, como lo destacan recientes informes de SIECA:

\footnotetext{
22 El análisis no incluye el TAC en Guyana y Surinam, ya que es muy escasa la información disponible.

23 Esta sección se apoya en los estudios elaborados por Ma. Florencia Millán (Millán, 2018)

${ }^{24} \mathrm{Si}$ bien en Panamá existe un importante ferrocarril que une ambos océanos, está destinado a tránsitos internacionales entre Panamá y Colón de cargas que no hacen el viaje por el Canal, por lo que no incide en la logística local.

${ }^{25}$ No se incluye Belice por falta de información
} 
"El flujo de mercancías registradas a través de las operaciones de tránsito terrestre al interior de la región centroamericana representó un monto de US\$14.627 millones en valor $F O B$ en 2017 , con un crecimiento del $9.3 \%$ respecto al año anterior. En cuanto al número de operaciones de tránsito terrestre de mercancías medidas a través de la Declaración Única de Tránsito (DUT) en 2017, estas ascendieron a 387.309 operaciones finalizadas en total. Tomando de referencia el país de inicio del tránsito el mayor número provienen de El Salvador con 140.717 operaciones, mientras que los principales países de destino han sido Nicaragua con 107.393 y Costa Rica con 78.560"

SIECA (2018) La Facilitación del Comercio en Centroamérica: acciones y estrategias después de Bali.

El Gráfico 7 resume los movimientos de carga por camión en la región; en él puede apreciarse la importancia de los tráficos entre países en relación con los movimientos internos.

Gráfico 7 - Tránsito terrestre en Centroamérica según origen y destino En número de operaciones; año 2017

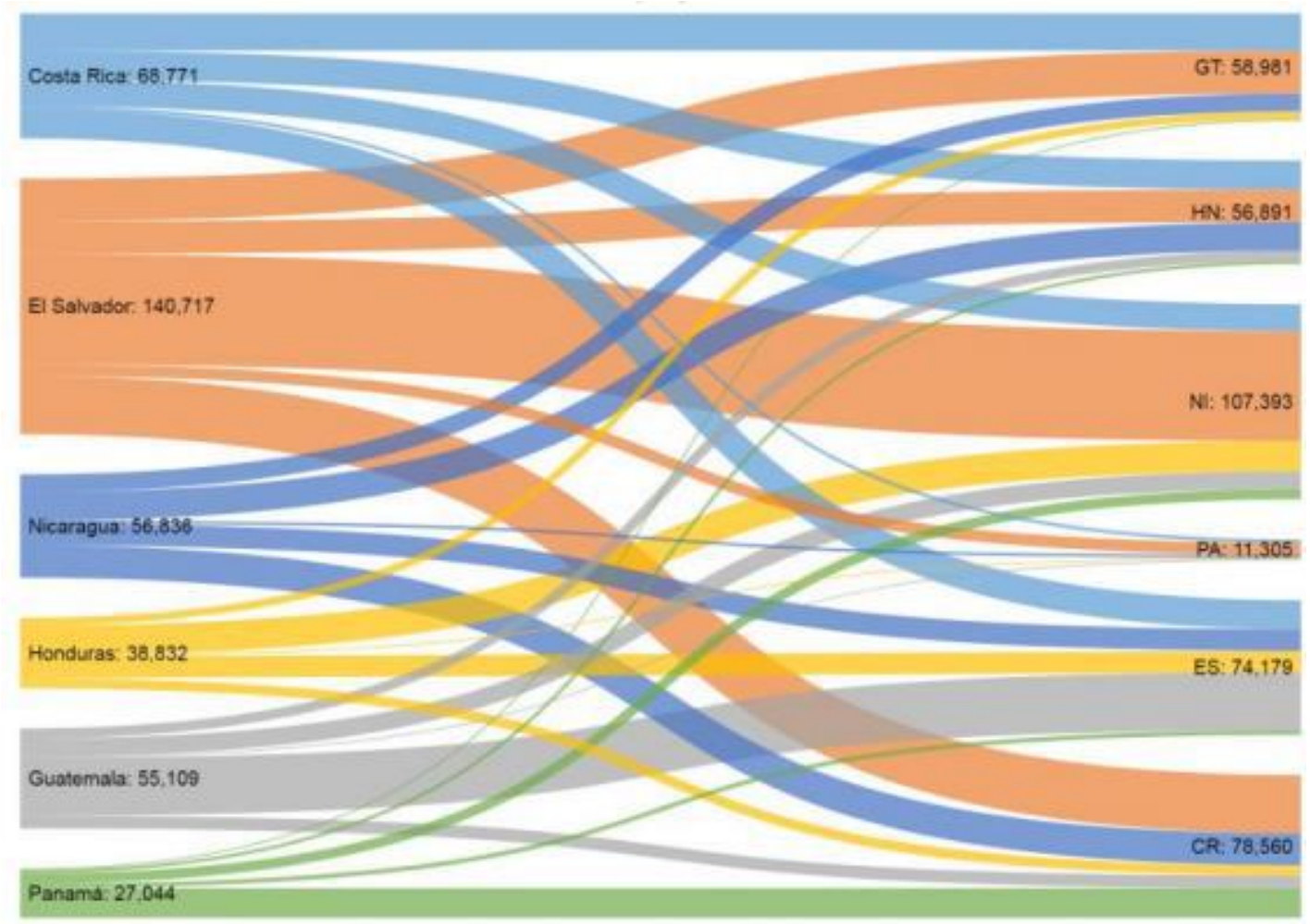

Fuente: SIECA

En el año 2012, el Banco Mundial realizó un diagnóstico de la situación del transporte terrestre mediante encuestas a transportistas, identificando una serie de dificultades en los servicios de transporte de carga: 
- Falta de acceso a crédito de las empresas transportistas, que repercute en unidades antiguas con alto costo operativo y emisiones.

- Viajes de retorno vacíos entre el $34 \%$ y el $78 \%$.

- Altos costos en seguridad de cargas ( $3 \%$ al $4 \%$ de los costos totales).

- Alto costo del combustible (40\% al $60 \%$ ) del total de costos.

- Demoras en los tiempos de viaje y esperas en controles y cruces de frontera.

En esta última dimensión la región centroamericana se encuentra en el proceso de implementación de la Declaración Única Centroamericana (DUCA) lo que significa un avance en el propósito de estandarización de requisitos y documentación vinculada con el comercio internacional. De manera general, los avances a nivel centroamericano en las medidas de corto plazo de gestión coordinada a partir de SIECA se resumen a continuación:

i. Declaración anticipada de mercancías: pendiente la implementación en 4 países de la región (Guatemala, El Salvador, Honduras y Panamá), en el caso de Nicaragua se encuentra aplicando la medida desde el 22 de junio de 2017 y Costa Rica aplica la resolución sólo para exportaciones.

ii. Coordinación para agilizar medidas migratorias: se ha aprobado la guía técnica para la agilización y coordinación de controles migratorios y el procedimiento migratorio centroamericano para el pre-chequeo de los conductores de transporte terrestre de carga. En los casos de Costa Rica, Panamá y Nicaragua aún se necesitan hacer desarrollos informáticos para la interconexión con el nodo central de la SIECA.

iii. Transmisión electrónica de certificados sanitarios y fitosanitarios: se encuentra aprobado el set de datos electrónico de la información contenida en los certificados sanitarios y fitosanitarios y la propuesta de instructivo de llenado del set de datos de la información contenida en los certificados sanitarios y fitosanitarios, lo cual será implementado una vez los países de la región tengan preparados y operando sus desarrollos informáticos. El siguiente paso será el intercambio electrónico de los certificados sanitarios y fitosanitarios. En ambos casos se emitirían disposiciones normativas regionales para su aplicación.

iv. Registro por medio de dispositivos de radiofrecuencia (RFID): La instalación de los dispositivos ha iniciado en algunos de los países de la región y tienen diferentes niveles de avances.

v. Utilización de Cámaras en pasos de frontera: existen diferentes niveles de avances en la instalación de cámaras, mayormente en el triángulo Norte, es decir Guatemala, Honduras y El Salvador.

Trabajos posteriores, basados en encuestas con operadores locales realizadas para el Banco Interamericano de Desarrollo en 2016, muestran las siguientes características del TAC en la sub-región:

- Eficiencia operativa: media a baja, con distancias anuales recorridas de entre 40.000 y 60.000 kilómetros. 
- Transporte internacional: desarrollado, con algunas trabas normativas y en pasos de frontera. Justamente aquí es el punto de mejora en la región con los planes de facilitación comercial, las aduanas con controles yuxtapuestos, que reducirán los tiempos de tránsito considerablemente. El transporte internacional es muy relevante en comparación con el desarrollo del TAC en el ámbito nacional.

- Organización empresarial: pocas empresas grandes, y predominancia de pequeños operadores (atl como ocurre en el resto de la región y en el mundo).

- Características de la flota: alta edad promedio (superior a los 20 años en algunos casos).

- Dificultades severas para la renovación de las unidades, con incorporación muy frecuente de vehículos usados.

De acuerdo con SIECA, para mediano y largo plazo hay tres ejes transversales de trabajo en la integración regional:

i. Plataforma Digital de Comercio Centroamericana (PDCC): SIECA con el apoyo técnico del BID, está trabajando para la implementación de la PDCC que está divida en tres fases: plataforma de interoperabilidad, mediador digital de servicios y gestor digital de servicios. El período de implementación es de 20182021.

ii. Tipificación e implementación por pares de países y pares de fronteras: consiste en tipificar cada uno de los pasos fronterizos de la región a partir de sus características funcionales, geográficas, de demanda de servicios, entre otros. Una vez tipificados, las propuestas de reforma de cada paso se desarrollarán a nivel binacional, por pares de fronteras.

iii. Fortalecimiento de Comités Nacionales de Facilitación del Comercio: planteados por el Acuerdo de Facilitación Comercial de la OMC, actualmente se trabaja en el seguimiento a través del Grupo Técnico de Facilitación del Comercio y las participaciones de los Comités Nacionales de Facilitación del Comercio

En síntesis, en Centroamérica las características sobresalientes del TAC están relacionadas a la fuerte incidencia del comercio regional y la relevancia de la facilitación comercial en cuanto a procesos e infraestructura en los cruces fronterizos. En este sentido los esfuerzos locales junto a los organismos multilaterales están logrando disminuir los tiempos de tránsito y la burocracia en los cruces de frontera ${ }^{26}$. Respecto a las cargas domésticas las dificultades que sobresalen en la región es la heterogeneidad, con muchos prestadores individuales, y algunas empresas grandes más eficientes; parámetros operativos con tiempos de viaje, retornos en vacío y kilómetros recorridos por año poco eficientes; dificultades para modernizar la flota, con cultura de utilización e importación de vehículos usados y sobrecostos por problemas de inseguridad en las rutas. La inversión en infraestructura para esta subregión fue inferior al $2 \%$ del PIB de los países, con Panamá, Nicaragua y Honduras con mejor desempeño, acercándose al 1,8\% de PIB 27.

\footnotetext{
26 EI BID está trabajando en los pasos fronterizos de Nicaragua, en un Sistema integrado de inspección, que reducirá los tiempos de trámites de 140 minutos a 30 minutos logrando la coordinación de 10 agencias. El primer puesto fronterizo en modernización es Peña Blanca.

27 Datos de Infralatam 2013.
} 
Se destaca el rol preponderante de la logística en Panamá: dada la importancia que el país tiene en el comercio internacional, el sector transporte representó el 12,6\% de su PIB. Panamá cuenta con prestadores logísticos de estándares internacionales, complementados con zonas económicas especiales, como la zona de libre comercio donde se ejecutan tareas logísticas de acopio y distribución de las mercaderías y las once zonas francas activas. La presencia del Canal de Panamá ha convertido a este país es poseedor de una plataforma logística integrada tanto por infraestructura como por servicios que permiten el desarrollo del comercio regional e internacional. Dentro de la infraestructura se encuentran los activos: puertos, aeropuertos, zonas económicas especiales, terminales, fronteras y los conectores (trenes, autopistas, carreteras) que conforman la red logística. El ferrocarril une la terminal pacífica de Panamá con la terminal atlántica de Colón. Tiene un movimiento anual de 800 mil contenedores ${ }^{28}$. En los servicios se encuentran las diferentes actividades prestadas por entidades públicas y privadas que permiten el movimiento efectivo de personas y mercancías a lo largo de la cadena de suministros. Éstos incluyen el manejo de mercancía, consolidación, servicios de brokerage, transporte ${ }^{29}$.

En cuanto a seguridad vial, la región de Centroamérica se encuentra por debajo de los estándares de mejores prácticas, en términos de cumplimiento de las leyes sobre conducción libre de alcohol, límites de velocidad, y algo mejor en cuanto al uso de cinturón de seguridad, comparado con otras regiones del mundo ${ }^{30}$. El anuario de transporte de Costa Rica arroja que el número de accidentes viales se incrementa año a año.

\subsection{Los Países Andinos}

En esta subregión, integrada por Perú, Bolivia, Ecuador, Colombia y Venezuela, se aprecia el mayor esfuerzo en inversión en carreteras, superando el $2 \%$ del PIB y con picos de hasta más de 5\%. En Bolivia la inversión en carreteras como porcentaje del PIB creció desde una base de 2,5\% en 2008 aproximadamente a casi el $6 \%$ en 2015 . En el caso de Colombia, se da una situación similar, donde en 2008 la inversión total en carreteras representó el 1,38\% del PIB y para 2015 llegó al 5,74\%. Lamentablemente no hay datos para Venezuela.

Las tendencias de atomización del sector transporte de cargas, con flotas más antiguas en las empresas de flotas más chicas, se repite en estos países. Sin embargo, ha habido esfuerzos de modernización, acentuándose la heterogeneidad de los prestadores del TAC.

Las características sobresalientes son:

- Eficiencia operativa: media, de aproximadamente 60.000 kilómetros anuales recorridos por camión.

\footnotetext{
28 Georgia Tech Panama. https://logistics.gatech.pa/es/assets/railroad/panama-canal-railway

29 Georgia Tech Panama. https://logistics.gatech.pa/es/platform

30 Datos del reporte de World Health Organization, Global Status Report on Road Safety, 2018.
} 
- Organización empresarial: pocas empresas grandes, aunque en crecimiento. Fuerte peso de los pequeños operadores, con sectores atrasados.

- Características de la flota: edad promedio elevada, aunque se verifica un proceso de renovación en marcha.

- Avances importantes en logística con ejemplos de desarrollo de centros logísticos en Colombia y Perú. En Colombia se ha hecho énfasis desde el gobierno y las políticas públicas en la operación combinada de los modos de transporte y la interconexión eficiente entre ellos. Además de esta situación se han hecho estudios de pre-inversión para plataformas logísticas en puntos geográficos claves de las cadenas de suministro locales y de importación y exportación. Un ejemplo de ello es la Plataforma del Eje Carretero, en fase pre-inversión, y la Plataforma Logística de Occidente, próxima a la terminal de carga del aeropuerto El Dorado, y la vía férrea que conecta con la costa Norte ${ }^{31}$. En Barranquilla se encuentra el Parque Logístico California, ya operativo. ${ }^{32}$

- En Perú en las inmediaciones de Lima, y del puerto de Callao se ubican diversos centros logísticos que brindan servicios de operación logística a diversos sectores productivos y comercio exterior.

- Centros urbanos crecientes, con demanda de servicios de logística urbana.

- Avances en infraestructura vial, la cual tenía un déficit notorio respecto del resto de la región.

- Poco avance en integración regional dado que el transporte internacional sufre restricciones a la circulación en tránsito con práctica del transbordo en frontera.

- Respecto a la siniestralidad, esta región tiene calificaciones aún peores que la región de Centro América con respecto a leyes de conducción libre de alcohol, límites de velocidad, uso de cinturón de seguridad. Ecuador es el país mejor calificado de esta subregión ${ }^{33}$. El anuario de transporte de Colombia corrobora un incremento sostenido en el número de accidentes y muertes viales, desde 2002 al presente ${ }^{34}$. Lo mismo ocurre con el número de accidentes en Ecuador, que se incrementaron en un $80 \%$ entre 2008 y $2015^{35}$.

En síntesis, esta región presenta avances en inversión en infraestructura vial, así como también en prestación de servicios logísticos en Colombia y Perú. Las desventajas radican en la menor integración regional, con trabas aún en los pasos fronterizos, así como un reducido grado de modernización empresarial en los prestadores del TAC.

\footnotetext{
31 https://www.caf.com/es/conocimiento/blog/2018/09/centros-logisticos-eficientes-para-una-colombiamas-competitiva/

32 https://revistadelogistica.com/logistica/la-puerta-de-oro-de-colombia-ya-cuenta-con-un-parquelogistico-de-talla-internacional/

33 Datos del reporte de World Health Organization, Global Status Report on Road Safety, 2018.

${ }^{34}$ Ministerio de Transporte, Estadísticas 2017, Colombia.

35 Instituo Nacional de Estadísticas y Censos INEC, Ecuador, gráficos 2015.
} 


\subsection{El Cono Sur}

Esta subregión incluye a Brasil, Paraguay, Argentina, Uruguay y Chile. EI TAC tiene un rol central en el transporte doméstico en cada uno de estos países, incluyendo los desafíos de la logística urbana en sus grandes áreas metropolitanas. El transporte internacional por camión ha tenido también un considerable desarrollo.

La inversión en carreteras en los países del cono sur ha sido moderada. Solo Paraguay ha superado el $2 \%$ del PIB en inversión total, pública y privada en carreteras. Para el caso de Brasil en los nueve años que van desde 2008 a 2016, la inversión ha sido inferior al $0,8 \%$ del PIB, con los dos últimos años muy malos. Para Argentina en 2008 la inversión total en carreteras fue del $0,9 \%$ del PIB y en 2011 del $0,4 \%$ del PIB; aun con estos bajos valores, la inversión vial representó más de $2 / 3$ de las inversiones en infraestructuras en el país en los últimos dieciocho años, pero con resultados cuestionables, especialmente entre 2003 y 2015, ya que, aunque el gasto vial se incrementó notablemente, tuvo su contrapartida en un acotado número de obras importantes y en una dudosa eficiencia social en la asignación de los recursos.

Se repiten las tendencias generales encontradas en las otras subregiones: atomización del sector, empresas más grandes con flotas más nuevas, en muchos casos expandiéndose hacia actividades logísticas, transporte propio de gran magnitud, y sectores de pequeñas empresas unipersonales donde la informalidad y la antigüedad de la flota son superiores.

- Eficiencia operativa: media a alta, con distancias medias anuales superiores a los 80.000 kilómetros (con algunos países por debajo). En particular Chile para 2017 según encuestas, superó los 120.000 kilómetros al año. Los vehículos de distribución urbana recorrieron en promedio entre 22.000 y $28.000 \mathrm{~km} /$ año. Brasil tuvo una distancia media promedio por camión superior a $145.000 \mathrm{~km} /$ año. En el caso de Argentina, los camiones pesados de carga hacen entre 120.000 y $145.000 \mathrm{~km} /$ año. Los vehículos de logística urbana recorren entre 15.000 y 18.000 km/año.

- Transporte internacional: desarrollado, con altos niveles de eficiencia, aunque en esta subregión no alcanza la importancia relativa que tiene en Centro América o México, debido al fuerte peso del transporte doméstico (interurbano y urbano).

- Limitaciones físicas y especialmente administrativas en los pasos de frontera.

- Organización empresarial: empresas de alta eficiencia y numerosos pequeños operadores; especialización creciente.

- Características de la flota: conviven segmentos muy modernos y numerosos camiones antiguos.

- Dificultades financieras y económicas para renovar la flota en el caso de los pequeños transportistas.

En el caso del transporte internacional, la región formada por Argentina, Bolivia, Brasil, Chile, Paraguay, Perú y Uruguay cuenta con el Acuerdo sobre Transporte Internacional Terrestre, ATIT, inscripto dentro del Tratado de Montevideo de 1980 de la ALADI. El mismo determina características técnicas y administrativas para hacer compatibles los tránsitos internacionales de camiones, choferes y cargas, aunque no resuelve las cuestiones 
aduaneras, que no son de su competencia. Un subgrupo de esos países (Argentina, Bolivia, Brasil, Paraguay) tienen además otras regulaciones que se resuelven en el llamado Sub Grupo 5 del Mercosur. Para atravesar las aduanas se utiliza el Manifiesto Terrestre Electrónico (MIC/DTA), que permite la presentación de los manifiestos tanto en el ingreso como en la salida. Actualmente se encuentra en consideración la implementación de otro sistema, el TIR (Transporte International Routier), ya impuesto en países europeos y asiáticos, basado en la filosofía de "operador seguro", por lo cual el vehículo permanece cerrado durante su camino desde el origen al destino, sin intervención aduanal intermedia. El sistema requiere de aprobación parlamentaria de los países adheridos. Actualmente Argentina es el único país que lo ha aprobado, en tanto que en Chile y Brasil está en estudio.

Un evento para destacar es el paro realizado por camioneros autónomos en Brasil en mayo de 2018, motivado por el pago del peaje por eje suspendido, el pago de peaje para financiamiento de programas sociales, y especialmente por el incremento del precio del diésel, que se había duplicado en los últimos dos años, desde una tarifa subsidiada muy inferior a los precios internacionales. Los cortes de carreteras en 24 Estados Federales ocasionaron faltante de alimentos, medicamentos y combustibles, y fue necesaria la asistencia de las fuerzas armadas para desbloquear las carreteras y llevar alivio a varias ciudades que se encontraban en emergencia por desabastecimiento y actividades diversas canceladas, incluyendo vuelos por falta de combustible. Las estimaciones de la Facultad de Ingeniería en Alimentos de la Universidad de Sao Pablo calcularon que el disturbio tuvo un costo fiscal de US $\$ 2,25$ miles de millones, y un costo por pérdidas de la producción US $\$ 8,3$ miles de millones billones. La posición inflexible de los transportistas autónomos obligó al gobierno a establecer la "Política Nacional de Pisos Mínimos del Transporte Rodoviario de Cargas 36", por la cual se fijan tarifas mínimas deben ajustarse periódicamente, y especialmente cuando el costo del combustible varíe más del 10\%37. Si bien el precio del diésel aumentando casi diariamente puede haber sido el disparador, la realidad indica que la recesión de Brasil generó una caída en la demanda de transporte y salida del mercado de camioneros autónomos ${ }^{38}$. Es decir, el paro ocurrió en un escenario de contracción de demanda con subida de costos para el sector. Sus efectos sobre la industria, el comercio y la sociedad pusieron en evidencia la trascendencia del TAC, y la nueva política de regulación tarifaria pone en evidencia la desprotección económica de la multitud de pequeños transportistas que trabajan a valores de subsistencia.

Si bien en el Cono Sur las inversiones en infraestructura han sido relativamente bajas (especialmente en Brasil y Argentina), ha habido avances en la adopción de normas más modernas de orden ambiental y social. Se evidencian notorios avances en la logística, con operadores que brindan servicios de calidad a la producción local y de comercio. En el tema siniestralidad, las calificaciones de los países del Cono Sur serían en promedio levemente superiores a las de Centro América y Países Andinos, en cuanto a conducción libre de alcohol, límites de velocidad y utilización de cinturón de seguridad. De todos modos, el cumplimiento de dichas normas sigue siendo escaso. Brasil entre 2010 y 2016

\footnotetext{
36 Ley $\mathrm{N}^{\circ} 13.703$

37 Ver capítulo 4.2

38 Ver capítulo 5.1
} 
logró reducir la tasa de accidentes viales en un $47 \% 39$. Los países de la región, al tener grandes extensiones como ser mediterráneos, cuentan con serios problemas de conexión entre las zonas productivas (mayormente agrícolas o mineras) con los puertos, la cual es resuelta por el TAC ante la ausencia de buenos sistemas de transporte ferroviario 0 hidroviario. Finalmente, la magnitud de la población urbana de esta subregión determina grandes desafíos en la logística urbana.

\subsection{México}

EI TAC tiene un rol relevante en México; no solo prevalece en la matriz modal de los movimientos domésticos de carga (durante 2017 generó 256 billones de ton-km, moviendo cargas por 546,6 millones de ton), sino que tiene un rol relevante el transporte internacional, particularmente en la frontera norte.

El tamaño de empresas, cantidad y unidades promedio por segmento indica una tendencia a la concentración, con más empresas más grandes y menos hombre camión. El número promedio de unidades de las empresas más grandes en 2017 llegó a 280 unidades, 50 para las empresas medianas y 11 para las pequeñas. La flota tiene una antigüedad promedio de 15 años.

En el desempeño del sector se destacan los siguientes aspectos:

- Eficiencia operativa: media a alta, con distancias anuales recorridas superiores a la media regional, en promedio del orden de los 100.000 kilómetros.

- Transporte internacional: muy desarrollado, de alta eficiencia hacia la frontera norte, con 70 mil vehículos diarios cruzando las fronteras (20 pasos fronterizos). Limitado para ingresar a Centroamérica. Muy relevante para la industria.

- Organización empresarial: empresas de alta eficiencia y numerosos pequeños operadores. Especialización creciente.

- Características de la flota: segmentos muy modernos, y circulación de bitrenes. Proceso de renovación en marcha. Existencia de un mercado de unidades usadas. Crecimiento de los segmentos de mayor porte, como remolques y semirremolques de seis ejes y tracto camiones de dos y tres ejes.

La normativa recientemente promulgada en México evidencia avances en temas ambientales y de seguridad de transporte de las cargas. Se destacan el Programa de Transporte Limpio, las normativas referidas al transporte de sustancias peligrosas (2003); la estrategia de seguridad vial 2011-2020 (2010), que tiene por objetivo reducir en un $50 \%$ las fatalidades.

México es el país con organización empresarial más desarrollada, con transporte internacional de alta eficiencia en la frontera con Estados Unidos, pero limitado para Centroamérica. La inversión respecto del PIB es muy baja en infraestructura, apenas

\footnotetext{
39 Anuario Estadístico de Transportes 2010-2016. Ministerio de Transporte, Puertos y Aviación Civil. Brasil.
} 
alcanza el 0,7\%. Sin embargo, hay buen desarrollo de la logística, aceptable eficiencia operativa del sector TAC y modernización en curso de unidades ${ }^{40}$.

\subsection{Un análisis comparativo de los comportamientos regionales}

En el análisis de las cuatro regiones planteadas (Centroamérica, Países Andinos, Cono Sur y México) aparecen numerosos problemas comunes, y otros diferentes. Entre los aspectos comunes se observa:

- Heterogeneidad, cada vez más marcada entre los pequeños transportistas individuales y las empresas grandes, que se acentúa ante la dificultad de las primeras de incorporar tecnologías más modernas por falta de capital para acceder a ellas.

- Avance hacia actividades de mayor valor agregado por parte de los transportistas de mayor tamaño, incorporando operaciones, depósitos y parques logísticos a su oferta

- Informalidad del empresariado del TAC, relacionada con las economías y dadores de cargas vigentes en el Continente.

- Tendencia a la incorporación de vehículos de mayor capacidad de carga y mayor eficiencia energética.

- Aplicación del TAC a cubrir las deficiencias de otros modos para la conexión entre las cargas y los puertos

- Interés de los estados por incorporar la problemática ambiental al TAC, el cual todavía es incipiente y moderado por parte de los operadores.

- Desregulación del sistema (excepto en Colombia), con algunas incorporaciones regulatorias o semi-regulatorias en los últimos años, especialmente para defender las fuentes de trabajo de los transportistas más pequeños.

- Dificultades para el acceso al crédito. Los transportistas (en especial los más pequeños) se autofinancian, lo cual limita sus posibilidades de incorporar tecnologías.

- Asimetría en los tipos y niveles de servicio de las cargas, lo cual promueve la existencia de muchos viajes vacíos por incompatibilidad entre la carga y la unidad de transporte.

- Escaso compromiso de los dadores de carga para mejorar la eficiencia logística del TAC (ejemplo: demoras en la carga y descarga, embalajes de dimensiones inadecuadas, etc)

En la Tabla 13 se resumen las principales diferencias en el TAC entre las subregiones de América Latina.

40 México mejoró desde la posición 56 a la 51 en la última edición del Índice de Desempeño Logístico (LPI). 
Tabla 13 - Particularidades del tAC en las subregiones de América latina

\begin{tabular}{|c|c|c|c|c|}
\hline & Centroamérica & Países Andinos & Conos Sur & México \\
\hline $\begin{array}{l}\text { Áreas de acción } \\
\text { relevantes }\end{array}$ & $\begin{array}{l}\text { Internacional } \\
\text { Doméstico }\end{array}$ & $\begin{array}{l}\text { Doméstico } \\
\text { Urbano }\end{array}$ & $\begin{array}{l}\text { Doméstico } \\
\text { Urbano } \\
\text { Internacional }\end{array}$ & $\begin{array}{l}\text { Doméstico } \\
\text { Internacional } \\
\text { Urbano }\end{array}$ \\
\hline $\begin{array}{l}\text { Desempeño } \\
\text { operativo medio }\end{array}$ & Débil & Débil & Medio & Medio-Alto \\
\hline $\begin{array}{l}\text { Inversión reciente } \\
\text { en infraestructura } \\
\text { vial }\end{array}$ & $\begin{array}{l}\text { Media } \\
\text { Coordinación } \\
\text { regional }\end{array}$ & $\begin{array}{l}\text { Alta en varios } \\
\text { países }\end{array}$ & $\begin{array}{l}\text { Baja en los países } \\
\text { más grandes }\end{array}$ & Baja \\
\hline Siniestralidad vial & Alta en promedio & Media alta & Media & Media \\
\hline $\begin{array}{l}\text { Facilitación } \\
\text { comercial }\end{array}$ & $\begin{array}{l}\text { Media, } \\
\text { mejorando }\end{array}$ & Muy débil & Media & Sin datos \\
\hline $\begin{array}{l}\text { Apoyo a la } \\
\text { renovación de } \\
\text { flotas }\end{array}$ & Sin datos & $\begin{array}{l}\text { Programas con } \\
\text { muy poco impacto }\end{array}$ & $\begin{array}{l}\text { Programas de } \\
\text { impacto muy } \\
\text { limitado }\end{array}$ & $\begin{array}{l}\text { Programas } \\
\text { medianamente } \\
\text { efectivos }\end{array}$ \\
\hline $\begin{array}{l}\text { Avances en } \\
\text { normas } \\
\text { regulatorias } \\
\text { ambientales }\end{array}$ & Sin datos & En algunos casos & Considerables & Considerables \\
\hline $\begin{array}{l}\text { Avances en } \\
\text { adopción de } \\
\text { normas } \\
\text { ambientales }\end{array}$ & Baja & $\begin{array}{l}\text { Media-baja } \\
\text { (depende del } \\
\text { segmento) }\end{array}$ & $\begin{array}{l}\text { Media (depende } \\
\text { del segmento) }\end{array}$ & $\begin{array}{l}\text { Media-Alta } \\
\text { (depende del } \\
\text { segmento) }\end{array}$ \\
\hline $\begin{array}{l}\text { Apoyo a la } \\
\text { adopción de } \\
\text { nuevas } \\
\text { tecnologías }\end{array}$ & Sin datos & Baja & Baja & Sin datos \\
\hline $\begin{array}{l}\text { Adopción de } \\
\text { nuevas } \\
\text { tecnologías }\end{array}$ & Baja & $\begin{array}{l}\text { Media-baja } \\
\text { (depende del } \\
\text { segmento) }\end{array}$ & $\begin{array}{l}\text { Media (depende } \\
\text { del segmento) }\end{array}$ & $\begin{array}{l}\text { Media-Alta } \\
\text { (depende del } \\
\text { segmento) }\end{array}$ \\
\hline
\end{tabular}




\section{Evaluación de la PROductividad del SECtOR}

\subsection{La brecha: entre países y entre segmentos de actividad}

Los capítulos anteriores, al describir el TAC en América Latina, sugieren que, en su conjunto, el sector presenta un desempeño relativamente débil si se lo compara con el de las economías desarrolladas. Esto parece confirmar que el TAC se modela a imagen de sus dadores de carga y los ambientes socio económicos en los que se desempeña, ya que las economías de América Latina también se presentan más débiles e informales que las desarrolladas. Y también muestran que, en adición a esa "brecha externa", existe una notable "brecha interna": la que separa el desempeño de los distintos segmentos del TAC en cada país. En toda la región aparecen segmentos con baja productividad que contrastan con operadores - generalmente nacionales - que parecen tener un desempeño de clase mundial. Esta brecha es creciente, incentivada por la adopción de nuevas tecnologías, de equipos de mayores dimensiones, de la expansión vertical de las empresas del TAC hacia las actividades logísticas, y de la concentración empresarial que está ocurriendo en todas las cadenas de abastecimiento.

La comparación de indicadores de desempeño de la región con otras regiones y países del mundo muestran un rezago considerable de ALC. Los dos indicadores básicos de productividad son la distancia recorrida por año por los vehículos y los coeficientes de ocupación de las bodegas. Respecto a la distancia recorrida en promedio por las unidades, se han realizado modelos que generan estimaciones por región, considerando la media a lo largo de la vida útil de las unidades (en los primeros años las distancias suelen ser sustancialmente mayores que en los últimos). Los resultados del modelo MoMo, por ejemplo, que cubren diversas regiones del mundo, se resumen en la Tabla 14 para tres categorías de camiones.

\section{TABLA 14 - ESTIMACIÓN DE LAS DISTANCIAS RECORRIDAS POR AÑO POR VEHÍ́CULOS DE} CARGA

En miles de km, año 2015

\begin{tabular}{|l|c|c|c|}
\hline & $\begin{array}{c}\text { Camión } \\
\text { liviano }\end{array}$ & $\begin{array}{c}\text { Camión } \\
\text { mediano }\end{array}$ & $\begin{array}{c}\text { Camión } \\
\text { pesado }\end{array}$ \\
\hline África & 9 & 18 & 29 \\
\hline ASEAN & 11 & 39 & 47 \\
\hline China & 8 & 25 & 36 \\
\hline EU28 & 18 & 51 & 73 \\
\hline India & 9 & 29 & 38 \\
\hline Japón & 9 & 31 & 43 \\
\hline América Latina & 11 & 30 & 51 \\
\hline México & 17 & 50 & 69 \\
\hline Medio Oriente & 15 & 47 & 59 \\
\hline Rusia & 12 & 36 & 50 \\
\hline Estados Unidos & 20 & 63 & 90 \\
\hline Promedio mundial & 13 & 37 & 52 \\
\hline
\end{tabular}


Los resultados muestran que en América Latina los camiones pesados recorren en promedio $51.000 \mathrm{~km}$ anuales (69.000 en México); la misma estimación arroja $90.000 \mathrm{~km}$ por año para Estados Unidos (menos que los 109.000 que estiman las estadísticas nacionales para los camiones pesados - Clase 8 -, diferencia que se explica en gran parte por la consideración de la reducción de actividad de las unidades a lo largo de su ciclo de vida). En los países de la Unión Europea la media es de $73.000 \mathrm{~km}$ año. El promedio mundial para los camiones pesados sería de $52.000 \mathrm{~km}$ (muy similar al de América Latina). Las relaciones son similares en los camiones livianos, y un poco más desfavorable en los medianos. En términos generales, puede concluirse que la distancia recorrida por las unidades del TAC en América Latina equivale al $60 \%$ de la que recorren en las economías más desarrolladas y equivalente al promedio mundial. Un análisis más detallado para ponderar estos resultados debería contemplar la calidad de las carreteras (que incide en la velocidad de circulación), las dimensiones geográficas de los países (que condicionan las distancias de los viajes), la existencia de otros modos en competencia, y los tiempos de espera de carga y descarga, que dependen de la eficiencia logística de las empresas a las que atiende el TAC.

Respecto a la ocupación de los vehículos, uno de los indicadores más representativos es la proporción de viajes vacíos que realizan los camiones, midiendo la proporción de vehículos-km recorridos con y sin carga a lo largo de un año. Las fuentes de información en este caso en ALC se limitan a estimaciones provistas por referentes calificados. Los valores en la región se ubican, en un gran promedio, en el rango del $40 \%$ de los vehículos$\mathrm{km}$ vacíos. Las estadísticas disponibles de la Unión Europea (ver

Gráfico 8) muestran que en los camiones operados comercialmente la proporción de vehículos-km vacío son del 23\% en el Reino Unido, 25\% en Francia, 28\% en los Países Bajos; en los camiones de transporte propio los valores son más elevados en todos los países, en el rango del $35 \%$ (Pasi, 2007). También muestran que esa proporción es mayor en el transporte doméstico ( $28 \%$ en promedio) que en el TAC internacional ( $15 \%$ ). Las estimaciones en América del Norte afirman que el recorrido en vacío de los camiones en ese país se sitúa entre el $15 \%$ y el $28 \%$, y que en los tramos con carga un $36 \%$ de la capacidad no se utiliza41. Debe tenerse en cuenta la particular densidad poblacional de América Latina, con grandes ciudades costeras que generan los bienes terminados (ya sea porque los producen o son el lugar de entrada de los bienes importados), que se despachan al interior casi no poblado de cada país42, del cual reciben en general bienes no manufacturados, generando relación una asimétrica entre los volúmenes y tipos de cargas producidos en cada zona: las regiones de menor industrialización generan grandes volúmenes (graneles agropecuarios y mineros, por ejemplo) y son receptoras de cantidades sustancialmente inferiores de productos manufacturados, y además los productos entrantes a una zona requieren equipos de TAC que no son los demandados por los productos salientes.

${ }^{41}$ http://business.edf.org/projects/green-freight-facts-figures.

http://www.ppmc-transport.org/implement-eco-driving-training-supported-by-on-board-devices-forcar-bus-and-rail-fleet-operators/

${ }^{42}$ Son excepciones México, con industrialización relativamente diversificada geográficamente, y la zona sur del Brasil 




Fuente: Pasi, 2007, con datos de Eurostat

La diferencia de productividad que se observa entre los segmentos del TAC dentro de los países de la región es mayor que la que separa a éstos de las economías más desarrolladas. Los segmentos más eficientes (servicios expresos, couriers, servicios especializados y operadores logísticos integrales) pueden presentar valores similares a los de estas últimas. Los ejemplos de países como Argentina mostraban que las unidades de los servicios expresos interurbanos (organizados generalmente mediante cross docking) tienen recorridos anuales similares a los de sus pares en los países más desarrollados, que resultaban prácticamente 10 veces superiores a los de otros camiones en el mismo país, como los que de afectan a la logística urbana o al movimiento de contenedores entre las terminales portuarias y los depósitos fiscales, o el triple de los que se dedican al transporte de granos. Ejemplos similares se podrían encontrar en todas las subregiones de ALC. La "brecha interna" sin duda está vinculada a la naturaleza de la prestación a la que está afectado el vehículo: un servicio expreso, que realiza largos viajes interurbanos, inevitablemente recorrerá distancias mayores que un camión dedicado a la distribución en un área urbana. Pero también refleja diferentes culturas operacionales, asociadas a distintos modelos empresariales: típicamente, el mejor desempeño que logran unidades empresarias con estructura corporativa y tecnología moderna de apoyo respecto a los operadores autónomos, que no cuentan con un centro de comercialización y gestión operativa centralizado. Uno de los corolarios de esta realidad es que - aún en el contexto desfavorable de las economías menos desarrolladas - algunas empresas en ALC pueden alcanzar niveles de desempeño de clase mundial.

Las estimaciones de precios cobrados por el TAC (expresados en centavos de dólar por ton- $\mathrm{km}$ ) en algunos países y regiones del mundo muestran valores sumamente elevados en Centroamérica, particularmente en los servicios domésticos, superiores por ejemplo a los de un amplio grupo de países africanos, y valores en línea con los de los países desarrollados en Brasil (Osborne, Pachon, \& Araya, 2013). Estimaciones hechas por el BID 
para el transporte de un contenedor de $40^{\prime}$ muestran valores de $6 \phi$ a $12 \phi$ por ton $\mathrm{km}$, con algunas excepciones (particularmente en las islas del Caribe, donde los valores son sustancialmente mayores). Estos valores de fletes no son más caros que los valores medios observados en países desarrollados que, si bien pueden ser más eficiente en su operación, generalmente enfrentan costos mayores en sus insumos.

La comparación internacional de indicadores operativos y de valores de fletes debe ser considerada con mucha cautela, ya que, además de poder reflejar viajes pactados en condiciones diferentes y medidos en distintos momentos, está afectada por la valoración de la moneda local (ante una devaluación de la moneda local, por ejemplo, los fletes expresados en dólares pueden reducirse sensiblemente). $Y$ también pone de manifiesto que, al ser mayor la varianza interna que la externa, los valores agregados que promedian todos los segmentos del TAC son de una utilidad limitada: es imperioso avanzar hacia bases de datos desagregadas, que permitan disponer de KPls por segmento. En este sentido, es interesante ver que en Argentina existen más de diez indicadores de variación de costos de transporte generados por una amplia diversidad de cámaras y asociaciones, obedeciendo a distintas situaciones operativas y de ubicación geográfica ${ }^{43}$.

\section{TABLA 15 - COMPARACIÓN INTERNACIONAL DE FLETES POR CAMIÓN}

\begin{tabular}{|l|c|}
\hline \multicolumn{1}{|c|}{ Región o país } & $\begin{array}{c}\text { US } \phi \text { por } \\
\text { ton-km }\end{array}$ \\
\hline $\begin{array}{l}\text { América Central } \\
\text { Domésticos } \\
\text { Internacionales }\end{array}$ & 17 \\
8
\end{tabular}

Fuente: Osborne, Pachon, \& Araya, 2013

\subsection{Principales causas de las debilidades del TAC en la región}

La conclusión, aún con las limitaciones que tienen los indicadores disponibles, es que el desempeño operativo de ALC en promedio es claramente menor que en los países desarrollados, aproximadamente en una proporción del 60\%, pero las diferencias entre

43 FADEEAC (Federación Argentina de Entidades Empresarias de Autotransporte de Cargas) genera un indicador general y una tabla de referencia para graneles; CEDOL (Cámara Empresaria de Operadores Logísticos) refleja cosos logísticos; APROCAM (Asociación de Propietarios de Camiones de Mendoza) genera dos indicadores, uno para contenedores y otro de cargas generales, al igual que CEDAC (Cámara Empresaria de Autotransporte de Cargas de Córdoba); CATAC (Confederación Argentina de Transporte Automotor de Cargas) genera un indicador para movimiento de contenedores en el puerto y una tabla de referencia para graneles; CATAMP (Cámara Argentina de Transporte Automotor de Materiales Peligrosos) genera dos indicadores para cargas peligrosas 
segmentos dentro de un mismo país son muy pronunciadas. Los fletes cobrados, por su parte, no son más altos.

Diversos factores contribuyen a estas "brechas", tanto internas como externas, que se encuentran entrelazados. Se los puede agrupar en varios conjuntos, de acuerdo al impacto que generan: (i) factores que reducen la productividad del sector, (ii) factores que incrementan adicionalmente el valor de los fletes, (iii) factores que atentan contra la calidad del servicio, y (iv) factores que incrementan las externalidades negativas.

\section{i. Factores que llevan a una menor productividad}

- Organización empresarial atomizada. La gran heterogeneidad existente en el tamaño y número de prestadores del servicio hace que exista una gran diferencia entre empresas altamente organizadas, y pequeñas y medianas empresas, así como prestadores individuales que carecen de capacidades para la gestión, el mantenimiento adecuado de la flota y la capacitación de los choferes. La atomización de la oferta hace que no haya posiciones dominantes, salvo excepciones, y en general es el dador de carga el que pone las condiciones operativas. La diversidad de formas empresariales atenta contra las posibilidades de que todo el sector mejore de manera homogénea, pero no es privativa de América Latina, ya que la misma situación de muchas empresas muy pequeñas 0 unipersonales, y de pocas empresas grandes, se da en todos los países del mundo. Debe reconocerse, sin embargo, que la gran informalidad imperante en el continente acentúa las diferencias entre muy grandes y muy pequeños para, por ejemplo, acceder a créditos para adquirir mejores tecnologías.

- Informalidad. La gran informalidad y corrupción imperante en casi todos los países de LAC se refleja en el TAC. A su vez, las empresas más formales favorecen que existan aspectos regulatorios exigentes con el objetivo de constituir una barrera de entrada para dejar fuera de mercado a los transportistas más informales

- Calidad y antigüedad de los equipos. En la mayoría de los países de LAC la calidad de los equipos de transporte es en promedio baja respecto de las economías desarrolladas, y antigüedad es alta. Sin embargo, al desagregar el análisis se observa que las empresas más grandes o que realizan servicios más complejos tienen equipos con la calidad del "primer mundo" y antigüedades equiparables. Esta tendencia de "muchos peores" y "pocos mejores" se ha acentuado en los últimos años, ante el explosivo desarrollo tecnológico de los camiones que se hace inaccesible para la gran masa de transportistas más pequeños.

- Relaciones con los dadores de carga. En general los dadores de carga toman ventaja de su posición dominante en la demanda frente a la oferta debilitada por la atomización, en especial en los tipos de carga que tienen menor valor agregado. En este sentido puede citarse: i) que los dadores de carga presionan por tarifas bajas ya que siempre "hay otro" para hacer la tarea, produciendo el constante empobrecimiento de los transportistas; ii) existen abundantes ejemplos de demoras excesivas los en los puntos de carga y descarga de cualquier naturaleza, que hacen que los camiones insuman muchas horas detenidos bajando su productividad; iii) los dadores de carga suelen demorar los pagos para obtener ventajas financieras 
perjudicando al transportista, ya que la actividad del TAC es altamente demandante de capital de trabajo; iv) hay abuso de la capacidad de carga de las unidades, obligando al transportista a cargar más cantidad que el peso admitido (especialmente en graneles agrícolas); v) existe escaso interés asociativo de los dadores de carga que son competidores entre sí para compartir viajes y aprovechar economías por el mejor uso de la bodega, probablemente por las cuestiones de informalidad en los negocios, lo que torna peligroso compartir información.

- Estado de la infraestructura vial: el bajo nivel de inversiones en infraestructura en casi toda la región produce que los viajes no puedan desarrollar la velocidad óptima por deterioro del camino, o que se produzcan atascos y congestiones por falta de ancho en las calzadas, y ausencia de vías alternativas y/o de escape. Estos factores atentan contra la cantidad de kilómetros que es posible producir en el tiempo. La infraestructura de baja calidad impide, además, pensar en que en el corto o mediano plazo pueda pensarse en adoptar ventajas tecnológicas que ya están presentes en los camiones, como por ejemplo el control de alineación automática con el camino, que depende de que las banquinas y su delineamiento sean muy buenos.

- Estado de la infraestructura de comunicaciones: la baja cobertura de comunicaciones en vastas regiones de LAC, impiden hacer uso de las ventajas de tecnologías basadas en ellas.

- Escasa incorporación de sistemas tecnológicos de asignación de cargas y rutas, especialmente en las empresas más pequeñas y atomizadas, lo que hace que los viajes sean más ineficientes

\section{ii. Factores que afectan al costo y al precio de venta}

- Carga impositiva. Es alta en la mayoría de los países del TAC, con el inconveniente que generalmente se paga al fisco contra el devengado del servicio y no contra su cobro, generando altos costos financieros que se trasladan a la tarifa.

- Los costos laborales y las demandas sindicales. En algunos países como Argentina son muy altas y producen que los transportistas pequeños prefieran no crecer para no tener que enfrentarse a delegados sindicales, o bien realizan maniobras tales como dividir la empresa en varias para no correr el riesgo de que se le asignen estos delegados.

- Precio del combustible. El combustible representa entre el 35 al $40 \%$ del costo de los viajes de larga distancia en los países de LAC. Su costo es alto, pero los transportistas están sujetos a que es determinado por agentes con los cuales no tienen poder de negociación (las petroleras). En algunos países el costo es más alto que en otro dependiendo de qué cantidad de combustible es importado. En países como Brasil o Argentina, que mantuvieron hasta aproximadamente 2015 valores altamente subsidiados para el combustible por razones políticas, se han producido graves crisis en el TAC cuando el valor se equiparó a los guarismos internacionales. En otros países como Chile, Perú o Colombia, donde se el precio del combustible siguió los valores internacionales históricamente, no han ocurrido situaciones de crisis, sino que se ha asumido la incidencia que representa en el costo. 
- Calidad de las infraestructuras vial y de comunicaciones, ya explicadas en el apartado anterior

- Falta de competencia en algunos casos. Se han encontrado referencias a ese problema sólo en tráficos nacionales en Centroamérica.

- Modalidad de contratación de los servicios. Como consecuencia de la organización empresarial atomizada descripta en el apartado anterior, hay sectores que contratan sus viajes uno a uno durante un período a diversos prestadores (típicamente esto ocurre en el sector de granos en Argentina, Brasil y Uruguay)., mientras que hay sectores más organizados que realizan contratos anuales que les aseguran disponibilidad de bodega en los momentos necesarios.

- La seguridad vial: del punto de vista social, la seguridad vial es crucial al momento de gestionar las rutas que conviven con peatones y/o con tránsito de pasajeros en vehículos privados o colectivos. Aún en los casos en que no son responsables del accidente, los camiones usualmente son mira de los reclamos sociales. El asunto es complejo de resolver ya que depende de numerosas variables (ya descriptos en el apartado anterior): mal estado de la infraestructura, antigüedad y baja calidad de los camiones, sobrepeso, capacitación empresarial y de los choferes, etc. La alta tasa de accidentes incide sobre los costos de los seguros y de las reparaciones de los daños a los bienes propios y de terceros.

- Seguridad de la carga respecto del hurto o robo: es un tema constante en Latinoamérica: suelen existir zonas en las cuales criminales pueden tomar las cargas, que obligan a limitar los horarios de circulación e imponen adicionales de costo al requerir custodias o sistemas adicionales de seguridad, generando costos que deben sumarse a los precios de venta, así como los mayores costos de los seguros. Esta situación ocurre en varios países de la región.

- Calidad y antigüedad de los equipos. Este aspecto, ya descripto en el apartado anterior, genera distorsiones en los costos y precios. En los mercados más informales o donde los dadores de carga abusan de su posición dominante, los precios de los fletes son llevados a la baja por la necesidad de subsistencia del día a día de los pequeños transportistas, que deben cuidar su flujo inmediato de fondos. Esta política termina destruyéndolos $e$, indirectamente, se afecta el costo global del transporte ya que los transportistas no logran renovar sus unidades por otras más eficientes.

- Relaciones con los dadores de carga. Las diversas condiciones impuestas por los dadores de carga, descriptas en el apartado anterior, generan mayores costos que finalmente se traducen en las tarifas.

- Escasa incorporación de sistemas tecnológicos de asignación de cargas y rutas, ya explicado en el apartado anterior

\section{iii. Factores que llevan a peor calidad de servicio}

- Estado de la infraestructura de telecomunicaciones, ya explicado en los apartados anteriores

- Escasa incorporación de sistemas tecnológicos de asignación de cargas y rutas, ya explicado en el apartado anterior 
- La inestabilidad de la economía: si bien la región ha experimentado crecimiento económico en los últimos años, vaivenes y recesiones como las ocurridas en Brasil y en Argentina impactan en la demanda por el servicio.

\section{iv. Factores que llevan a mayores externalidades negativas}

- Falta cumplimiento de reglas. Tales como las atinentes a la educación vial, falta de cumplimiento de las legislaciones sobre pesos y velocidades máximas,

- La baja tasa de incorporación de conductores profesionales, así como su capacitación, afectan los aspectos enumerados de manera directa.

- Debilidad en los controles. Relacionada con el punto anterior, la informalidad en cuanto a cumplimiento de la ley en los países de Latinoamérica genera que, a pesar de existir marcos normativos respecto de ejes, pesos, tránsito internacional, condiciones de seguridad, etc., las mismas no sean cumplidas.

- Edad de las flotas. Si bien en varios países ha habido programas de renovación de flotas, la antigüedad promedio continúa por encima de países más desarrollados. Cuestiones como acceso al crédito del camionero individual, así como la puesta en desuso de las unidades usadas continúan sin ocurrir.

- Calidad de los combustibles, los nuevos equipos poseen mejores sistemas de combustión, e inclusive con monitoreo de emisiones. En este punto, la antigüedad de la flota, con unidades superiores a 20 años atenta contra el cuidado del medio ambiente y permite la utilización de combustibles más baratos y de peor calidad que generan emisiones contaminantes y de GEI.

\section{GRÁFICO 9 - EdAd COMPARAdA DE LAS FLOTAS DEL TAC}



Fuente: McKinnon, 2015 


\section{LAS BUENAS PRÁCTICAS EN EL TAC: EXPERIENCIAS INTERNACIONALES}

Las experiencias internacionales de políticas para mejorar el desempeño del TAC de los últimos años apuntan fundamentalmente a dos objetivos: la eficiencia, a través del lean management, la incorporación de tecnología y la mejora en las prácticas logísticas, y la sostenibilidad ambiental, buscando reducir las externalidades negativas que genera el sector, fundamentalmente emisiones y siniestros, y que finalmente también colabora para mejorar la eficiencia, especialmente en el consumo de energía. Una revisión de las iniciativas recientes muestra que, en términos generales, la atención de las entidades públicas está centrada primariamente en disminuir las externalidades negativas que genera el TAC (por ejemplo, mediante la regulación de la calidad de los combustibles, las exigencias en las motorizaciones, o las normas para mejorar la seguridad vial) y, en segundo término, en la eficiencia (por ejemplo, mediante la habilitación de vehículos de mayor porte). En el ámbito privado las empresas transportistas, al igual que los diversos actores de la cadena de abastecimiento, también han impulsan transformaciones, aunque con distintas prioridades: un mayor énfasis en la productividad y en la eficiencia a través de mejoras operativas, pero también un interés creciente en la sostenibilidad ambiental, incorporando la logística verde en sus políticas de responsabilidad social.

Tras revisar las experiencias recientes, se eligieron cinco casos, que se desarrollan a continuación, que reflejan las tendencias en materia de buenas prácticas en el TAC:

- Programas para mejorar la seguridad vial mediante la certificación de los procesos clave de las empresas transportistas

- Programas para descarbonizar el TAC y avanzar hacia una logística verde

- Conjunto de buenas prácticas impulsadas por los actores de la cadena de suministros

- Regulaciones para mejorar la seguridad controlando las horas de trabajo de los conductores

- Promover la utilización de vehículos más limpios mediante cargos por uso de infraestructura

\subsection{Mejorar la seguridad vial mediante la certificación de procesos clave}

De acuerdo con la Organización Mundial de la Salud (OMS) ${ }^{44}$, las lesiones causadas por el tránsito son la octava causa mundial de muerte, y la primera entre los jóvenes de 15 a 29 años. Las tendencias actuales indican que, de no mediar mejoras, los accidentes de tránsito se convertirán en $\mathbf{2 0 3 0}$ en la quinta causa de muerte. Entre los factores de solución se encuentran tecnologías aplicadas a la seguridad activa y pasiva. Como se comenta en la sección 4.4., si bien las nuevas tecnologías pueden ayudar al conductor y ayudar a reducir la gravedad de los accidentes, es fundamental una mejor capacitación de los

44

https://www.who.int/violence_injury_prevention/road_safety_status/2013/report/summary_es.pdf?ua=1 
conductores y otros usuarios de la carretera, ya que, sin un alto nivel de capacitación, el impacto beneficioso de la tecnología es limitado. En este sentido en Europa, recientemente (2018), se ha propuesto revisar las regulaciones sobre seguridad vial para hacer que "algunas características de seguridad importantes sean obligatorias, tales como asistencia de velocidad inteligente, el frenado de emergencia autónomo o la visión directa mejorada para camiones ${ }^{45 "}$ (Comisión Europea, 2018). Estas sin dudas medidas encarecerán las unidades de transporte.

Por otra parte, la decisión de las Naciones Unidas de declarar el lapso 201 0-2020 como "Década de Acción para la Seguridad Vial", impulsó al ente normalizador internacional ISO a desarrollar y publicar en 2012 la norma ISO 39.001 de Sistemas de Gestión de la Seguridad Vial (SGSV), la cual es una herramienta que permite ayudar a las organizaciones a reducir, y en última instancia eliminar, los muertos y heridos graves derivados de los siniestros de tránsito. En la norma se establecen requisitos armonizados, basados en la experiencia internacional y de aplicación en todos los países, en apoyo de todas las organizaciones del sector público o privado que utilizan las vías de tránsito, ayudándolas a mejorar la seguridad vial de una manera estructurada, integral y sencilla. El uso de esta norma tiene, como efecto colateral, la disminución en el consumo de combustible y en la emisión de gases contaminantes y de efecto invernadero, ya que el manejo seguro implica muchas técnicas coincidentes con las de manejo eficiente.

Un ejemplo de programa público para mejorar la seguridad vial (atento a que en muchos países los camiones están sobrerrepresentados en su participación en siniestros) es el Programa de Acreditación de Vehículos de Australia (NHVAS: National Heavy Vehicle Accreditation Scheme). Es una iniciativa de tipo auto-regulatorio: los operadores que adhieren prestan conformidad (compliance) al cumplimiento de una serie de estándares en tres áreas: el mantenimiento de los vehículos y la previsión de la fatiga de materiales, el control del procedimiento de carga y la gestión de los horarios de trabajo de los conductores, en unos niveles superiores a los que establece la reglamentación. Tras ser verificado el cumplimiento de estos altos estándares por parte de auditores (independientes, aprobados por el ente regulador, que es la NHVR en Australia), se extienden la acreditación a la empresa, que puede ser otorgada en distintos niveles. Una vez acreditada, la empresa puede adherir unas etiquetas a su flota de vehículos que les otorga un trato preferencial en los puntos de control y unos márgenes de tolerancia respecto a ciertos parámetros (con un alcance que depende la categoría de la acreditación). Por ejemplo, una empresa que demuestra tener procesos robustos de mantenimiento, de control de la carga de sus vehículos y de gestión de horarios de los conductores puede transportar hasta 3 ton por encima de los máximos admitidos ${ }^{46}$, evitar las revisiones vehiculares anuales y acordar ocasionalmente turnos de trabajo extendidos. La lógica subyacente es que los operadores que cumplan en exceso las normas que apuntan a la seguridad obtengan algunas ventajas competitivas mediante concesiones en

\footnotetext{
45 Comisión Europea: ANNEX 1 to the Communication from the Commission to the European Parliament, the Council, the European Economic and Social Committee and the Committee of the regions: "Europe on the move - Sustainable Mobility for Europe: safe, connected and clean". Comisión Europea, mayo 2018. Disponible en agosto 2018 en https://goo.gl/9NE5V9

46 La extrema informalidad existente en LAC y descripta en otros capítulos induce a pensar que un sistema de premios como este podría prestarse a un uso fraudulento para poder llevar más carga.
} 
los límites establecidos por las regulaciones. El ente regulador se reserva la potestad de realizar auditorías al azar para verificar el cumplimiento de los estándares por parte de los operadores. El programa - cuyos costos de la implantación y de los auditores son absorbidos por las empresas - ha sido exitoso en Australia, donde se han enrolado más de 90.000 vehículos, número que va creciendo al 10\% anual desde 2012. (Walker, 2017).

Este programa fue replicado en Sudáfrica, como RTMS: Road Transport Management System. Pero en este caso la gobernanza del programa está en manos de un comité de dirección en el que participan múltiples actores de la industria, incluidos los entes gubernamentales nacionales y provinciales, cargadores, aseguradores, comercializadores de vehículos y entidades de investigación. El financiamiento de este comité lo proveen los participantes, particularmente un instituto nacional de investigación (en el caso de Australia ese rol lo cumple un ente regulador nacional, la NHVR). La representación de los cargadores ha tenido efectos positivos, particularmente en las prácticas de carga. Para 2016 había 8.000 vehículos operando bajo el RTMS. (Walker, 2017).

\subsection{Programas para un Transporte Sustentable}

Entendiendo al término "logística" como uno ampliamente utilizado para describir el transporte, almacenamiento y manejo de productos a medida que pasan del origen de la materia prima, a través del sistema de producción hasta su punto final de venta o consumo, en los últimos cincuenta años sus actividades centrales han sido fundamentales para el desarrollo económico y el bienestar social, y una llave determinante para los negocios, en donde el paradigma dominante para quienes administran y estudian la logística ha sido comercial, y su principal objetivo, y en muchos casos el único, ha sido organizar la logística de manera de maximizar la rentabilidad, pero sin incluir los costos ambientales y sociales más amplios, tradicionalmente excluidos del balance, que han sido ignorados en gran medida hasta recientemente (McKinnon, 2015). En este sentido, es notable el aporte de John Elkington ${ }^{47}$, que en 1997 introdujo el concepto de Triple Bottom Line (TBL - Triple Línea de Base), que plantea que el resultado financiero final de una empresa no debe ni puede escindirse del impacto de sus resultados sociales y ambientales, es decir, que la TBL está destinada a promover el objetivo de la sostenibilidad en las prácticas comerciales: para medir el costo total de hacer negocios, deben ser considerados los temas sociales y ambientales.

Durante los últimos diez a quince años, en un contexto de creciente preocupación pública y gubernamental para el ambiente, las empresas han estado bajo una creciente presión para reducir el impacto medioambiental de sus operaciones logísticas. Este impacto es diverso, en términos del rango de externalidades y de las distancias sobre las cuales se experimentan sus efectos adversos. En forma general, la distribución de bienes perjudica la calidad del aire local, genera ruido y vibraciones, causa accidentes y contribuye significativamente al calentamiento global. El impacto de la logística en el cambio climático ha atraído una atención cada vez mayor en los últimos años, en parte porque

47 Autoridad mundial en responsabilidad corporativa y desarrollo sostenible. Actualmente trabaja en la intersección de los movimientos de sostenibilidad, emprendimiento e innovación. 
los controles más estrictos sobre la contaminación y las mejoras en la seguridad vial han aliviado los otros problemas ambientales, pero también porque las nuevas investigaciones científicas han revelado que el calentamiento global presenta un problema mucho mayor y una amenaza más inmediata de lo que se pensaba anteriormente (McKinnon, 2015).

De acuerdo con el World Economic Forum, se estima que la logística emite entre el $15 \%$ y el $18 \%$ de los GEl producidos por la actividad humana, distribuidos de la siguiente manera:

\section{TABLA 16 - PaRticipación en las emisiones de GEI de las actividAdes logísticas}

\begin{tabular}{|l|l|l|}
\hline \multirow{4}{*}{ Transporte } & Terrestre - Camión & $57 \%$ \\
\cline { 2 - 3 } & Acuático & $18 \%$ \\
\cline { 2 - 3 } & Avión & $7 \%$ \\
\cline { 2 - 3 } & Terrestre - Ferrocarril & $5 \%$ \\
\hline Inmuebles & $13 \%$ \\
\hline \multicolumn{2}{|l|}{ Total } & $100 \%$ \\
\hline
\end{tabular}

Fuente: Elaboración propia en base a World Economic Forum. Supply Chain Decarbonization, 2009

Puede observarse la alta incidencia del TAC en las emisiones de GEls de la logística. A su vez el transporte por carretera es la mayor fuente de demanda mundial de diésel, con aproximadamente la mitad del total mundial. De acuerdo con la Agencia Internacional de la energía (AIE), a nivel mundial, más de un tercio de las emisiones de CO2eq relacionadas con el transporte, y el $7 \%$ del total de $\mathrm{CO} 2$ eq relacionado con la energía, provienen del transporte de carga por carretera 48 ", como se ve en el gráfico a continuación:

48 Agencia Internacional de Energía (AIE): El futuro de los camiones: Implicaciones para la energía y el medio ambiente. París, 2017. Disponible en octubre 2018 en

https://www.iea.org/publications/freepublications/publication/TheFutureofTruckslmplicationsforEnergy andtheEnvironment.pdf 


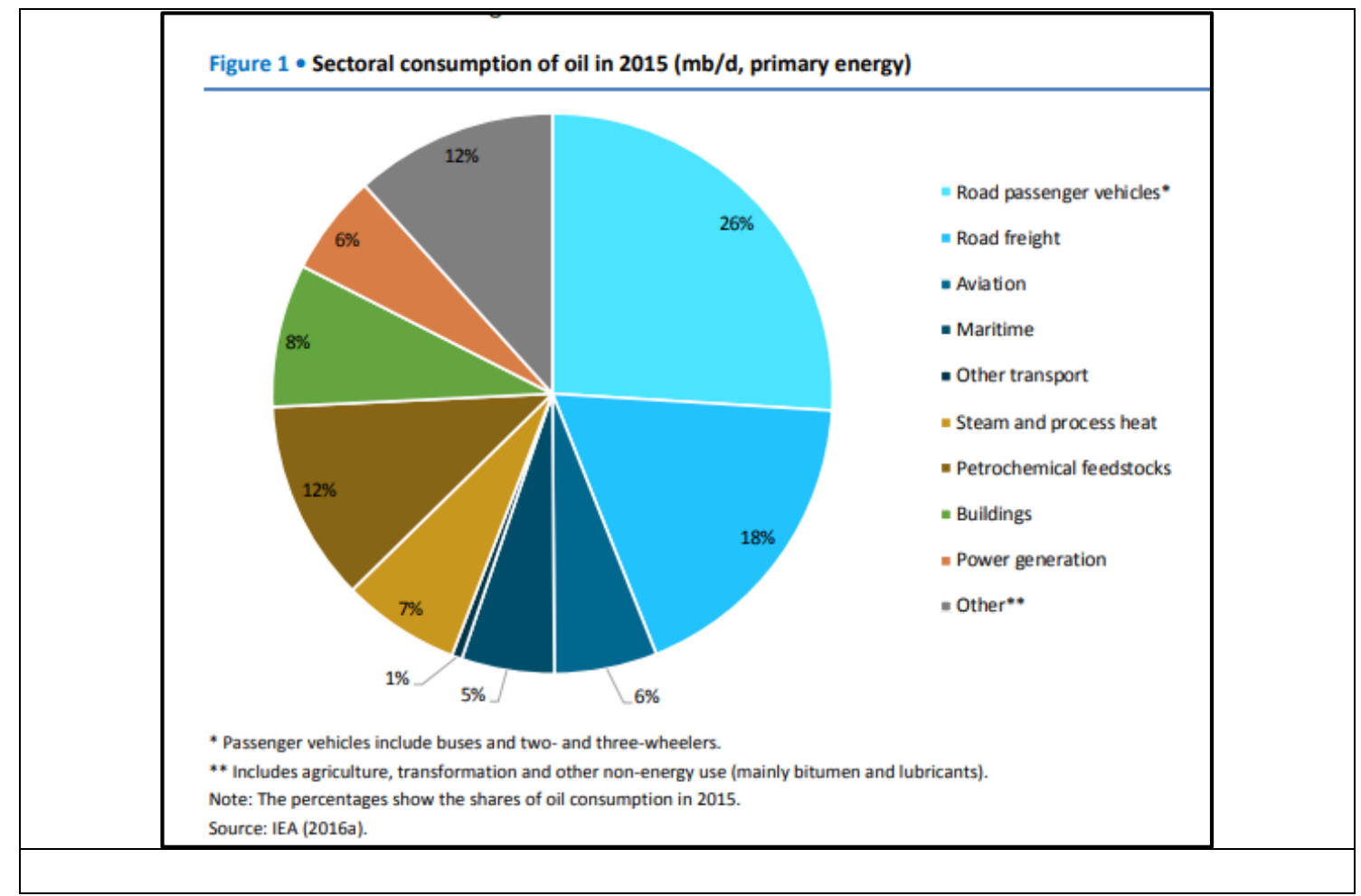

Fuente: Agencia Internacional de Energía (2017)

Además de la producción de GEl, la combustión de diésel y nafta es responsable de la contaminación ambiental originada por el material particulado (PM) (también llamado humo negro), formado por moléculas de monóxido de carbono que afecta las vías respiratorias y es tóxico; óxidos de nitrógeno (NOx) que son cancerígenos; y óxidos de azufre, que afectan las vías respiratorias y causan la llamada "lluvia ácida" que afecta a todos los seres vivos.

Si bien las actividades logísticas repercuten negativamente sobre el ambiente, las acciones para que disminuyan sus efectos suelen repercutir beneficiosamente en la ecuación económica de las empresas. Más aun, muchas organizaciones ven en las políticas de sustentabilidad una fuerza para la innovación, desde el diseño y la entrega de sus productos y servicios principales, hasta el desarrollo de nuevos modelos comerciales y soluciones que generan crecimiento: la industria está reinventando la forma en que los productos se diseñan, fabrican, usan y recuperan, a medida que cambian los modelos de negocios y operaciones hacia una economía circular y de menor uso de recursos naturales, para lo cual es necesario establecer cadenas de suministro sustentables, reduciendo el impacto ambiental de productos y servicios en cada etapa de la cadena de valor.

En tal contexto, las acciones posibles para lograr un TAC "verde", "sustentable" o "amigable con el ambiente" se pueden agrupar en:

- Dispositivos tecnológicos y buenas prácticas asociadas

- Formas de conducción (manejo eficiente) 
- Buenas prácticas empresariales y logísticas

- Acciones de instituciones del Estado o privadas

Entre las acciones de instituciones del estado o privadas existen numerosos programas e iniciativas, la mayoría de los cuales obedece a la adhesión voluntaria de los distintos actores del TAC (transportistas, dadores de carga, proveedores del sector y el estado), de manera de generar una comunidad donde se comparten informaciones sobre tecnologías, procedimientos y resultados obtenidos. Sintéticamente, los programas para transportistas y dadores de carga siguen el modelo SmartWay de los Estados Unidos, o los programas europeos como el Objectif $\mathrm{CO} 2$ de Francia, y se definen como sistemas de asociación voluntaria que vinculan actores del sector público y privado para incentivar la adopción de estrategias, herramientas, tecnologías y conocimientos que contribuyan a mejorar la eficiencia en el uso de la energía y disminuir las emisiones contaminantes en el transporte automotor. Todos los programas, comparten como principio la necesidad de efectuar reconocimientos públicos a quienes se adhieren y cumplen con los compromisos asumidos. Si bien según el tipo de programa y las especificidades locales varían las condiciones a cumplir para recibir los reconocimientos (tipo, forma y periodicidad), la posibilidad de que transportistas y dadores de carga puedan demostrar sus méritos frente a la sociedad y sus clientes en materia de ahorros de energía y emisiones contaminantes constituye un factor central que motoriza su adhesión y fidelidad a los programas.

La siguiente tabla sintetiza algunos de los principales programas del mundo, con sus características principales:

TABLA 17 - ENFOQUES ORGANIZADORES DE DIFERENTES PROGRAMAS DE TRANSPORTE

\begin{tabular}{|c|c|c|c|c|}
\hline Acción & País & \multicolumn{3}{|c|}{ Énfasis } \\
\hline SmartWay USA & USA & \multirow{2}{*}{$\begin{array}{c}\text { Que el transportista use tecnologías, } \\
\text { proveedores y capacitaciones } \\
\text { certificadas por el programa }\end{array}$} & \multirow{2}{*}{$\begin{array}{c}\text { Informaciones de cursos } \\
\text { y tecnologias certificadas } \\
\text { por el programa }\end{array}$} & \multirow{7}{*}{$\begin{array}{c}\text { Alimentación } \\
\text { con datos del } \\
\text { transportista } \\
\text { para } \\
\text { devolverlos } \\
\text { procesados }\end{array}$} \\
\hline SmartWay Canadá & Canadá & & & \\
\hline Transporte Limpio & México & $\begin{array}{c}\text { Evaluación de logros de transportistas } \\
\text { y dadores de carga }\end{array}$ & \multirow{5}{*}{$\begin{array}{c}\text { Informaciones de cursos } \\
\text { y tecnologías disponibles } \\
\text { en el mercado }\end{array}$} & \\
\hline Objectif $\mathrm{CO} 2$ & Francia & \multirow{4}{*}{$\begin{array}{c}\text { Seguimiento de la evolución de } \\
\text { compromisos asumidos de manera } \\
\text { formal por el transportista con el } \\
\text { programa }\end{array}$} & & \\
\hline $\begin{array}{l}\text { Lean \& Green } \\
\text { Logistics }\end{array}$ & $\begin{array}{c}\text { Países Bajos, } \\
\text { Alemania, Bélgica, } \\
\text { Luxemburgo e Italia }\end{array}$ & & & \\
\hline $\begin{array}{l}\text { LERS-Logistics } \\
\text { Emissions Reduction } \\
\text { Scheme }\end{array}$ & Reino Unido & & & \\
\hline Eco Stars & $\begin{array}{l}\text { Regiones de UK, } \\
\text { Rotterdam, Cantabria, } \\
\text { Parma en Italia y } \\
\text { otros }\end{array}$ & & & \\
\hline
\end{tabular}

Al momento de realizar este informe, en la Argentina está en etapa de prueba del Programa Transporte Inteligente, descripto en capítulos anteriores. 


\section{Recuadro 6 - Prácticas sustentables para una logística Verde en Argentina}

Prestadores locales de transporte y logística en Argentina están mostrando un interés creciente por la sustentabilidad del servicio que desempeñan. Vale la pena mencionar dos iniciativas de empresas con presencia multimodal en países limítrofes.

La primera iniciativa tiene que ver con utilización de combustible de gas licuado de petróleo (GLP) para la flota de transporte, el cual disminuye las emisiones de CO2 y los costos operacionales de los camiones, y presenta ventajas del punto de vista del equipo de gas, respecto al GNC. El GLP precisa tanques más livianos y carece de riesgo de explosión. Este gas es extraído en varias refinerías del país. Los transportistas que han comenzado a utilizarlo están movilizándose para gestionar la provisión de GLP en estaciones de servicio a lo largo de las rutas argentinas.

La segunda iniciativa tiene que ver con la visión sustentable de la operación del negocio de transporte y logística. En este caso la empresa no sólo se concentra en minimizar el impacto de emisiones sino también de reforestar. Se basa en dos pilares, optimizar el funcionamiento de los recursos y el plan de forestación. En el primer pilar, se utilizan tractores Euro 5 que generan menores emisiones de $\mathrm{CO} 2$ que los tractores convencionales. Los depósitos de almacenamiento tienen un sistema de funcionamiento con paneles aislantes que minimizan el impacto de uso de energía para mantener la temperatura así como iluminación natural y funcionamiento diurno. Adicionalmente, se organiza la distribución de manera tal de hacer más eficiente el trayecto de las mercancías, ahorrando combustible y cantidad de $\mathrm{km}$ recorridos. Diariamente se intenta disminuir la cantidad de materiales para embalar un cargamento o utilizar insumos biodegradables. Alternativamente se ofrece el servicio de carga a piso en furgones cerrados, evitando la utilización de envoltorios, aprovechando al máximo la capacidad de la unidad transportadora. Finalmente el ciclo incluye el reciclado de los desechos así como la reutilización de los pallets. En el segundo pilar, la reforestación, la empresa de transporte destina el 3\% de la facturación al cultivo en zonas desérticas, bajo el programa de desarrollo agrícola sustentable con el objetivo de compensar el impacto en las emisiones de CO2 y contribuir a la reducción de la huella de carbono.

\subsection{Buenas prácticas impulsadas por los actores de la cadena de suministros}

Siendo el TAC una actividad fundamentalmente realizada por privados, no es llamativo que los actores involucrados propongan y desarrollen buenas prácticas. El interés no se limita sólo a los operadores, sino también a los generadores de carga: cada uno, en su rol dentro de la cadena de abastecimiento, tiene interés en un mejor desempeño del TAC aunque, como se verá, con perspectivas ligeramente diferentes. Un estudio reciente realizó una encuesta entre productores, distribuidores y transportistas en España, identificando las mejores prácticas para el TAC y consultando a numerosos actores sobre la prioridad relativa que otorgaban a cada una (Fernández Vazquez-Noguero, 2018). En la opinión de las 100 empresas que respondieron, las cinco propuestas que recibieron la mayor prioridad fueron: el establecimiento de slots de tiempo para las operaciones de carga y descarga (que supone la coordinación entre dador de carga y transportista), el rediseño de los embalajes, la utilización de software para optimizar rutas, la utilización de software para la gestión de flotas (centrados en la organización del despacho y la operación de los equipos), y el uso de elementos reutilizables de transporte (paletas, cajones y todo tipo de contenedores). El Gráfico 11 muestra las prácticas consultadas y las prioridades establecidas por los actores. 


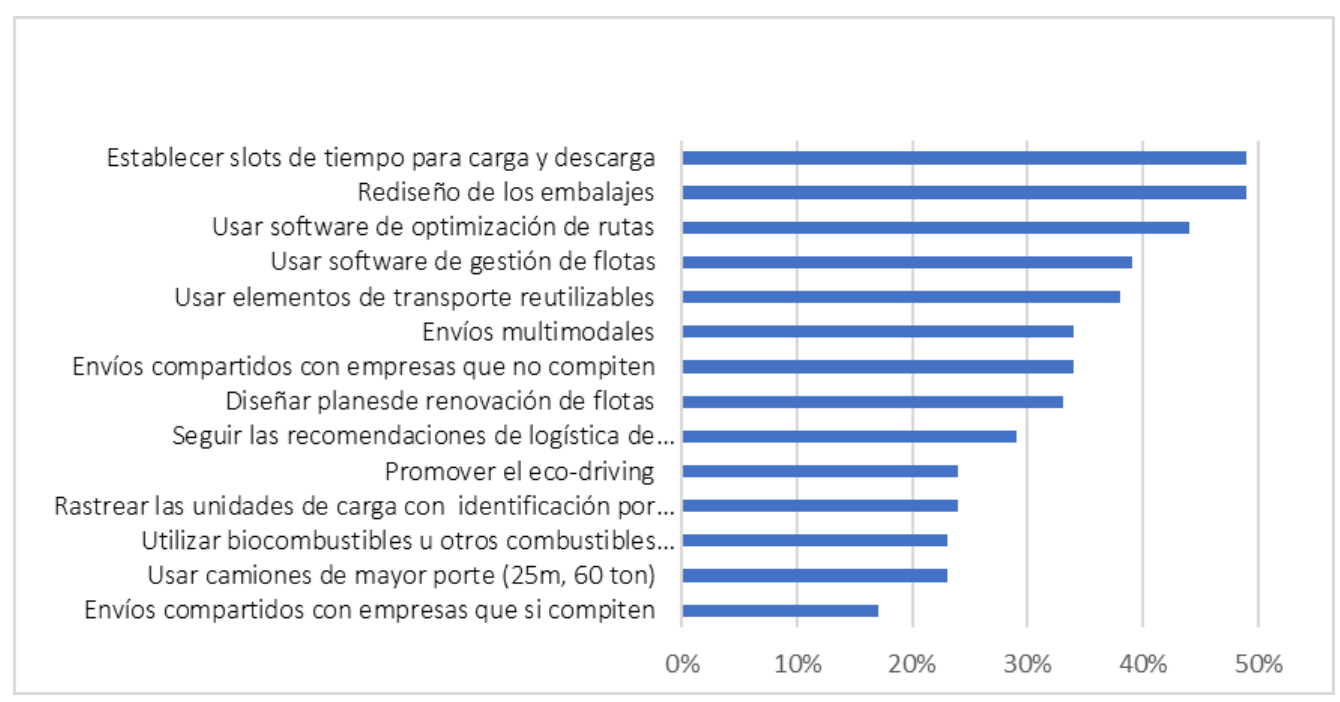

Fuente: Fernández Vazquez-Noguero, 2018

Analizando la perspectiva de cada uno de los actores de la cadena de abastecimiento (Tabla 18), el mayor interés de los transportistas está en la incorporación de tecnología de TIC (software para optimizar rutas y gestionar flotas) y en los planes de renovación de equipos. El énfasis de los fabricantes (industrias dadoras de carga) se centra en establecer slots de tiempo para la carga y descarga y en el rediseño de los embalajes (para facilitar la logística) ${ }^{49}$. El mayor interés de los distribuidores mayoristas está en la optimización de las rutas, en establecer slots de tiempo para la carga y descarga, en el rediseño de los embalajes y en los planes para renovar flota. Finalmente, en el caso de las firmas del retail el mayor interés se expresó en el uso de elementos de transporte reutilizables.

49 Es interesante reflexionar, como se explicó en capítulos anteriores, que este es también un problema muy importante en LAC para mejorar la eficiencia y lograr que los vehículos recorran más cantidad de kilómetros por unidad de tiempo. Sin embargo en LAC esta mejora no es promovida por los dadores de carga, que externalizan su ineficiencia en la carga-descarga en el transportista. 
TABLA 18 - Mejores PRÁcticas de ACUeRdo CON LA PERSPeCtiva de los ACtORES

\begin{tabular}{|c|c|c|c|c|}
\hline & Fabricantes & Transportistas & Mayoristas & $\begin{array}{c}\begin{array}{c}\text { Ventas al por } \\
\text { menor }\end{array} \\
\end{array}$ \\
\hline Usar software de optimización de rutas & $36 \%$ & $63 \%$ & $75 \%$ & $27 \%$ \\
\hline Establecer slots de tiempo para carga y descarga & $51 \%$ & $44 \%$ & $50 \%$ & $45 \%$ \\
\hline Rediseño de los embalajes & $51 \%$ & $50 \%$ & $50 \%$ & $36 \%$ \\
\hline Diseñar planesde renovación de flotas & $20 \%$ & $56 \%$ & $50 \%$ & $45 \%$ \\
\hline Usar software de gestión de flotas & $34 \%$ & $56 \%$ & $42 \%$ & $36 \%$ \\
\hline Usar elementos de transporte reutilizables & $36 \%$ & $31 \%$ & $33 \%$ & $64 \%$ \\
\hline Envíos compartidos con empresas que no compiten & $34 \%$ & $44 \%$ & $33 \%$ & $36 \%$ \\
\hline Envíos multimodales & $37 \%$ & $25 \%$ & $25 \%$ & $36 \%$ \\
\hline Seguir las recomendaciones de logística de fabricantes/distribuidores* & $27 \%$ & $38 \%$ & $25 \%$ & $27 \%$ \\
\hline Rastrear las unidades de carga con identificación por radiofrecuencia & $20 \%$ & $31 \%$ & $25 \%$ & $36 \%$ \\
\hline Promover el eco-driving & $22 \%$ & $31 \%$ & $25 \%$ & $27 \%$ \\
\hline Usar camiones de mayor porte $(25 \mathrm{~m}, 60$ ton $)$ & $22 \%$ & $13 \%$ & $42 \%$ & $27 \%$ \\
\hline Utilizar biocombustibles u otros combustibles alternativos & $24 \%$ & $25 \%$ & $17 \%$ & $27 \%$ \\
\hline Envíos compartidos con empresas que si compiten & $17 \%$ & $19 \%$ & $17 \%$ & $18 \%$ \\
\hline
\end{tabular}

* RAL de ACECOC

Fuente: Fernández Vazquez-Noguero, 2018

En la región ha habido propuestas de los actores de la cadena de suministros respecto a la logística en general y al TAC en particular, entre las que pueden destacarse las actuaciones de la Asociación Latinoamericana de Logística (ALALOG) y de la Cámara Interamericana de Transporte (CIT). La primera (ALALOG) es una entidad abierta, sin fines de lucro, que reúne a las Asociaciones y Cámaras Logísticas de diferentes países, cuyo principal objetivo es la difusión, el intercambio de experiencias y el desarrollo de la actividad logística, integrada por representantes de Argentina, Bolivia, Brasil, Ecuador, México, Paraguay, Perú, Uruguay y Venezuela. En cuanto a la CIT, está formada por dieciocho países de la región (Argentina, Bolivia, Brasil, Chile, Colombia, Costa Rica, Ecuador, El Salvador, Guatemala, Honduras, México, Nicaragua, Panamá, Paraguay, Perú, República Dominicana, Uruguay y Venezuela), y tiene como objetivos principales coordinar y defender a nivel internacional los intereses de los transportistas y sus órganos de representación (en todos los modos), y promover estudios para el desarrollo y la mejora del transporte internacional

Entendiendo como "Buenas Prácticas" a toda experiencia que se guía por principios, objetivos y procedimientos apropiados o pautas aconsejables que se adecuan a una determinada perspectiva normativa, o a un parámetro consensuado, como así también a toda experiencia que ha arrojado resultados positivos, demostrando su eficacia y utilidad en un contexto concreto, existen en LAC diversas iniciativas para documentarlas, aunque en general se trata de manuales de empresas (normalmente dadoras de carga), para aplicarlas a sus propias operatorias. No obstante, hay otras iniciativas más formales, como por ejemplo los listados de Buenas Prácticas de las oficinas de la organización GS1 en Perú, Colombia y Argentina, o el manual de buenas Prácticas Logísticas de la Cámara Empresaria de Operadores Logísticos (CEDOL) de Argentina, el Manual de Buenas Prácticas de la Asociación Logística (ALOG) de Chile 


\subsection{Mejorar seguridad y eficiencia controlando las horas de trabajo}

En los Estados Unidos se han emitido normas tendientes a mejorar la seguridad vial estableciendo controles electrónicos y limitando los horarios máximos de trabajo admitidos, reforzando el cobro de penalidades. La obligatoriedad de utilizar un registro electrónico de las horas de trabajo del conductor (ELD), reemplazando los registros en papel, limita la posibilidad de adulteración. Respecto las horas de servicio (HOS), tras meses de advertirlo, las autoridades estatales comenzaron a cobrar penalidades en las infracciones, apoyadas en los datos provistos por los ELD. Actualmente se están discutiendo los períodos máximos de servicio continuo y los intervalos de descanso. La aplicación conjunta de estas políticas ha impactado negativamente en la productividad del TAC en un orden estimado del $3 \%$ al $8 \%$. Algunos segmentos lo han sufrido especialmente, como el transporte de productos agrícolas, las cargas con estacionalidad pronunciada o el transporte de rollizos. Las estimaciones van desde una pérdida de capacidad del 15 al 20 por ciento para algunas empresas de transporte por carretera. Las rutas que anteriormente requerían un día de tránsito ahora pueden requerir el doble de tiempo para acomodar las horas de los conductores 50 . Ha producido también una mayor demanda de lugares de descanso en las rutas, que resultan insuficientes. Pero estas políticas también han tenido un impacto positivo: el control de las horas de control está forzando a las empresas a optimizar los recorridos, los tiempos de carga y descarga y la planificación operativa en general: pequeños ajustes pueden resultar en beneficios significativos. Otro efecto colateral es que hace más leal la competencia entre operadores.

Estas nuevas normas entran en vigor en momentos que se produce un severo faltante de conductores, resultante de una mayor demanda por el crecimiento de la economía del país y de las actividades logísticas en general, y especialmente por el impacto del crecimiento del e-commerce, que demanda servicios de distribución. Para superar esta restricción se ha iniciado un programa piloto que admite un lote de conductores menores de 21 años para conducir vehículos de 40 ton en tráficos troncales (desde 1935 no podían conducir camiones pesados), lo que es visto como un retroceso en materia de seguridad. ${ }^{51}$

\subsection{Vehículos más limpios debido a los cargos por uso de la infraestructura}

Suecia y Alemania, países que han tenido un desarrollo económico similar durante los últimos diez años, han aplicado políticas diferentes de cargos a los vehículos del TAC por la utilización de la infraestructura vial. Suecia aplica la Euroviñeta basada en el tiempo de circulación para cobrar por el uso de las carreteras. Alemania, por su parte, introdujo peajes diferenciados basados en la distancia recorrida en las autopistas y carreteras principales y en la clase Euro del combustible utilizado a partir de 2005, y ha subsidiado la compra de camiones limpios entre 2007 y 2013 . Adicionalmente, Suecia permite

\footnotetext{
50 Braun, Greg: Trucking Capacity Shortage - The State of Affairs. Publicado en C3 Solutions. Disponible en agosto 2018 en https://goo.gl/xMGS39

51 Supply Chain Management Review: Trucking Regulation Update: Winds of change? October, 2018
} 
camiones de más de 40 toneladas para transportes nacionales, mientras que Alemania no. Estas políticas impactan en los resultados fiscales, la composición de la flota de camiones, los vehículos-km y las emisiones. Un estudio comparativo (Viert, Schleussner, \& Mandell, 2015) ha concluido en que la política alemana de transporte de mercancías por carretera ha generado ingresos sustancialmente mayores y una flota de camiones más limpia, reduciendo comparativamente las emisiones. Es notable que los transportistas suecos usan sus camiones más limpios en Alemania y los menos limpios en Suecia (con lo que la política de un país afecta a los vecinos).(Viert, Schleussner, \& Mandell, 2015). 


\section{Perspectivas en los mercados y la tecnología}

Al igual que otras actividades, ante el TAC se presentan numerosas tendencias que van a incidir en su futuro, aunque con una considerable incertidumbre. En este capítulo se tratan dos tendencias clave: las referidas a los mercados del TAC (la cantidad y calidad de servicios demandados, los cambios en la estructura de la oferta y los modelos de negocio) y los impactos que tendrán en el sector las tecnologías propias de la Cuarta Revolución Industrial.

\subsection{Tendencias en los mercados de carga del TAC}

El volumen de cargas en el mundo ha venido creciendo a tasas superiores a las del PIB. Estudios recientes de la UE afirman que esa tendencia continuará: la demanda de transporte, en general, aumentará (ya que se espera que el transporte de mercancías aumente un $80 \%$ para 2050), y la tendencia a la urbanización continuará, con lo cual aumentará la congestión ${ }^{52}$. Estudios de la IRU estiman un escenario de crecimiento en el cual la cantidad de ton-km producidas en el planeta en 2030 será $55 \%$ superior a las producidas en 2015 , y $155 \%$ superior en 2050 en relación a 2015 (IRU, 2018). El proceso de urbanización impactará sobre las demandas del TAC, dado que el aumento de la población urbana (que ya supera al $50 \%$ de la población mundial) implica cambios fundamentales en los conceptos de suministro para las áreas urbanas. "Los expertos creen que los vehículos comerciales ligeros se utilizarán cada vez más para la distribución de la última milla" y "las redes mejor controladas harán que los centros de distribución y, por lo tanto, también los vehículos comerciales pesados se acerquen cada vez las áreas metropolitanas, con el resultado de que los camiones medianos de distribución perderán una parte significativa del transporte de mercancías en la Tríada ${ }^{53}$ en manos de camiones comerciales mucho más livianos para distribuir, y pesados para llegar a los centros de distribución. A nivel mundial, el segmento mediano se estancará en 2026". 54

Las tendencias hacia una mayor demanda incidirán en la organización del sector: siguiendo la tendencia de los dadores de carga, es de esperar que las empresas de transporte y logística se concentren en holdings y empresas más grandes, buscando mayor volumen para lograr mejor eficiencia por incremento de escala y para atender a clientes cada vez más concentrados, mejorando la capacidad de sus unidades e incorporándoles mejoras tecnológicas que desplazan del mercado a los transportistas de menor tamaño que no pueden acceder a las innovaciones (IRU, 2018). La tendencia a la concentración constituye una respuesta al desarrollo de cargadores con creciente poder de negociación, lo que genera un contexto que dificulta la supervivencia de operadores individuales. Es de esperar también que muchas de esas grandes empresas de TAC se expandan en su rango de actividades, prestando servicios logísticos y de valor agregado, y que se propaguen los mecanismos de alquilar y compartir equipos, particularmente para los picos de actividad.

\footnotetext{
52 European Commission, Directorate-General for Communication Citizens information (2014)

53 La Tríada: conjunto de países formado por Norte América, 28 países europeos y los países desarrollados de Asia

${ }^{54}$ Schiller, Thomas; Maier, Michael; Büchle, Martin: Global Truck Study 2016. The truck industry in transition. Deloitte, 2017
} 
Otra tendencia destacable es la expansión de los nuevos canales de venta y distribución, particularmente en el ámbito urbano, debido al impacto del crecimiento del e-commerce. Su incidencia es aún pequeña en ALC comparada con las economías desarrolladas, por lo que es de esperar que tenga un crecimiento sustancial. Los altos estándares de servicio que impone el comercio electrónico dirigido a consumidores individuales (B2C), caracterizado por lapsos y volúmenes de entrega muy reducidos, trazabilidad y cumplimiento estricto de las entregas, está impactando también en las transacciones entre firmas (B2B), que pasan a tener requerimientos similares (Recuadro 7). El incremento del consumo, la urbanización y el cuidado ambiental en las ciudades seguramente implicarán la mayor inserción de las unidades de menor porte en la distribución urbana, con vehículos más limpios. No está claro si los grandes gestores de los sistemas de venta por internet desarrollarán sus flotas propias o realizarán alianzas con operadores del mercado, reafirmando una tendencia hacia una mayor concentración.

\section{RECUADRO 7 - EXPECTATIVAS DE SERVICIO IMPULSADAS POR EL B2C}

- Precisión en cumplir con la entrega en el horario y lugar pactados

- Opciones de puntos de entrega

- Visibilidad plena

- Políticas de devolución y retorno flexibles

- Disponibilidad permanente de stocks

- Resolución inmediata de problemas

Fuente: DHL (2018) The logistics transport evolution: The road ahead

Algunas tendencias en el mercado que merecen destacarse son: los nuevos modelos de negocio (las bolsas de carga), la informalidad, y el control de las reglas de carga y descarga.

\section{Bolsas de carga y plataformas digitales}

Las denominadas "bolsas de carga" fueron lanzadas a principios del siglo como una innovación en la forma de contratar los servicios de transporte y de mejorar la utilización de la capacidad de carga de los camiones y reducir los viajes en vacío. Las bolsas de carga consisten en un espacio virtual de encuentro entre la oferta y la demanda de servicios de transporte de carga, a través de plataformas electrónicas. Estos servicios no han tenido aún el éxito esperado en ALC. En Europa y Estados Unidos debieron mutar del concepto de simple "matching" entre las partes, a desarrollar bases de datos con información legal, financiera y de permisos, tanto de oferta como de demanda, convirtiéndose en fiscalizadores de la información ofrecida por las partes; aun así, tampoco lograron los niveles de actividad esperados. A las variantes anteriores se suman nuevas alternativas basadas en la nube de datos, en la potencia informática de los equipamientos actuales y en los conceptos de autogestión libre de intermediaros que se impone en la sociedad moderna en general, como Uber Freight (el "Uber de los camiones"), Descartes o Amazon. En el caso de Uber Freight la propuesta no ha tenido éxito hasta el momento; la causa principal es que los generadores de carga 
(especialmente los grandes) difícilmente aceptan cualquier operador, prefiriendo una red de transportistas confiables, más allá de las alternativas que les presente la plataforma ${ }^{55}$.

No obstante que aún no han logrado imponerse, estos nuevos modelos de negocio generan expectativas hacia el futuro, combinados con otras innovaciones tecnológicas (Recuadro 8).

\section{RECUADRO 8- UNA VISIÓN FUTURISTA DEL TRANSPORTE DE CARGAS}

Hay especialistas que proponen un futuro de total automatización, en el cual cada paquete a ser transportado contendrá un chip con la información de la ruta y entrega aparejada a dicho bien. De esta manera, una red de transportes autónomos, igualmente automatizados, captarán la señal digital del paquete, y un algoritmo calculará el mejor viaje disponible, para maximizar el uso de las bodegas y cumplir los tiempos de entrega. El sistema funcionará en la nube. El paquete entonces será recogido por el camión autónomo, entregado en un centro de consolidación, donde un robot lo almacenará en el lugar correcto según la información del chip. Seguidamente, será cargado por otro robot para salir a su destino final en camiones eléctricos, y ser entregado al consumidor final de acuerdo con el día y horario predeterminado. Este sistema de cadenas de suministros digitalizadas, con el sistema automatizado de pareo de cargas podría reducir los costos del TAC en un $47 \%$ en la UE en el año 2030 . El ahorro provendría mayormente de mano de obra de conductores y de empresas de freigth fowarding. Los tiempos de entrega se reduciría en un $40 \%$.

The Era of Digitalized Trucking: Charting your transformation to a new business model. Richard Viereckl, Gerhard

A su vez parecería estar emergiendo una nueva generación de bolsas de carga, basadas en las crecientes posibilidades de procesamiento de grandes bases de datos localizadas en espacios virtuales. El Recuadro 9 detalla las tendencias que se observan en las nuevas bolsas de carga, que ofrecen perspectivas promisorias y pueden contribuir a la mayor eficiencia en la utilización de los equipos.

55 Banker, Steve: Is Uber Freight on The Verge of Going Out of Business? Forbes, Abril de 2018 
Los datos generados en los procesos digitales pueden utilizarse para mejorar el proceso de matching mediante una medición en tiempo real del precio dinámico del transporte de cargas LTL. Algunos operadores de tecnología ofrecen tarifas dinámicas a los clientes, gracias al control de sus propios datos que les permiten entender tendencias como la estacionalidad, las fluctuaciones semanales y mensuales, o solo los contratos específicos que causan backhauls (retornos vacíos) y reflejarlos en los cambios de precios casi a diario, con lo cual el transportista optimiza sus posibilidades de llenar sus camiones con carga y mejora el precio pagado por el dador de la carga. El desarrollo de aplicaciones que permitan conectar a los transportistas con los dadores de carga en tiempo real permitiría eliminar intermediaciones y optimizar el uso de bodegas y de precios pagados (Grasis, 2016).

Un ejemplo en este sentido es BlackBuck), una plataforma desarrollada en la India. En este país los remitentes pagan tarifas a varias capas de corredores para encontrar propietarios de camiones para cada trabajo. BlackBuck está orientado al modelo de carga completa (FTL) para envíos interurbanos. Permite a más de 80.000 propietarios de camiones independientes encontrar cargas y ofertar por ellos, pero además informa los precios de manera transparente evitando intermediaciones, y está desarrollando otros servicios para mejorar la calidad de vida de los camioneros, como un programa de tarjetas de combustible con descuentis. Entre los inversores en BlackBuck se incluyen grandes firmas de capital de riesgo globales e inversores estratégicos locales con experiencia en tecnología, y la CFI del Grupo del Banco Mundial.

En China, la CFI ha invertido en la plataforma Truck Alliance, que ya ha registrado más de un tercio de los seis millones de conductores de camiones del país, y actualmente alberga 70,000 transacciones. Una de las fortalezas de Truck Alliance es reconocer que cerrar el vacío de información entre la oferta y la demanda es solo el primer paso: se espera que la creación de confianza entre los conductores y los cargadores, al establecer un mecanismo de seguimiento de los bienes durante todo el proceso, proporcionará resultados más duraderos. Para ello Truck Alliance también proporciona servicios auxiliares a los conductores de camiones, como tarjetas de pase de peaje, seguros de camiones y conductores, y financiamiento para camiones nuevos. Está en el proceso de lanzar tarjetas de descuento de combustible, comercio de camiones usados y servicios de posventa. La CFI también está invirtiendo en América Latina, en la plataforma Liftit, que conecta a los conductores de camiones con los dadores de carga en Colombia y México. Esta plataforma también facilita compras comunitarias para los asociados y capacitación en buenas prácticas en el negocio. El financiamiento de la CFI apunta al lanzamiento de la compañía en otros países de América Latina, como Argentina, Brasil y Chile.

Otra plataforma disruptiva es ConvoyGo, en los Estados Unidos, perteneciente a la plataforma Convoy, que preselecciona y certifica a los camioneros y supervisa su desempeño (por ejemplo, demoras) de manera continua, así como los requisitos de seguros y demás regulaciones aplicables. Cuenta además con un sistema de cotización en tiempo real; el dador de carga puede priorizar transportistas que sean de su mayor confianza, y calificar la calidad del servicio. El transportista a su vez puede conocer el historial del dador de la carga en cuanto a sus preferencias, posibilidad de demoras, cumplimiento de pago, etc. ConvoyGo ofrece también semirremolques, que pueden ser utilizados por cualquier conductor en la red de Convoy, sin tarifas de alquiler directo; los transportistas pueden encontrar, reservar y completar una carga con la aplicación, sin necesidad de invertir en remolques (ni el transportista ni el dador de carga). La carga o descarga puede demorar lo que sea necesario: el transportista recién tomará el remolque cuando sea informado por la aplicación de que la carga está completa. 


\section{La formalización de los servicios del TAC}

La informalidad atenta contra el incremento del profesionalismo y la productividad en el TAC; ha habido intentos de mitigarla, pero los avances son aún pocos. Aunque las empresas más informales son las más pequeñas, los negocios informales y la contratación de personal de manera irregular atraviesa las compañías de todas las magnitudes en mayor o menor medida. Este tema sobrepasa al mercado del TAC; es de carácter estructural y solo puede ser corregido mediante acciones concretas de Estado, por lo que lograr doblegarla depende de las mejoras industriales, productivas y comerciales que puedan impulsarse por la aplicación de leyes y normas más duras en toda la economía de cada país.

\section{El control de las reglas de carga y descarga}

Los dadores de carga suelen trasladar a los transportistas sus propias ineficiencias logísticas: en el caso de carga y descarga estos últimos sufren de tiempos muertos importantes que les impiden desarrollar más viajes, ya que los dadores de carga planifican mal los tiempos de preparación, solicitan los camiones a destiempo, etc. En Argentina, por ejemplo "muchos centros de distribución exigen las entregas en pallets monoproducto, sin importar cuán reducida sea la carga, para facilitar su control. En consecuencia, muchas veces el pallet es desaprovechado y representa mayor peso que la mercadería. Teóricamente, este requisito está orientado a agilizar los procesos de entrega en los centros de distribución, pero, en ocasiones $y$, de todas formas, estos pueden demorar hasta seis horas" 56 .

\subsection{Las nuevas tecnologías y el TAC}

Los cambios tecnológicos están generando un impacto en el TAC, que indudablemente será mayor en los próximos años. Estos cambios se producirán tanto a nivel de los vehículos como de la organización comercial y operativa de las flotas, en tres grandes áreas: la digitalización e interconexión de los vehículos, haciendo uso de la telemetría para mejorar la eficiencia, la seguridad y la calidad de servicio ${ }^{57}$, el desarrollo de vehículos autónomos y el de nuevos sistemas de propulsión (Recuadro 10).

56 Selva Rodolfo. Abastecimiento en la Ciudad de Buenos Aires en la revista Concepto Logístico Nro 21. ARLOG, Buenos Aires, noviembre 2018

57 La telemetría es una técnica automatizada de comunicaciones utilizada para medir a distancia diferentes magnitudes físicas, como distancia, temperatura, presión, entre muchas otras. Es una aplicación de la $I O$. Permite obtener datos a partir de una red interconectada de objetos mediante la instalación de sensores, y así monitorear y controlar diversos procesos de manera remota. 
- Telemática y digitalización

- Monitoreo del vehículo, para el control de velocidad, consumo de combustible, fallas, atención remota del mantenimiento de las unidades

- Conducción y seguridad. Estatus del conductor, modalidad de conducción, tareas administrativas, sistemas pasivos y activos de seguridad

- Gestión de la flota y de la cadena de abastecimiento. Optimización dinámica de rutas, seguimiento, control de carga (peso, temperatura)

- Vehículos autónomos

- Basado en IO; práctica del platooning.

- Nuevos sistemas de propulsión

- Limitaciones al diésel; avances hacia estándar Euro 6

- Descarbonización: reducción de emisiones, vehículos más limpios, y tendencia hacia vehículos eléctricos o híbridos.

- Híbridos y eléctricos; más PHEV (híbridos con regeneración) que BEV (eléctricos puros, con baterías)

El avance hacia la digitalización de los camiones, al igual que ocurre en los automóviles, implica la aparición de nuevos actores, particularmente las empresas de tecnología, que apuntan a participar del negocio que tradicionalmente gestionaron las OEM (Deloitte, 2017).

En cuanto a las tecnologías en las unidades de transporte, "la digitalización será el principal motor de cambio en el mercado de camiones. Los sistemas telemáticos en camiones se convertirán en estándar en los mercados de la Tríada. Las soluciones de TI y software integrarán estrechamente a los transportistas en los sistemas de la cadena de valor de la Industria 4,058". Estas tecnologías (genéricamente conocidas como Tecnologías de la Información y la Comunicación -TICs), comprenden la optimización dinámica de rutas, sistemas para controlar el estilo in individual de conducción, atención remota del mantenimiento de la unidad, ayudas para la conducción, etc. "El almacenamiento digital y el intercambio de datos son fundamentales para que el sector del transporte pueda alcanzar un nivel óptimo, permitiendo hacer una buena planificación de todos los envíos de forma que cada camión en tránsito tenga su carga completa, siga una ruta óptima y sea considerado una parte integral de la cadena de suministro $59 "$.

De acuerdo con la IRU, en los países de la Tríada "la industria del transporte por carretera reconoce que en un entorno empresarial cada vez más competitivo, la innovación basada en la tecnología tiene el potencial de desbloquear inmensas oportunidades. Ve la adopción exitosa de tecnología como clave para la supervivencia a largo plazo"60. Sin

\footnotetext{
58 Schiller, Thomas; Maier, Michael; Büchle, Martin: Global Truck Study 2016. The truck industry in transition. Deloitte, 2017

59 Jeftic, Zeljko. La transformación del transporte global a través de la digitalización. Publicado por la IRU en febrero 2018. Disponible en agosto 20187 en https://www.iru.org/es/recursos/noticias/latransformacion-del-transporte-global-traves-de-la-digitalizacion

60 IRU (2018)
} 
embargo, el documento advierte sobre el riesgo de que se abra una brecha entre los jugadores pioneros en el extremo de la transformación tecnológica, y los que no logren incorporarlas, ya que "algunos operadores de transporte en todo el mundo aún no han adoptado las nuevas tecnologías más básicas, lo que no puede hacerlo debido a los altos costos o la falta de habilidades y conocimientos técnicos"61.

En los aspectos de innovación de tecnologías aparecen los vehículos autónomos: tanto las empresas tradicionales del sector (como Volvo, Scania, etc.), como las empresas basadas en nuevas tecnologías como Uber, Tesla o Google, se encuentran abocadas al desarrollo de camiones sin chofer. Algunos ejemplos:

- En el caso de Uber, sus camiones autónomos "están certificados hasta el momento bajo el nivel SAE 2, ya que el objetivo no es sustituir al conductor, sino ayudar en trayectos de largo alcance en autopistas de alta velocidad. Los camiones de Uber ya han iniciado pruebas en las carreteras de San Francisco con miras a expandirse a otras regiones de Estados Unidos, donde el objetivo es crear alianzas con compañías que requieran de estos servicios y así impulsar las regulaciones necesarias para su uso"62.

- Volvo está trabajando en su proyecto "Vera", "un concepto desarrollado por Volvo Trucks, cuya finalidad sería ofrecer el transporte de mercancías en áreas controladas y todo conectado a una central que gestionaría el movimiento y operación de estos camiones. Mientras que los proyectos de compañías como Tesla - Nikola apuestan por camiones para trayectos de largo alcance, el Volvo Vera se enfocaría en operar en zonas relativamente pequeñas y privadas, como puertos, fábricas, centros logísticos y campus corporativos, donde podrían trabajar las 24 horas del día sin la necesidad de un conductor"63.

- En el caso de Google, su proyecto se denomina Waymo y está desarrollando una exploración técnica para "entender cómo funcionan sus sensores y sistemas en un vehículo diferente (a los ya desarrollados automóviles), buscando encontrar una posible adaptación a vehículos grandes, con una conducción bastante diferente" 64 .

- Una variante son los sistemas de "platooning", que consiste en la "unión de dos o más camiones en convoy, utilizando tecnología de conectividad y sistemas de soporte de conducción automatizados. Estos vehículos mantienen automáticamente una distancia cercana y establecida entre sí cuando están conectados para ciertas partes de un viaje, por ejemplo, en autopistas. El camión a la cabeza del pelotón actúa como líder, con los vehículos detrás reaccionando y adaptándose a los cambios en su movimiento, que requieren poca o ninguna acción por parte de los conductores. En primera instancia, los conductores mantendrán el control en todo momento, por lo que también pueden decidir abandonar el pelotón y conducir de forma independiente. (Se postula que el sistema) tiene un gran potencial para hacer

61 IRU (2018)

62 Portal Xataca.com. ver https://www.xataka.com/vehiculos/uber-nos-muestra-en-video-su-nuevo-yflamante-camion-autonomo-adelantandose-a-google-y-tesla, disponible en octubre 2018

63 Portal Xataca.com. Ver: https://www.xataka.com/vehiculos/nuevo-concepto-futurista-camion-electricovolvo-no-necesita-cabina-conductor-porque-tambien-autonomo, disponible en octubre 2018

${ }^{64}$ Portal Xataca.com.Ver: https://www.xataka.com/vehiculos/hay-un-camion-autonomo-entre-tanto-cocheinteligente-de-google, disponible en octubre 2018 
que el transporte por carretera sea más seguro, limpio y más eficiente en el futuro. Es por eso que los fabricantes de camiones están ansiosos por llevar a estos pelotones a las carreteras de Europa, y las primeras pruebas de la vida real ya están en marcha" ${ }^{65}$. Más allá de las dificultades tecnológicas que aún restan resolver, es crucial para su desarrollo fortalecer la cooperación entre todas las partes interesadas relevantes, incluyendo a los operadores de infraestructura vial, operadores logísticos, compañías de seguros y responsables políticos.

Un informe elaborado conjuntamente en 2017 por la Asociación Europea de Fabricantes de Automóviles (ACEA), la Federación Internacional de Trabajadores del Transporte y la International Road Transport Union (IRU), en un proyecto dirigido por el Foro Internacional del Transporte de la OCDE, alerta que "la automatización del transporte por carretera ahorrará costes, reducirá las emisiones y mejorará la seguridad en carretera. Sin embargo, la pérdida de empleos para los transportistas exige una transición bien gestionada. Los gobiernos deben reflexionar sobre la gestión de la transición hacia los camiones sin conductor, a fin de evitar trastornos sociales potenciales por la pérdida de empleos. Los camiones de conducción autónoma contribuirán al ahorro de costes, la reducción de las emisiones y la mejora de la seguridad en carretera. Asimismo, podrían dar respuesta a la falta de transportistas profesionales que sufre el sector del transporte por carretera, pero de acuerdo con un escenario posible, los camiones automatizados podrían reducir la demanda de transportistas entre un $50 \%$ y un $70 \%$ en los Estados Unidos y Europa antes de acabar 2030, con la consiguiente desaparición de hasta 4,4 millones de empleos sobre una previsión de 6,4 millones de profesionales del transporte por carretera"66.

En particular en Latinoamérica, en el caso de Chile, la adopción de tecnologías ha ocurrido a través de los vehículos nuevos que cumplen con las normas Euro sobre emisiones, actualmente Euro5, acompañados de sistemas de monitoreo y evaluación de la emisión a lo largo de la vida útil del vehículo. Así mismo, el uso de sistemas GPS que inicialmente se utilizaron para monitorear la seguridad del vehículo, ahora se usan para gestionar información de cargas y seguimiento por parte de los dadores de cargas. Se espera que continúe automatización de los vehículos, el procesamiento de la información para minimizar los viajes en vacío y mejora de las cadenas logísticas (Muñoz Santana, 2018)67. En el caso de Brasil, los camiones nuevos tienen mejores sistemas de seguridad, como frenado automático, o sistemas que los mantienen en el carril de viaje. Sin embargo, los pequeños camioneros no se adecúan.

\subsection{La perspectiva de los fabricantes de camiones}

Los fabricantes y plantas de montaje de camiones que atienden el mercado de América del Sur están, casi todos, ubicados en Brasil, a causa de las mayores dimensiones de su mercado que el de cualquiera de los otros países o, incluso, del mercado del resto del continente. Scania, Volvo, Man-Volkswagen, Iveco (CNH Industrial), Daimler (Mercedes

\footnotetext{
65 European Automobile Manufacturers Association (ACEA). Ver: https://www.acea.be/uploads/publications/Platooning roadmap.pdf, disponible en octubre 2018

66 Publicado por la IRU en https://www.iru.org/es/recursos/noticias/camiones-sin-conductor-un-nuevoinforme-plantea-medidas-globales-en-materia, disponible en octubre 2018
} 
benz) proveen camiones desde Brasil al propio país, a América del Sur, a Medio Oriente y África.

Los modelos ofrecidos están alineados con muy poco tiempo de diferencia con los que se ofrecen en los países de sus casas matrices, introduciendo novedades tecnológicas como cajas de cambio robotizadas, motorizaciones más eficientes y menos contaminantes, sistemas de seguridad activa basados en tecnologías de la información, ayudas para la conducción, etc.

La diferencia en el valor de compra de estos modelos en relación con modelos usados de los propios países o a usados importados ${ }^{68}$ es cada vez mayor. Los fabricantes sostienen que lo que debe medirse es el Costo Total de Adquisición (el costo total desde la compra hasta el fin de la vida útil de la unidad, incluyendo el de operación), que resulta más bajo en los modelos de última generación por su mayor eficiencia. Sin embargo, y teniendo en cuenta lo mencionado en la sección referida a la dinámica de la renovación de flotas, se observa que la propuesta de los nuevos modelos con su mayor valor de compra acentúa que la posibilidad de adquisición de unidades nuevas para la renovación/ampliación de flota sea se limite a las empresas de mayor porte y con mejor gestión económicofinanciera. Los mismos fabricantes ofrecen financiación, que generalmente es utilizada para la venta a firmas grandes, que adquieren numerosas unidades a la vez (en el orden de diez o más).

En el orden técnico, en el caso de América del Sur, que los camiones sean fabricados en el Brasil, para atender su propio y tan grande mercado, determina que algunas de sus características técnicas sean más aptas para los caminos de ese país, con lo cual las configuraciones estándar tienen cajas de cambio y conjuntos eje-diferencial aptos para los caminos de serranía y montaña, que no son las mejores en otros países llanos como Argentina o Uruguay. En el caso de México, la oferta está muy relacionada con los camiones que atraviesan la frontera con Estados Unidos, por lo que las características técnicas se ajustan a los convenios con ese país.

La automatización entendida como transporte sin conductor, explicada en el apartado anterior, parece aún lejana en América Latina y Caribe. Sin embargo, estas tecnologías avanzan a pasos agigantados y las alarmas que se están generando en los países más evolucionados con respecto a la repercusión sobre los trabajadores y propietarios unipersonales de camiones debería empezar a ser contemplada por las políticas públicas. Sin duda estas tecnologías aumentarán aún más la brecha entre transportistas eficientes e ineficientes.

${ }^{68}$ No en todos los países se permite la importación de vehículos usados. 


\section{LOS RETOS DEL TAC Y LAS OPCIONES DE POLÍTICA PÚBLICA}

\subsection{Situación actual, tendencias, obstáculos y aspiraciones}

La situación actual del TAC en América Latina fue desarrollada en los capítulos anteriores. A modo de síntesis, puede resumirse en cinco características clave, cuyo alcance presenta variaciones entre los países de la región:

- El rol clave del transporte terrestre para la competitividad actual y futura de la región. No obstante, hay falencias notables de datos y escasos análisis.

- La eficiencia del sector es relativamente baja en promedio, aunque con comportamientos muy dispares según los segmentos de actividad. La productividad de las unidades es baja y la edad promedio de la flota es elevada. El desempeño está muy condicionado por las demandas y por las condiciones comerciales y operativas de los dadores de carga.

- El sector genera externalidades negativas muy potentes: emisiones de contaminantes y $\mathrm{GEl}$, siniestros viales y congestión. $Y$ es responsable de un alto consumo de hidrocarburos.

- La estructura de la oferta está atomizada y caracterizada por una elevada informalidad (ambos fenómenos mundiales). Los contratos formales son poco frecuentes. Hay una diferenciación creciente entre operadores grandes y formales (con poder económico y financiero) y los operadores pequeños, que se acentúa con las nuevas tecnologías.

- Los mercados están básicamente desregulados (aunque con excepciones) en materia económica; las regulaciones técnicas (ambientales y de seguridad) - por el contrario - son crecientes, y provenientes de ámbitos gubernamentales diversos.

Las tendencias generales que se registran en el sector pueden resumirse en las siguientes:

- Una demanda creciente en términos de volúmenes de carga

- Una demanda de mayor calidad de servicio (plazos, flexibilidad, visibilidad, etc.), y un vínculo creciente con la logística

- Un fuerte impacto potencial de las nuevas tecnologías, tanto en la oferta como en la demanda de servicios

- La emergencia de nuevos canales de comercialización y modelos de negocio, que generan demandas diferentes al TAC

- La incidencia de la mitigación del cambio climático en el sector, el principal en el transporte de cargas.

Las aspiraciones de los países respecto al TAC pueden resumirse en un objetivo general, y dos particulares. El Objetivo General es el de un TAC que contribuya a la competitividad de las economías de los países de la región y que reduzca las externalidades negativas que 
genera su actividad. Estas aspiraciones deben alcanzarse en un contexto caracterizado por multiplicidad de cambios simultáneos (en los mercados, en la tecnología, etc.), enfrentando diversos obstáculos para implementar transformaciones. Los objetivos específicos se refieren a: (i) Contribuir a la competitividad de las economías y la integración regional, reduciendo el precio de los servicios y mejorando su calidad, y (ii) Reducir las externalidades negativas, descarbonizando y descontaminando el sector, contribuyendo a un transporte más limpio, una mayor seguridad vial y una menor congestión.

Avanzar tras esos objetivos requerirá superar varios obstáculos, entre los que se destacan:

- las escasas capacidades institucionales para la elaboración de políticas y el control (fiscalización efectiva), variando según los países.

- La baja profesionalidad en varios de los actores, particularmente en los operadores individuales del TAC y en muchos dadores de carga, que tienen un débil manejo de la logística.

- La falta de datos básicos suficientemente desagregados, que permita reconocer el desempeño y los problemas en los diversos segmentos del TAC

- La volatilidad de precios de combustibles, que inciden sensiblemente en los costos de los operadores

- La falta de asignación de recursos financieros para impulsar programas dirigidos al TAC

Un problema que aún es incipiente en ALC pero que muy probablemente se irá agudizando es la falta de conductores de camiones. Otro obstáculo destacable es la baja propensión a la combinación entre modos de transporte, problema más propio de la gestión pública de la logística de cargas que estrictamente del TAC.

\subsection{Las prioridades de política pública}

Atendiendo a la situación actual del sector, las tendencias internas y externas que afectarán su desempeño, las aspiraciones de política pública respecto al TAC y los obstáculos existentes para avanzar en su concreción, se propone un conjunto de áreas de acción prioritarias de actuación para orientar las políticas públicas referida al TAC en los países de la región con un horizonte de mediano plazo:

1. Mejorar la eficiencia y la calidad del servicio

2. Descarbonizar la actividad y reducir otros impactos ambientales

3. Minimizar los siniestros

4. Fortalecer las instituciones y la coordinación entre los actores

5. Mejorar la infraestructura y los nodos operativos

A continuación se citan las principales iniciativas dentro de cada uno de estas áreas de actuación.

Mejorar la eficiencia y la calidad del servicio: 
- Promover la digitalización en operación y comercialización; en gestión de flotas y ruteo; en telemática y control.

- Facilitar camiones de mayores dimensiones en tráficos selectos

- Evitar volatilidad en precios de combustibles; peajes carreteros que reflejen el costo real.

- Desarrollo de Pymes, cambio cultural, apoyo a pequeños operadores, mecanismos asociativos y de articulación

- Seguridad (vigilancia): acciones para reducir robos

\section{Descarbonizar la actividad y reducir otros impactos ambientales:}

- Programas de renovación de flotas y desguace de unidades viejas. Involucrar a los vendedores, buscar atajos para financiar a los pequeños operadores con líneas accesibles.

- CPI, políticas de impuestos vinculados a las emisiones (i.e., valor de las tasas anuales)

- Impulsar/facilitar programas autorregulados (tipo SmartWay)

- Reforzar requerimientos y controles sobre la importación de vehículos usados

\section{Minimizar los siniestros:}

- Limitaciones de velocidad de los equipos

- Condiciones de trabajo; horarios de conducción y su fiscalización

- Certificación de empresas seguras, con incentivos diversos (siguiendo el modelo de Australia). Control vehicular, control de turnos de trabajo, control de modalidades de carga

\section{Fortalecer las instituciones y la coordinación entre los actores}

a) Desarrollo de capacidades en el sector público:

- Fortalecer capacidades de formular y gestionar políticas y de fiscalización y control en los gobiernos nacionales (y subnacionales donde correspondiera).

- Impulsar una iniciativa de generación de datos desagregados, en línea con el sistema estadístico nacional y apuntando al uso de nuevas técnicas de captura de datos. Desarrollo de KPI y de tareas de análisis y monitoreo, incentivando la investigación.

b) Actividades específicas:

- Apoyo a la formalización; impulso a contratos plurianuales 
- Desarrollo de capital humano: formación de conductores y de profesionalización empresarial, de transportistas y de dadores de carga

- Coordinación intersectorial: con áreas de medio ambiente, energía, desarrollo urbano, trabajo, telecomunicaciones, hacienda (impuestos a los combustibles, carga tributaria en general). Coordinación nacional-subnacional

- Coordinación entre actores: mesas de trabajo, involucrar dadores de carga: normas de carga/descarga, turnos, embalajes y su reutilización, etc.

- Armonización internacional, facilitación del comercio en frontera (en lo referente al TAC) y en las reglas y mecanismos de la circulación internacional

\section{Mejorar la infraestructura y los nodos operativos}

- Mejoras en la red vial en general: en su capacidad y en sus estándares, asegurando el mantenimiento. Desde caminos rurales a autopistas troncales. Propiciar la medición del nivel de servicio por parte de terceros.

- Mejorar los accesos a grandes nodos de carga y descarga (puertos, mercados centrales, etc.)

- Logística urbana: rediseño de los sistemas de distribución para reducir los impactos sobre la circulación y el ambiente

- Impulso a la mayor cobertura de la banda ancha móvil a lo largo de los corredores y del territorio en general, para asegurar conectividad a los equipos a lo largo de su recorrido.

- Desarrollo de redes de nodos operativos: instalaciones de carga y descarga, centros de transbordo, parques logísticos, e instalaciones del tipo.

\subsection{Consistencia y monitoreo}

Con el fin de verificar el vínculo entre los objetivos propuestos y las actuaciones sugeridas, en la Tabla 19 se listan las acciones propuestas y los tres principales objetivos sugeridos en la sección anterior: reducir el costo a los usuarios, mejorar la calidad del servicio y reducir las externalidades negativas. La evaluación del posible impacto es estrictamente cualitativa, buscando destacar aquellas medidas que - de acuerdo con la apreciación de los autores - tendrían mayor efectividad en el cumplimiento de los objetivos. 
TABLA 19 - ACCIONES PROPUESTAS E IMPACTOS ESPERADOS

\begin{tabular}{|c|c|c|c|c|}
\hline $\begin{array}{l}\text { Áreas de } \\
\text { actuación }\end{array}$ & Acciones de política & $\begin{array}{l}\text { Reducción } \\
\text { de precios }\end{array}$ & $\begin{array}{l}\text { Mejora en } \\
\text { la calidad } \\
\text { del } \\
\text { servicio }\end{array}$ & $\begin{array}{c}\text { Reducción } \\
\text { de } \\
\text { externali- } \\
\text { dades } \\
\text { negativas }\end{array}$ \\
\hline \multirow{5}{*}{$\begin{array}{l}\text { Mejorar la } \\
\text { eficiencia y la } \\
\text { calidad del } \\
\text { servicio }\end{array}$} & Promover digitalización & 9 & & 9 \\
\hline & Habilitar vehículos de mayores dimensiones & ( ) & & \\
\hline & Controlar volatilidad de precios de combustibles & (1) & & \\
\hline & Aроуо a Pymes, cambio cultural de pequeños operadores, asociatividad & & & () \\
\hline & Mejorar condiciones de seguridad (vigilancia) & 9 & (1) & \\
\hline \multirow{4}{*}{$\begin{array}{l}\text { Descarbonizar } \\
\text { el TAC y reducir } \\
\text { otros impactos } \\
\text { ambientales }\end{array}$} & Programas de renovación de flotas y desguace de unidades viejas & & & \\
\hline & Adecuar tasas a las emisiones & & & 9 \\
\hline & Impulsar programas autorregulados tipo SmartWay & & & $\Theta$ \\
\hline & Control sobre importación de vehículos usados & & & (1) \\
\hline \multirow{3}{*}{$\begin{array}{l}\text { Minimizar los } \\
\text { siniestros }\end{array}$} & Limitaciones de velocidad de los equipos & & & (1) \\
\hline & Condiciones de trabajo, horarios de conducción y fiscalización & & & $\Theta$ \\
\hline & Incentivar certificación de empresas seguras & & & \\
\hline \multirow{7}{*}{$\begin{array}{l}\text { Fortalecer las } \\
\text { capacidades } \\
\text { públicas y la } \\
\text { coordinación }\end{array}$} & Organización y capacidades de las entidades del sector público & 9 & 9 & 9 \\
\hline & Iniciativa de generación de datos & (1) & (1) & (1) \\
\hline & Apoyo a la formalización y el uso de contratos & (1) & (1) & (1) \\
\hline & Desarrollo de capital humano (formación de conductores y empresarios) & & 9 & $\Theta$ \\
\hline & Coordinación intersectorial y nacional-subnacional & (1) & (1) & (1) \\
\hline & Coordinación entre actores; mesas de trabajo & (1) & (1) & (1) \\
\hline & Armonización normativa y facilitación comercial & (1) & (1) & (1) \\
\hline \multirow{5}{*}{$\begin{array}{l}\text { Mejorar la } \\
\text { infraestructura y } \\
\text { los nodos } \\
\text { operativos }\end{array}$} & Mejoras en la red vial en todos sus niveles & 9 & $\Theta$ & 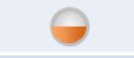 \\
\hline & Mejoras en los accesos a los grandes nodos de carga/descarga & 9 & (9) & \\
\hline & Rediseño de los sistemas de distribución urbana & & () & $\Theta$ \\
\hline & Mayor cobertura de la banda ancha móvil & & 9 & \\
\hline & Desarrollo de redes de nodos logísticos & 9 & $\Theta$ & \\
\hline
\end{tabular}

Para reconocer el impacto de las políticas nacionales de apoyo al TAC es conveniente desarrollar mecanismos de monitoreo, identificando indicadores clave (KPI) que permitan evaluar el desempeño y los avances. A título de ejemplo, se proponen algunos indicadores:

- $\mathrm{Km}$ recorridos por año por los camiones, en promedio

- Viajes vacíos como \% de los viajes totales

- \% de bodega ocupada en viajes con carga

- Edad promedio de la flota

- Emisiones de GEI

- Participación en siniestros viales

- Tiempos de carga/descarga 
La mayor riqueza de estos indicadores se logrará en la medida en que estén desagregados por tipo de equipo y de servicio, permitiendo así reconocer los distintos segmentos que conforman el TAC.

\section{La necesidad de consolidar a los pequeños operadores}

Un reto clave que surge de la realidad actual del transporte automotor de cargas en la región es la disparidad que se va acentuando entre los operadores pequeños -en muchos casos informales- y los grandes operadores. Nuevas tecnologías de cuidado ambiental, monitoreo de cargas y seguridad vial y de la carga, enfatizan esta diferencia. Los operadores más grandes modernizan sus flotas y sus sistemas de trabajo, mientras que los más pequeños van enfrentando mayores dificultades para sobrevivir, lo que hace desafía a los Estados a encontrar formas de ayudar a la transformación de estos pequeños transportistas como, por ejemplo, lo han hecho en el transporte público urbano. Ello implica una tarea de capacitación y desarrollo empresarial, ateniendo a las particularidades culturales de los pequeños operadores. Si bien algunos podrán adaptarse a los nuevos estándares de servicios, posiblemente otros no lo logren. Una política de apoyo a este sector podría consistir en la fomentar la formación de asociaciones de transportistas que además de aumentar la escala de la operación y mejorar el servicio, debería combinar con nuevas tecnologías y aplicaciones para la gestión comercial, las operaciones de carga y descarga y la seguridad en general.

\subsection{Comparación con la agenda 2015}

Una comparación de la agenda propuesta con la que surgía del análisis realizado en el año 2015 muestra que las orientaciones propuestas no difieren mayormente.

TABLA 20 - COMPARACIÓN DE LAS AGENDAS DE 2015 Y 2019

1. Un TAC profesional y de alta productividad

2. Un TAC integrado en redes logísticas intermodales

3. Un TAC ecoeficiente, limpio y seguro

4. Un TAC que facilite la integración comercial y productiva de la región

5. Un TAC basado en políticas, regulaciones y mecanismos de control sólidos
1. Mejorar la eficiencia y la calidad del servicio

2. Descarbonizar la actividad y reducir otros impactos ambientales

3. Minimizar los siniestros

4. Fortalecer las instituciones y la coordinación entre los actores

5. Mejorar la infraestructura y los nodos operativos

Si bien los temas son similares, se observa un importante cambio de énfasis en algunos de ellos, particularmente en lo referente al cambio climático y la seguridad vial, y se resalta notablemente el cambio que pueden producir (y que ya están produciendo) las nuevas tecnologías. Otro aspecto que ha ganado importancia en este nuevo análisis es la 
necesidad de una mayor atención a la coordinación institucional (entre áreas responsables de políticas públicas) y con los dadores de carga, que constituyen actores clave para que el TAC mejore su desempeño. 


\section{REFERENCIAS BIBLIOGRAFICAS}

Arthur D. Little. (2015). Urban Logistics - How to unlock value from last mile delivery for cities, transporters and retailers. The Future of Urban Mobility (FUM) Lab.

Barbero, J. (2010). La logística de cargas en América Latina y el Caribe: una agenda para mejorar su desempeño. Washington, DC: BID - IDB-TN-103.

Barbero, J., \& Guerrero, P. (2017). El transporte automotor de cargas en América Latina. Washington, DC: BID - IDB-MG-482.

Barbero, J., \& Uechi, L. (2012). Assessment of Transport Data Availability and Quality in Latin America. Washington, DC: BID - IDB-TN-315.

Berti da Cóstä, B. (2018). Transporte rodoviario no Brasil. Porto Alegre.

CIDATT. (2014). Perú: Informe sobre el Desarrollo del Transporte Terrestre de Carga de Ámbito Nacional, 2014 . Lima: CIDATT.

Confederacao Nacional do Transporte. (2018). Anuário CNT do Transporte 2018. Brasilia: CNT.

Deloitte. (2017). Global Truck Study 2016 - The truck industry in transition. Deloitte Global.

Delucchi, M. y. (2011). External costs of transport in the United States. En A. De Palma, R. Lindsey, E. Quinet, \& R. Vickerman, A Handbook of Transport Economics (págs. 341 -368). Cheltenham: Edward Elgar.

DHL Supply Chain. (2018). The logistics transport evolution: The road ahead. DHL Supply Chain Limited.

Eurostat. (2018). Railway freight transport statistics . Luxembourg: Office for Official Publications of the European Communities: EU - Statistics Explained.

Fernández Vazquez-Noguero, M. e. (2018). Best Practices in Road Transport: An Exploratory Study. Journal of Industrial Engineering and management, 250-261.

Fiadone, R. (2018). El desempeño del transporte automotor de cargas. Propuestas para su mejora. Buenos Aires.

Grasis, A. (2019). Big Data, Dynamic Freight Pricing and Bid Savings (maybe). https://cerasis.com/dynamic-freight-pricing/: Cerasis.

Hahn, J. \&. (2015). Empirical evaluation on the efficiency of the trucking industry in Korea. KSCE Journal of Civil Engineering, Volume 19, Issue 4, pp 1088-1096.

Hahn, J.-S. y. (May 2015, Volume 19, Issue 4). Empirical evaluation on the efficiency of the trucking industry in Korea. KSCE Journal of Civil Engineering, 1088-1096.

IEA. (2017). The Future of Trucks. Implications for energy and the environment. Paris: OECD/IEA.

International Council of Clean Transportation. (2018). Market Analysis of Heavy Duty Commercial Trailers in Europe.

IRU. (2018). The future of road transport. Ginebra: IRU.

ITF. (2018). Data Led Governance of Road Freight Transport. Improving Compliance. Paris: OECD - ITF Corporate Partnership Board Report.

ITF. (2018). Towards Road Freight Decarbonisation - Trends, Measures and Policies. Paris: ITF Policy Papers, OECD Publishing.

Kahn, A. (1988). The Economics of Regulation - Principles and Institutions. Cambridge, MA: The MIT Press.

Katz, R. (2018). Informe Sectorial de Telecomunicaciones. New York: Mimeo.

Kauppila, J. (2015). International trade and freight by 2050; Multi-year Expert Meeting on Transport, Trade Logistics and Trade Facilitation. Ginebra: UNCTAD. 
McKellips, F., \& Calver, M. (2016). Productivity Trends in the Canadian Transport Sector: An Overview. Ottawa: Centre for the Study of Living Standards (for Transport Canada).

McKinnon, A. (2015). Environmental sustainability. A new priority for logisitcs managers. En A. e. McKinnon, Green Logitics. Improving the environmental sustainability of logistics (págs. 3-31). London: Kogan Page Limited.

McKinnon, A. (2015). Performance measurement in freight transport: Its contribution to the design, implementation and monitoring of public policy. International Transport Forum - Kuenhe Logistics University.

Millán, M. (2018). El desempeño del transporte automotor de cargas. Propuestas para su mejora. Mendoza.

Mulholland, E. (2017). Techno-economic and socio-economic modelling of energy in road transport to inform climate policy. PhD Thesis. Cork, Ireland: University College Cork.

OECD. (1997). Liberalization and structural reform in the freight transport sector in Europe. Paris: OECD Publishing.

OECD. (2011). Moving Freight with Better Trucks: Improving Safety, Productivity and Sustainability. Paris: OECD Publishing.

OECD. (2017). Review of the Regulation of Freight Transport in Mexico. Paris: OECD Publishing.

Osborne, T., Pachon, M., \& Araya, G. (2013). What drives the high price of road freight transport in Central America? Washington DC: World bank - Report 85771.

Pasi, S. (2007). Average loads, distances and empty running in road freight transport 2005 . Eurostat - Statistitcs in focus. $117 / 2207$.

PIARC B4 Freight Technical Committee. (2018). Good Practices on Multi-Modal Freight Transport Policies and Truck Management on Highways. Paris: World Road Assocation (PIARC).

Proost, S. (2011). Theory of external costs. En A. De Palma, R. Lindsey, E. Quinet, \& R. Vickerman, A Handbook of Transport Economics (págs. 319 - 340). Cheltenham: Edward Elgar.

PwC - Strategy\&. (2018). The era of digitized trucking - Charting your transformation to a new business model. Berlin: PwC Strategy\& Germany.

Robles Linares, B. (2018). Transporte automotor de cargas el caso de México. México DF. Santa Muñoz, R. (2018). El autotransporte carretero de cargas en Chile. Mimeo.

Santana, R. (2018). El transporte automotor de cargas en Chile. Santiago de Chile.

SIECA. (2018). La Facilitación del Comercio en Centroamérica: acciones y estrategias después de Bali. Centros de Estudio para la Integración Económica.

SLoCaT. (2018). Transport and Climate Change Global Status Report 2018. Available at: http://slocat.net/tcc-gsr.

Smokers, R. e. (2017). Decarbonising Commercial Road Transport. La Haya: TNO Innovations for life. Netherlands Organisation for Applied Scientific Research.

Tanco, M. y. (2018). Caracterización del Sector del Transporte de Carga Carretero. Montevideo: CINOI - Centro de Innovación en Organización Industrial.

The World Bank \& IRU. (2016). Road Freight Transport Services Reform - Guiding Principles for Practitioners and Policy Makers. Washington, DC: World Bank.

Transport Canada. (2008). Estimates of the Full Cost of Transportation in Canada. Ottawa. 
UNECE. (2017). The UNECE Transport Statistics for Europe and North America - Volume LVIII. New York and Geneva: United Nations.

Viert, I., Schleussner, H., \& Mandell, S. (2015). Road Freight Transport Policies and their Impact - a Comparative Study of Germany and Sweden. Estocolmo: Center for Transport Studies - Stockholm.

Walker, C. (2017). From state to market: regulation of road transport in Australia and South Africa. En M. Hadjiisky, L. Pal, \& C. Walker, Public Policy Transfer (págs. 79-100). Cheltenham: Edward Elgar.

WEF-IDB. (2018). Supply Chain 4.0 - Global Practices and Lessons Learned for Latin America and the Caribbean. Geneva: WEF. 